\title{
Cross Sections for Electron Collisions with $\mathrm{NO}, \mathrm{N}_{2} \mathrm{O}$, and $\mathrm{NO}_{2}$
}

Mi-Young Song ${ }^{a}{ }_{1}{ }^{1}$ Jung-Sik Yoon, ${ }^{1}$ Hyuck Cho, ${ }^{2}$ Grzegorz P. Karwasz, ${ }^{3}$ Viatcheslav Kokoouline, ${ }^{4}$ Yoshiharu

Nakamura, ${ }^{5}$ and Jonathan Tennyson ${ }^{6}$

1) Plasma Technology Research Center, National Fusion Research Institute, 814-2, Osikdo-dong, Gunsan, Jeollabuk-do,54004, South Korea ${ }^{\text {a) }}$

${ }^{2)}$ Department of Physics, Chungnam National University, Daejeon 34134, South Korea

3) Faculty of Physics, Astronomy and Applied Informatics, University Nicolaus Copernicus, Grudziadzka 5, 87-100, Toruń, Poland

4) Department of Physics, University of Central Florida, Orlando, FL 32816, USA

5) 6-1-5-201 Miyazaki, Miyamae, Kawasaki, 216-0033, Japan

6) Department of Physics and Astronomy, University College London, Gower Street, London WC1E 6BT, $U K$

(Revised 1 October 2019)

Cross section data are compiled from the literature for electron collisions with oxides of nitrogen $\left(\mathrm{N}_{x} \mathrm{O}_{y}\right)$ molecules: the species nitric oxide $(\mathrm{NO})$, nitrous oxide $\left(\mathrm{N}_{2} \mathrm{O}\right)$ and nitrogen dioxide $\left(\mathrm{NO}_{2}\right)$ are explicitly considered. Cross sections are collected and reviewed for total scattering, elastic scattering, momentum transfer, excitations of rotational, vibrational and electronic states, dissociation, ionization, and dissociative attachment. For each of these processes, the recommended values of the cross sections are presented. The literature has been surveyed up to the end of 2017. These results are supplemented by a re-analysis of the swarm measurements for $\mathrm{NO}$ and new calculated cross sections for rotational excitation of $\mathrm{N}_{2} \mathrm{O}$, and for rotational excitation and electronic excitation of $\mathrm{NO}_{2}$.

PACS numbers: $34.80 . \mathrm{Bm}, 52.20 . \mathrm{Fs}$

Keywords: electron collisions, total cross sections, ionization, dissociation, attachment, evaluation

\section{INTRODUCTION}

Nitrogen oxides $\left(\mathrm{N}_{x} \mathrm{O}_{y}\right)$ are easily generated in atmospheric plasma using $\mathrm{N}_{2}$ and $\mathrm{O}_{2}$ gas. Nitrogen oxides are regulated as corrosive substances, and research on how to remove them is becoming of increasing importance. In our atmosphere, nitrogen oxides are generated as a byproduct of the combustion of fossil fuels, and most of them are unstable, so they are present in the atmosphere in very small amounts, meaning it can be difficult to detect their presence. The impact on the environment is almost negligible. But two nitrogen compounds that have a great effect on the environment are $\mathrm{NO}$ and $\mathrm{NO}_{2}$. NO accounts for about $95 \%$ of the nitrogen oxides generated in the combustion of fossil fuels, and mostly undergoes rapid oxidized to $\mathrm{NO}_{2}$ which is harmful to both the human body and the natural environment. $\mathrm{N}_{2} \mathrm{O}$ is not created in the combustion of fossil fuels, but is known to be generated in selective catalytic reduction (SCR) reactions and is a known cause of global warming. This paper follows our previous compilations of electron collision data for the methane ${ }^{1}$, acetylene ${ }^{2}$ and $\mathrm{NF}_{3}{ }^{3}$. It presents recommendations for electron collision cross section with nitric oxide (NO), nitrous oxide $\left(\mathrm{N}_{2} \mathrm{O}\right)$ and nitrogen dioxide $\left(\mathrm{NO}_{2}\right)$. For a number of important processes we were unable to identify reliable cross sections; recommendations for future work are presented in the conclusion.

\footnotetext{
a)Electronic mail: corresponding author at mysong@nfri.re.kr
}

All three species considered possess permanent electric dipole moments; these have important consequences for the electron collision cross sections ${ }^{4}$. Table I summarizes key properties of $\mathrm{NO}, \mathrm{N}_{2} \mathrm{O}$ and $\mathrm{NO}_{2}$ : their electric dipole moments, polarizabilities and electron affinities. We note that Hargreaves et al..$^{5}$ have recently provided a comprehensive update on the spectroscopic properties of these species.

\section{NO}

Nitrous oxide is a stable, open shell species with a ${ }^{2} \Pi$ ground electronic state; it has a well characterized spectrum, see Wong et al. ${ }^{12}$. Figure 1 depicts its lowlying potential energy curves. These curves comprise both Rydberg-like states which converge on the more strongly bound ground state of $\mathrm{NO}^{+}$, as represented by the $A, C, D$ and $B^{\prime}$ states and valence states of which the $a, B, b, L^{\prime}, L, I$ and $G$ states are shown in Fig. 1.

\section{A. Total Scattering Cross Section}

In spite of the importance of nitrogen oxides for atmospheric chemistry, relatively few measurements of total cross sections (TCS) for NO have been made. Recommended TCS were given, among others, by Karwasz et al. ${ }^{13}$, Anzai et al. ${ }^{14}$, Zecca et al. ${ }^{15}$ and Itikawa ${ }^{16}$. The total cross section (TCS) for NO was measured at $1-50$ $\mathrm{eV}$ by Brüche ${ }^{17}$ who used Ramsauer's type spectrometer 
TABLE I. Properties of $\mathrm{NO}, \mathrm{N}_{2} \mathrm{O}, \mathrm{NO}_{2}$.

\begin{tabular}{|c|c|c|c|}
\hline Property & $\mathrm{NO}$ & $\mathrm{N}_{2} \mathrm{O}$ & $\mathrm{NO}_{2}$ \\
\hline \multicolumn{4}{|l|}{ Dipole moment $^{6}$} \\
\hline$\left(1 \mathrm{D}=3.33 \times 10^{-30} \mathrm{Cm}\right)$ & $0.157 \mathrm{D}$ & $0.167 \mathrm{D}$ & $0.316 \mathrm{D}$ \\
\hline Polarizability ${ }^{7}\left(10^{-24} \mathrm{~cm}^{3}\right)$ & 1.698 & 2.998 & 2.910 \\
\hline Electron Affinity (eV) & $0.026 \pm 0.005^{8}$ & $-0.03 \pm 0.10^{9}$ & $2.273 \pm 0.005^{10}$ \\
\hline Ionization Potential $^{11}(\mathrm{eV})$ & $9.264438 \pm 0.00005$ & 12.886 & $9.586 \pm 0.002$ \\
\hline Bond Dissociation energy ${ }^{11}\left(\mathrm{D}_{298}^{0} / \mathrm{kJ} / \mathrm{mol}^{-1}\right)$ & $630.57 \pm 0.06$ & $167.4 \pm 0.4\left(\mathrm{O}-\mathrm{N}_{2}\right), 480.7 \pm 0.4(\mathrm{~N}-\mathrm{NO})$ & $306.301(\mathrm{O}-\mathrm{NO})$ \\
\hline
\end{tabular}

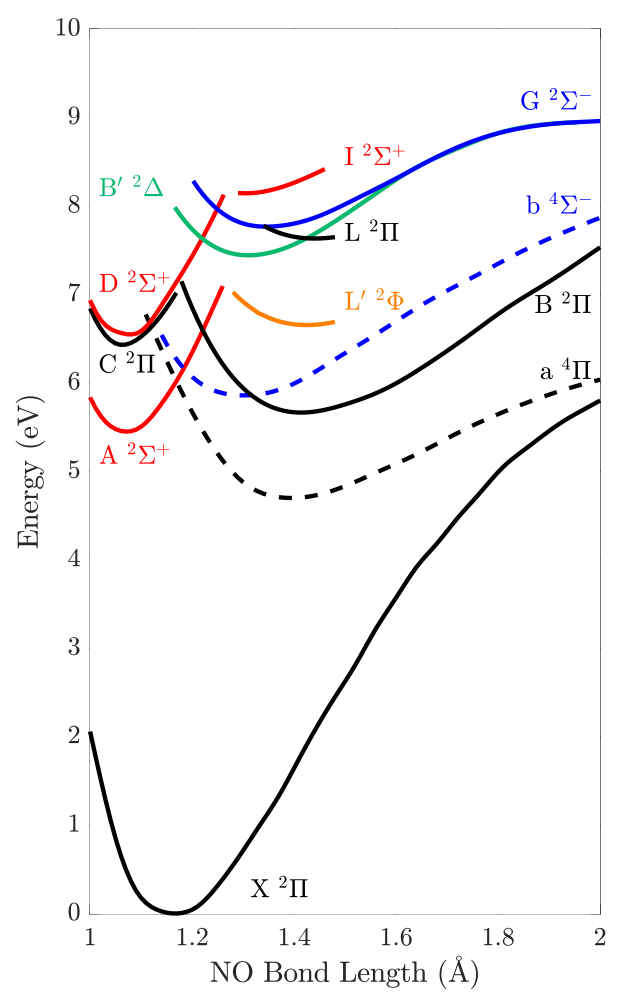

FIG. 1. low-lying potential energy curves for NO.

(i.e. with a perpendicular magnetic field); at $0.03-10$ $\mathrm{eV}$ by Zecca et al. ${ }^{18}$, who used a linear configuration and the retarding-field analyzer with the energy resolution of some 30 - $50 \mathrm{meV}$; at $100-1400 \mathrm{eV}$ by Dalba et al. ${ }^{19} \mathrm{us}^{-}$ ing an enlarged versions of Ramsauer-type geometry; at 0.5 - $160 \mathrm{eV}$ by Szmytkowski and Maciag ${ }^{20}$ and at $0.4-$ $250 \mathrm{eV}$ by Szmytkowski et al. ${ }^{21}$ who used an electrostatic spectrometer with about $70 \mathrm{meV}$ energy resolution; and at $0.16-2 \mathrm{eV}$ by Alle et $a .^{22}$ with a time-of-flight spectrometer with the energy resolution better than $20 \mathrm{meV}$ at $0.5 \mathrm{eV}$. Above $2 \mathrm{eV}$ the matching between different sets of data ${ }^{18-21}$ is good, within $5 \%$. A resonant structure in TCS below $2 \mathrm{eV}$ was first measured by Zecca et al. ${ }^{18}$ and confirmed by Szmytkowski and Maciag ${ }^{20}$. Measurements of Alle $e t a l{ }^{22}$ showed a deep structure, with TCS varying from $16.9 \times 10^{-16} \mathrm{~cm}^{2}$ (at $0.296 \mathrm{eV}$ ) to $7.3 \times 10^{-16} \mathrm{~cm}^{2}$ at $0.348 \mathrm{eV}$, see Fig. 2. The resonant structure was earlier observed in vibrational excitation functions and energy loss spectra and was identified as due to capturing of the incoming electron into ${ }^{3} \Sigma^{-}$and ${ }^{1} \Delta$ states of the $\mathrm{NO}^{-}$ temporary anion.

Allan et al. ${ }^{23,24}$ measured differential cross sections at fixed angles $\left(135^{\circ}\right)$ in the energy range $0.05-2 \mathrm{eV}$ using a hemispherical spectrometer with $7 \mathrm{meV}$ energy resolution. These measurements resolved transitions between the two fine structure-split ${ }^{2} \Pi_{1 / 2}$ and ${ }^{2} \Pi_{3 / 2}$ states (separated by $15 \mathrm{meV}$ ), which occur via the resonant states. The measured cross sections show sharp peaks that for the interchange of the ${ }^{2} \Pi_{1 / 2}$ and ${ }^{2} \Pi_{3 / 2}$ states are within the energy resolution of the apparatus. Position of these peaks correspond to the vibrational progressions of the ${ }^{3} \Sigma^{-}$and ${ }^{1} \Delta \mathrm{NO}^{-}$states. It turned out the cross sections for collisions interchanging the ${ }^{2} \Pi_{1 / 2}$ and ${ }^{2} \Pi_{3 / 2}$ states (both inelastic ${ }^{2} \Pi_{1 / 2} \rightarrow^{2} \Pi_{3 / 2}$ and super-elastic $\left.{ }^{2} \Pi_{3 / 2} \rightarrow^{2} \Pi_{1 / 2}\right)$ are of the same magnitude (in their resonant maxima) as elastic collisions, say of $1.3 \times 10^{-16} \mathrm{~cm}^{2} / \mathrm{sr}$ at $0.28-0.3 \mathrm{eV}$, see Fig. 3 in Allan et $a .^{24}$. Outside the resonant peaks, the measured elastic differential cross section (at $135^{\circ}$ ) is half of the value at the maximum. These values validate in a rough estimate (if multiplying the differential cross section by $4 \pi$ ) the TCS of Alle et al. ${ }^{22}$, within combined errors of the two experiments. Also the width of the resonant peaks in TCS are compatible with the $15 \mathrm{meV}$ splitting and the rotational broadening of the transitions. The TCS digitalized from Alle et al.'s letter ${ }^{22}$ are given in the supplementary material of this paper. Allan's measurements of vibrational excitations ${ }^{24}$ showed also that below 0.5 $\mathrm{eV}$ the main contribution to TCS comes from the spinorbit fine transitions, i.e. with as little as $15 \mathrm{meV}$ energy loss/gain. Therefore these transitions do not contribute significantly to the energy balance as measured in swarm experiments $^{25}$. At energies above $200 \mathrm{eV}$ the data of Dalba et $a .^{19}$ from Trento are the only ones available; they were obtained with a worse angular resolution than the series of subsequent measurements from that $\mathrm{Lab}^{26}$.

Therefore, the NO cross sections can be underestimated in their high-energy limit. In order to check it, in Fig. 3 we present the Bethe-Born (B-B) plot, where TCS in the high-energy range are approximated by a following formula

$$
\sigma(E)=A / E+B \log (E) / E
$$

Here, the energy is expressed in Rydbergs, Ry $=13.6$ $\mathrm{eV}$ and the cross sections is expressed in atomic units $a_{0}^{2}=0.28 \times 10^{-16} \mathrm{~cm}^{2}$. Parameters of the fit for $\mathrm{NO}$ 


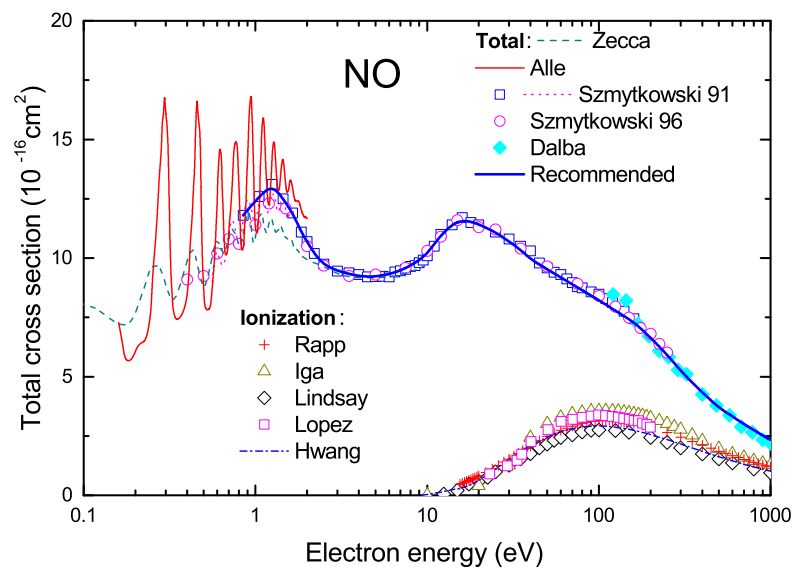

FIG. 2. Total cross sections for electron scattering from nitric oxide, NO. Experimental absolute TCS are from ref. ${ }^{20}-$ squares, from ref. ${ }^{21}$ - circles, from ref. ${ }^{22}$ - full curve. from ref. ${ }^{19}$ - full diamonds; normalized data from ref. ${ }^{18}$ - broken line and from ref. ${ }^{20}$ - dotted line. Thick line is present recommended TCS. Ionization integral cross section - experiments: Rapp and Englander-Golden ${ }^{28}$, Lindsay et al. ${ }^{29}$, Iga et al. ${ }^{30}$, Lopez et al. ${ }^{31}$; BEB model by Hwang et $a l .{ }^{32}$.

are $A=-90 \pm 10$ and $B=370 \pm 10$. Recommended values (see table II and Fig. 2) are essentially the same as in ref. $^{27}$ - above $2 \mathrm{eV}$ the mean values from Ref. ${ }^{18,20,21}$. Uncertainty of the recommended TCS at $2-500 \mathrm{eV}$ is $\pm 5 \%$. Recommended values above $500 \mathrm{eV}$, in Ref. ${ }^{27}$ based on data of Dalba et al. ${ }^{19}$, have been corrected upwards, to follow the B-B fit; the uncertainty is $\pm 10 \%$. Below 2 $\mathrm{eV}$ we recommend absolute values of Szmytkowski and Maciag $^{20}$ that are averaged over their different experimental runs, i.e. include some energy drift; therefore these points do not show the pronounced resonant structure. These averaged values agree with measurements of Brüche ${ }^{17}$ done with a coarse energy resolution (no vibrational structure was seen in total cross section in $\mathrm{N}_{2}$ either, when measured by Ramsauer's method). The uncertainty of recommended values in $\mathrm{NO}$ below $2 \mathrm{eV}$ is $\pm 15 \%$.

\section{B. Elastic Scattering Cross Section}

Mojarrabiet $a l .{ }^{37}$ reported the elastic differential cross section (DCS) of NO for the electron energy of 1.5-40 $\mathrm{eV}$ and for the angular range of $10^{\circ}-130^{\circ}$. This is the only available observed DCS for the NO molecule. The numerical values are tabulated and presented in Table III and Fig. 4, respectively. We recommend this result for the elastic DCS of NO. However, there has been some confusion concerning the NO integral cross section (ICS). Mojarrabi et al. ${ }^{37}$ reported the ICS as well as the DCS. Subsequently, Jelisavcic et $a l .{ }^{38}$ reported ICS for the electron energy range of $0.4-2.04 \mathrm{eV}$, which disagreed with the measurements of Mojarrabi et al. ${ }^{37}$ in overlapping energy region. Later, Brunger et al. ${ }^{39}$ discovered that

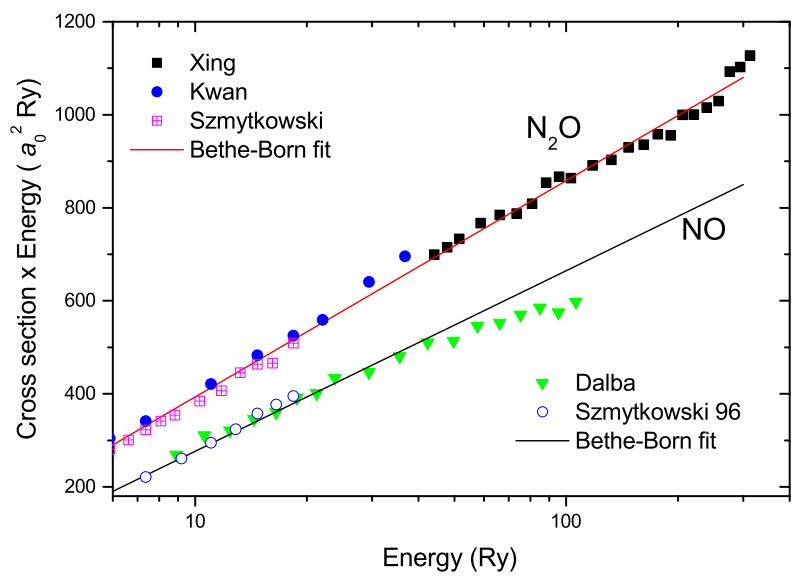

FIG. 3. Bethe-Born plot for TCS in NO and $\mathrm{N}_{2} \mathrm{O}$. Experimental TCS in NO are from ref. ${ }^{19,21}$; points above $500 \mathrm{eV}$ from ref. ${ }^{19}$ are subject to the angular resolution error and therefore were not included in the fit. Experimental TCS in $\mathrm{N}_{2} \mathrm{O}$ are from ref. ${ }^{33-35}$. A regression line for $\mathrm{NO}_{2}$ would coincide with that for $\mathrm{N}_{2} \mathrm{O}$, due to much poorer quality of data (measurements of Zecca et al. ${ }^{36}$ are underestimated above $1400 \mathrm{eV}$, similarly to those of Dalba et al.for NO).

TABLE II. Recommended TCS (in $10^{-16} \mathrm{~cm}^{2}$ ) for electron scattering on nitric oxide NO. In the region $2-200 \mathrm{eV}$, recommended values are based on experimental data ${ }^{18-21}$ in relative energy overlaps. Values at $600-1000 \mathrm{eV}$ are obtained from parameters of the Bethe-Born plot, see Fig. 2. The overall uncertainty of TCS is $\pm 5 \%$ at $2-500 \mathrm{eV}$ and $10 \%$ at higher energies. Below $2 \mathrm{eV}$ recommended values are based on absolute measurements by Szmytkowski and Maciag ${ }^{20}$, where the resonant structure was averaged; the uncertainty is $\pm 15 \%$. The energy determination is $0.1 \mathrm{eV}$ up to $10 \mathrm{eV}$, rising to 2 $\mathrm{eV}$ at $1000 \mathrm{eV}$.

\begin{tabular}{cccccc}
\hline $\begin{array}{c}\text { Electron } \\
\text { energy }\end{array}$ & $\begin{array}{c}\text { TCS } \\
\text { Electron } \\
\text { energy }\end{array}$ & $\begin{array}{c}\text { TCS } \\
\text { Electron } \\
\text { energy }\end{array}$ \\
\hline \hline 0.85 & 11.8 & 9 & 9.92 & 120 & 7.86 \\
1.05 & 12.6 & 10 & 10.2 & 150 & 7.44 \\
1.25 & 13.1 & 12 & 11.0 & 170 & 7.13 \\
1.45 & 12.5 & 15 & 11.5 & 200 & 6.64 \\
1.65 & 11.9 & 17 & 11.6 & 250 & 5.93 \\
1.85 & 11.1 & 20 & 11.4 & 300 & 5.25 \\
2.0 & 10.7 & 25 & 11.1 & 350 & 4.75 \\
2.2 & 10.2 & 30 & 10.7 & 400 & 4.34 \\
2.5 & 9.70 & 35 & 10.3 & 450 & 4.00 \\
3.0 & 9.47 & 40 & 9.97 & 500 & 3.70 \\
3.5 & 9.32 & 45 & 9.73 & 600 & 3.32 \\
4.0 & 9.25 & 50 & 9.53 & 700 & 3.00 \\
4.5 & 9.22 & 60 & 9.18 & 800 & 2.75 \\
5.0 & 9.23 & 70 & 8.89 & 900 & 2.52 \\
6.0 & 9.32 & 80 & 8.64 & 1000 & 2.34 \\
7.0 & 9.48 & 90 & 8.42 & & \\
8.0 & 9.68 & 100 & 8.22 & & \\
\hline \hline
\end{tabular}

there had been an error made by Mojarrabi et al. in integrating their elastic DCS, and reported a revised set of ICS. Fujimoto and Lee ${ }^{40}$ calculated the ICS for higher electron energies in the range $5-500 \mathrm{eV}$, using a complex 
optical potential consisting of static, exchange, correlation-polarization plus absorption contributions. Their result is in good agreement with the corrected result of Mojarrabi et al. Combining these two ICS sets, Itikawa ${ }^{16}$ recommended the elastic ICS by joining them in the region of around $40-50 \mathrm{eV}$, and estimated the uncertainty to be $25 \%$. The recommended ICS is given in Table IV and Fig. 5. For a more detailed discussions see Itikawa $^{16}$.

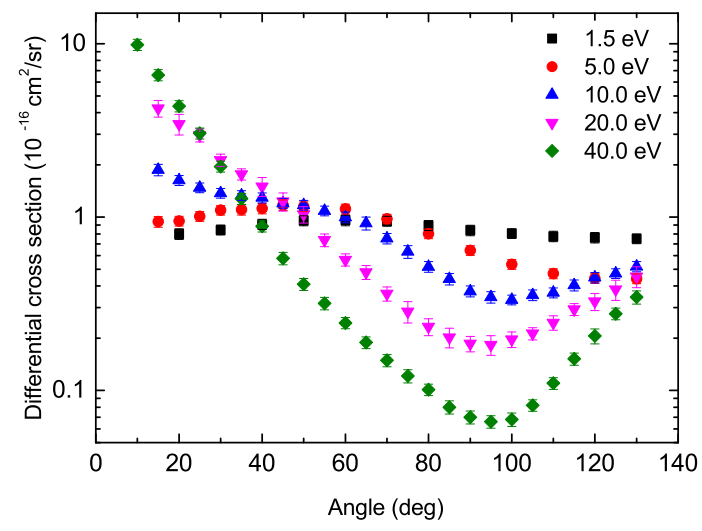

FIG. 4. Recommended elastic DCS for NO at five selected energies

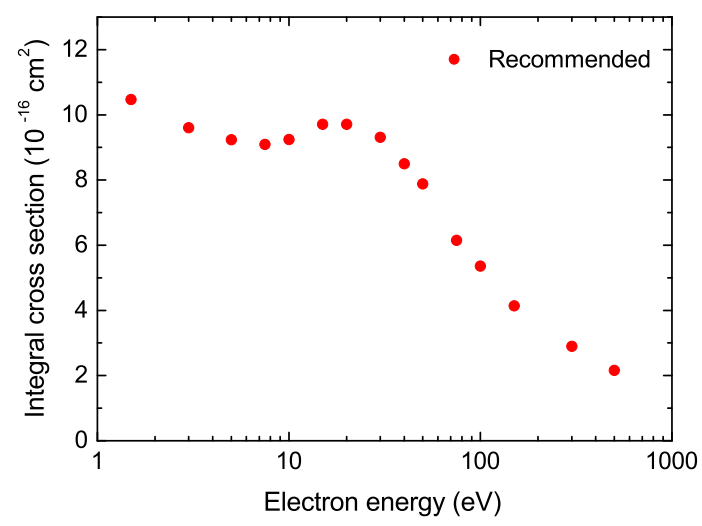

FIG. 5. Recommended elastic ICS for NO

\section{Momentum Transfer Cross Section}

Itikawa $^{41}$ and Phelps $^{42}$ reported momentum transfer cross section for the NO molecule, but both explained data were uncertain and were subject to revisions. Takeuchi and Nakamura ${ }^{43}$ also reported an elastic momentum transfer cross section determined from their electron swarm data measured in pure $\mathrm{NO}$ and $\mathrm{NO}-\mathrm{Ar}$ mixtures, but they were not aware of the resonant character of the cross section in low energy range and also failed to take into account the two sub-states of the electronic ground state of NO.

As explained in the preceding section, Mojarrabi et $a l .{ }^{37}$ measured absolute elastic DCS and also reported momentum transfer cross section as well as the integral elastic cross section and the latter data were later corrected by Brunger et al. ${ }^{39}$ The situation for the momentum transfer cross section of Mojarrabi et al. also seems very much the same as in the integral elastic cross section, and, therefore, their elastic DCSs are extrapolated to $0^{\circ}$ and $180^{\circ}$ in the manner that the resultant ICS agrees with their corrected ICS within about $2 \%$ or less and an MTCS is estimated here. Fujimoto and Lee ${ }^{40}$ also reported theoretical elastic MTCSs for the energy range 5 - $500 \mathrm{eV}$. The latter two MTCSs differ between 15 and 20 $\mathrm{eV}$ reflecting difference in DCSs at higher scattering angles $\left(\geq 100^{\circ}\right)$ as seen in Figs. 2(b) and 3(a) of Fujimoto and $\mathrm{Lee}^{40}$.

One of the present authors (YN) reviewed all electron swarm data measured by Takeuchi and Nakamura ${ }^{43}$ (see Appendix) and determined a new set of electron collision cross sections from the revised swarm data with the help of resonant character of cross sections measured by high resolution electron beam experiments ${ }^{24,38}$. The elastic MTCS is determined mainly from swarm data measured in pure NO with using the vibrational excitation cross sections for NO (see Section II F below) determined from swarm data measured in dilute NO-Ar mixtures almost independently of the elastic momentum transfer of NO. Because of the limited $\mathrm{E} / \mathrm{N}$ range of swarm data in pure NO, the highest energy range of the derived MTCS is limited to about $40 \mathrm{eV}$. The swarm-derived elastic MTCS is shown in Fig. 6 as recommended. It merges smoothly into the theoretical one at $40-50 \mathrm{eV}$ and shows the shape resonance peak at $22 \mathrm{eV}$ with magnitude comparable to the theory. The electron swarm method is incompetent at determining the details of the resonance structure in lower energy range $0.1-2 \mathrm{eV}$ in principle and must depend heavily on electron beam methods and theoretical calculations: the method can only adjust the magnitude of peaks and bottoms in certain energy range by watching the electron energy distribution function and swarm parameters simultaneously. The result is compared with Allan's DCS multiplied by $4 \pi$ in Fig. 6 . NO is polar and its elastic momentum transfer cross section increases as decreasing the incident electron energy decreases. Itikawa ${ }^{41}$ and Phelps ${ }^{42}$ reported larger momentum cross sections at low energy which presumably include equivalent rotational excitation cross sections (See Section IID).

\section{Rotational Excitation Cross Sections}

As Itikawa ${ }^{16}$ stated in his most recent review, there is no theoretical or experimental study on rotational excitation cross sections for NO. Rotational excitation and deexcitation, however, are most effective collision processes for thermalization of slow electrons in gases through the long range interaction between electrons and molecular multipoles. The interaction is weak and the Born approximation is often employed to calculate the rotational cross sections at this low energies ${ }^{44}$. Rotational excitation and 
TABLE III. Recommended elastic DCS for NO. DCS's and uncertainties $(\delta)$ are in the units of $10^{-16} \mathrm{~cm}^{2} \mathrm{sr}^{-1}$.

\begin{tabular}{|c|c|c|c|c|c|c|c|c|c|c|c|c|c|c|c|c|c|c|}
\hline \multirow{2}{*}{$\begin{array}{c}\text { Angle } \\
\text { (deg) }\end{array}$} & \multicolumn{2}{|c|}{$\overline{1.5 \mathrm{eV}}$} & \multicolumn{2}{|c|}{$3.0 \mathrm{eV}$} & \multicolumn{2}{|c|}{$5.0 \mathrm{eV}$} & \multicolumn{2}{|c|}{$7.5 \mathrm{eV}$} & \multicolumn{2}{|c|}{$10.0 \mathrm{eV}$} & \multicolumn{2}{|c|}{$15.0 \mathrm{eV}$} & \multicolumn{2}{|c|}{$20.0 \mathrm{eV}$} & \multicolumn{2}{|c|}{$30.0 \mathrm{eV}$} & \multicolumn{2}{|c|}{$40.0 \mathrm{eV}$} \\
\hline & DCS & $\delta$ & DCS & $\delta$ & DCS & $\delta$ & DCS & $\delta$ & DCS & $\delta$ & DCS & $\delta$ & DCS & $\delta$ & DCS & $\delta$ & DCS & $\delta$ \\
\hline 10 & & & & & & & & & & & & & & & 9.874 & 0.741 & & \\
\hline 15 & & & 812 & 056 & 941 & 067 & 1.330 & .089 & 870 & 0.142 & .600 & 0.248 & .236 & 0.470 & 6.484 & 0.674 & 594 & 0.488 \\
\hline 20 & 0.799 & 0.057 & 0.850 & 0.055 & 0.949 & 0.062 & 234 & 33 & 1.629 & 0.109 & .907 & 0.282 & .444 & 0.468 & 4.490 & 0.489 & .364 & .319 \\
\hline 25 & & & 0.908 & .067 & 1.010 & 0.065 & 1.186 & 31 & 1.475 & 0.094 & 2.424 & 0.293 & .968 & 0.258 & 3.387 & 0.271 & .042 & .222 \\
\hline 30 & 0.843 & 0.056 & 0.942 & 0.069 & 1.095 & 0.070 & 1.202 & .079 & 1.375 & 0.088 & 1.922 & 0.185 & 2.132 & 0.171 & 2.290 & 0.195 & 1.958 & 0.143 \\
\hline 35 & & & 0.993 & 0.065 & 1.104 & 0.076 & 1.209 & 0.077 & 1.333 & 0.087 & 1.639 & 0.118 & 1.764 & 0.131 & 1.671 & 0.160 & 1.275 & 0.093 \\
\hline 40 & 0.910 & 0.062 & 1.028 & 0.066 & 1.121 & 0.077 & 1.221 & 0.087 & 1.292 & 0.084 & 1.409 & 0.094 & 1.502 & 0.188 & 1.323 & 0.147 & 0.885 & 0.066 \\
\hline 45 & & & 1.056 & 0.072 & 1.174 & 0.083 & 1.193 & 0.078 & 1.200 & 0.082 & 1.264 & 0.096 & 1.231 & 0.148 & 0.987 & 0.106 & 0.578 & 0.048 \\
\hline 50 & 0.955 & 0.063 & 1.081 & 0.071 & 1.148 & 0.074 & 1.207 & 0.082 & 1.172 & 0.076 & 1.109 & 0.095 & 1.036 & 0.112 & 0.739 & 0.112 & 0.410 & 0.033 \\
\hline 55 & & & 1.064 & 0.070 & & & 1.130 & 0.074 & 1.086 & 0.070 & 0.910 & 0.085 & 0.737 & 0.063 & 0.576 & 0.079 & 0.318 & 0.026 \\
\hline 60 & 0.960 & 0.068 & 1.074 & 0.073 & 1.114 & 0.072 & 1.067 & 0.070 & 0.996 & 0.071 & 0.739 & 0.062 & 0.567 & 0.045 & 0.417 & 0.046 & 0.245 & 0.018 \\
\hline 65 & & & 1.054 & 0.068 & & & & & 0.920 & 0.078 & 0.622 & 0.042 & 0.481 & 0.044 & 0.296 & 0.043 & 0.189 & 0.015 \\
\hline 70 & 0. & 0.063 & 1.004 & 0.066 & 6 & 63 & 73 & 59 & 0.752 & 0.052 & 0.529 & 0.034 & 0.361 & 0.034 & 0.249 & 0.040 & 0.149 & 0.012 \\
\hline 75 & & & 0.928 & 0.061 & & & & & 0.631 & 0.052 & 0.428 & 0.039 & 0.285 & 0.040 & 0.193 & 0.029 & 0.121 & 0.011 \\
\hline 80 & 0.895 & 0.059 & 0.864 & 0.058 & 0.802 & 0.052 & 0.647 & 0.045 & 0.517 & 0.037 & 0.343 & 0.039 & 0.233 & 0.026 & 0.157 & 0.031 & 0.101 & 0.008 \\
\hline 85 & & & 0.810 & 0.054 & & & & & 0.439 & 0.033 & 0.284 & 0.022 & 0.202 & 0.026 & 0.148 & 0.026 & 0.080 & 0.007 \\
\hline 90 & 0.838 & 0.058 & 0.742 & 0.057 & 0.642 & 0.042 & 0.496 & 0.033 & 0.373 & 0.027 & 0.278 & 0.021 & 0.186 & 0.019 & 0.138 & 0.017 & 0.070 & 0.006 \\
\hline 95 & & & 0.696 & 0.052 & & & & & 0.345 & 0.026 & 0.274 & 0.021 & 0.183 & 0.024 & 0.137 & 0.021 & 0.066 & 0.005 \\
\hline 100 & 0.805 & 0.052 & 0.622 & 0.042 & 0.534 & 0.034 & 0.409 & 0.027 & 0.333 & 0.021 & 0.305 & 0.023 & 0.197 & 0.021 & 0.136 & 0.017 & 0.068 & 0.006 \\
\hline 105 & & & 0.625 & 0.044 & & & & & 0.355 & 0.025 & 0.326 & 0.025 & 0.213 & 0.017 & 0.166 & 0.021 & 0.082 & 0.006 \\
\hline 110 & 0.774 & 0.053 & 0.597 & 0.045 & 0.472 & 0.031 & 0.395 & 0.025 & 0.366 & 0.025 & 0.382 & 0.025 & 0.246 & 0.024 & 0.206 & 0.021 & 0.110 & 0.009 \\
\hline 115 & & & 0.568 & 0.043 & & & & & 0.404 & 0.029 & 0.436 & 0.041 & 0.294 & 0.023 & 0.262 & 0.028 & 0.152 & 0.012 \\
\hline 120 & 0.761 & 0.053 & 0.538 & 0.034 & 0.443 & 0.028 & 0.421 & 0.027 & 0.448 & 0.031 & 0.472 & 0.035 & 0.326 & 0.037 & 0.315 & 0.058 & 0.206 & 0.020 \\
\hline 125 & & & 0.526 & 0.036 & & & & & 0.473 & 0.030 & 0.511 & 0.043 & 0.382 & 0.051 & 0.417 & 0.064 & 0.277 & 0.021 \\
\hline 130 & 0.750 & 0.049 & 0.517 & 0.035 & 0.441 & 0.029 & 0.470 & 0.031 & 0.519 & 0.035 & 0.536 & 0.040 & 0.454 & 0.062 & 0.498 & 0.093 & 0.345 & 0.030 \\
\hline
\end{tabular}

TABLE IV. Recommended elastic ICS for NO in the units of $10^{-16} \mathrm{~cm}^{2}$. Energy in $\mathrm{eV}$.

\begin{tabular}{cl}
\hline Energy & ICS \\
\hline 1.5 & 10.47 \\
3.0 & 9.604 \\
5.0 & 9.239 \\
7.5 & 9.095 \\
10 & 9.241 \\
15 & 9.714 \\
20 & 9.707 \\
30 & 9.314 \\
40 & 8.500 \\
50 & 7.880 \\
75 & 6.150 \\
100 & 5.360 \\
150 & 4.140 \\
300 & 2.900 \\
500 & 2.160 \\
\hline
\end{tabular}

de-excitation cross sections given by Takayanagi ${ }^{45}$ based on the Born approximation are used with the dipole moment of $\mathrm{NO}\left(0.158 \mathrm{D}^{46}\right)$ as the starting data for the present two-term Boltzmann equation analysis. The assumed gas temperature is $300 \mathrm{~K}$. The energy difference of the two sub states, $\Omega=1 / 2$ and $3 / 2$, of $\mathrm{NO}$ is only 15 $\mathrm{meV}$, and at $300 \mathrm{~K}$ the two states coexist in the gas with the ratio of the thermal population $\frac{n_{1 / 2}}{n_{3 / 2}}=\frac{0.64}{0.36}$. Rotational excitation and de-excitation cross sections for $J$ up to $\Omega+30$ were included in the Boltzmann calculation. The electron drift velocity in pure NO was measured by Takeuchi and Nakamura ${ }^{47}$ over the $E / N$ range $0.4-500$ Td ( $E$ and $N$ are the electric field strength and the gas number density and $\left.E / N=1 \mathrm{Td}=1 \times 10^{-17} \mathrm{Vcm}^{2}\right)$. The measured drift velocity changes rather monotonously with $E / N$ on log-log scale over the entire $E / N$ range and the calculated one with using the Takayanagi's rotational excitation and de-excitation cross sections, on the other hand, breaks into a straight line of slope 1 at about $E / N=0.8 \mathrm{Td}$ as decreasing $E / N$. The scaling factor of 0.3 or smaller is actually required in order to place the break to $E / N$ lower than $0.4 \mathrm{Td}$. With the scaling factor of 0.3 , sum of 122 rotational cross sections, excitation and de-excitation, amounts to $8.6 \times 10^{-16} \mathrm{~cm}^{2}$ at electron energy $0.01 \mathrm{eV}$. Examples of the rotational excitation and de-excitation cross sections for the states

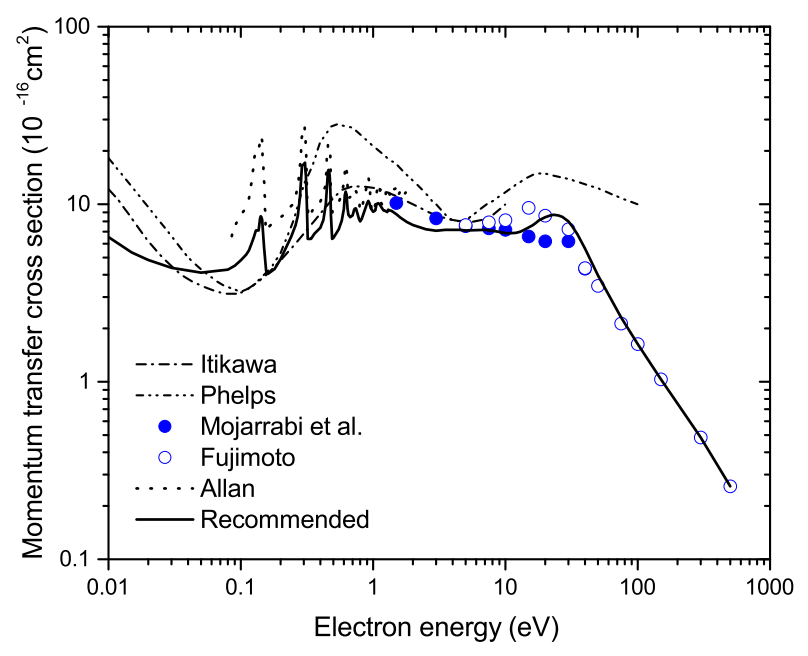

FIG. 6. Momentum transfer cross section of NO. Dashed and single dotted line, Itikawa ${ }^{41}$; dashed and double dotted line, Phelps ${ }^{42}$; Solid circle, Mojarrabi et al. ${ }^{37}$; open circle, Fujimoto and Lee ${ }^{40}$; dotted line, Allan ${ }^{24}$ 's DCS times $4 \pi$; and solid line, recommended. 
corresponding to the maximum of the Boltzmann factor for $300 \mathrm{~K}$, multiplied by the scaling factor 0.3 , are shown in Fig. 7. Open and full circles, respectively, show deexcitation and excitation cross sections, and black and colored symbols show $\Omega$ is $1 / 2$ and $3 / 2$, respectively.

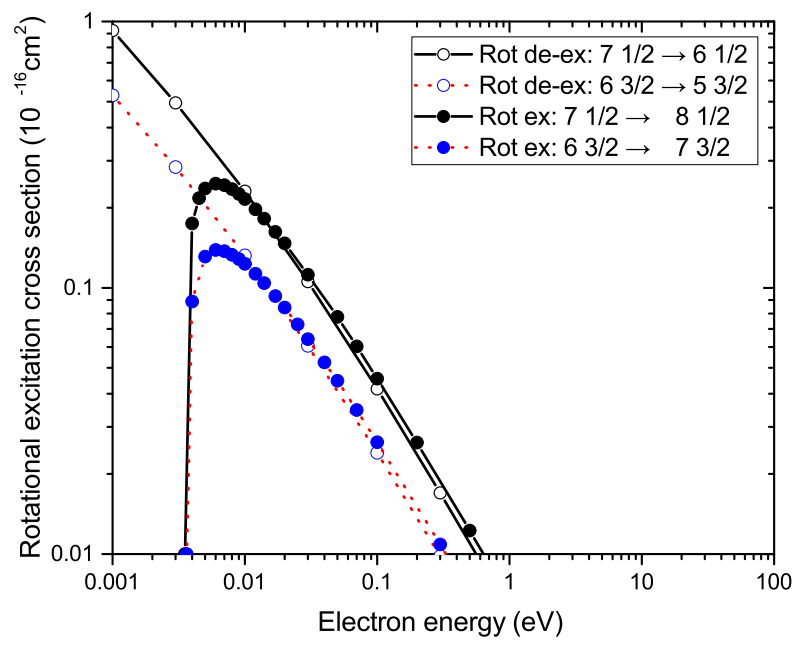

FIG. 7. An example set of rotatonal excitation and deexcitation cross sections at $300 \mathrm{~K}$. Open and full circles, respectively, show de-excitation cross section and excitation cross section. Black and colored symbols show $\Omega=1 / 2$ and $3 / 2$, respectively.

\section{E. Spin-orbit transition cross sections}

As mentioned in the preceding section the ${ }^{2} \Pi$ ground electronic term of NO is split into two sub-states. Their energy difference is only $15 \mathrm{meV}$ and their interactions with free electrons had not been studied until Allan ${ }^{23}$ measured the electron impact cross section for the transition between them for the first time. $\operatorname{Allan}^{24}$ also measured the absolute differential scattering cross section (see section $\mathrm{B}$ ) and absolute differential inelastic $\left({ }^{2} \Pi_{1 / 2} \rightarrow{ }^{2} \Pi_{3 / 2}\right)$ and super-elastic $\left({ }^{2} \Pi_{3 / 2} \rightarrow{ }^{2} \Pi_{1 / 2}\right)$ cross sections at the scattering angle $135^{\circ}$. Scattering is predominantly of resonant character but the magnitude of the resonance peaks is almost the same as vibrational resonance, although the energy loss/gain $(0.015 \mathrm{eV})$ per collision is more than an order of magnitude smaller. Assuming that both inelastic and super-elastic scattering are isotropic and the NO gas consists of the two ground electronic states at thermal equilibrium at $300 \mathrm{~K}$, the equivalent set of cross sections for the spin-orbit transitions can be constructed from his experimental DCSs with scaling factors of 0.8 and 0.6 for inelastic and superelastic scattering, respectively, as shown in Fig. 8, and this set of cross sections is confirmed to be consistent with experimental electron swarm parameters in $\mathrm{NO}^{43}$ in the $E / N$ range $1-10 \mathrm{Td}$ through the Boltzmann equation analysis.

\section{F. Vibrational Excitation Cross Sections}

Mojarrabi et al. ${ }^{37}$ measured absolute differential cross sections for vibrational $(0 \rightarrow 1,2,3,4)$ excitation of the NO ground electronic state and determined integral vibrational $(0 \rightarrow 1,2)$ cross sections in the energy range $7.5-40 \mathrm{eV}$. Allan ${ }^{23}$ measured detailed structure of vibrational excitation DCSs at the scattering angle $135^{\circ}$ with high energy-resolution apparatus. Campbell et al. ${ }^{48}$ constructed a set of vibrational excitation cross sections from the experimental results of Mojarrabi et $a l .{ }^{37}$ and Jelisavcic et $a .^{38}$ and also from a swarm study of Josić et al. ${ }^{25}$ The numerical data of the set can be downloaded from the Flinders database at the website LXCat (www.lxcat.net) ${ }^{49}$. Itikawa ${ }^{16}$ recommended this set of cross sections for vibrational excitations of NO molecules. The vibrational excitation cross section data of the Flinders database were also used to re-analyze electron swarm data for NO-Ar mixtures and the analysis revealed that the set of the Flinders database were needed a constant scale factor of 2 for crude agreement with experimental results in the two NO-Ar mixtures. ${ }^{47}$ In the course of electron swarm analysis explained in Section $\mathrm{C}$ a set of vibrational excitation cross sections consistent with measured swarm data in pure $\mathrm{NO}$ and NO-Ar mixtures. ${ }^{47}$ was also derived. The results for the vibrational excitations $(0 \rightarrow 1,2,3)$ are shown in Figure 9 . Enhancement in energy range $1-2 \mathrm{eV}$ is needed to reproduce the prominent maximum of the electron drift velocity in the $4.99 \%$ NO-Ar mixture, and steep decrease of the cross sections in the energy range $2-3 \mathrm{eV}$ and the following deep minimum $\left(<10^{-18} \mathrm{~cm}^{2}\right)$ up to about 7 $\mathrm{eV}$ are necessary for the noticeable peak structure observed in the longitudinal diffusion coefficient of electrons normalized to the gas number density, $\mathrm{ND}_{L}$, in NO-Ar mixtures (see Appendix). The present recommendation

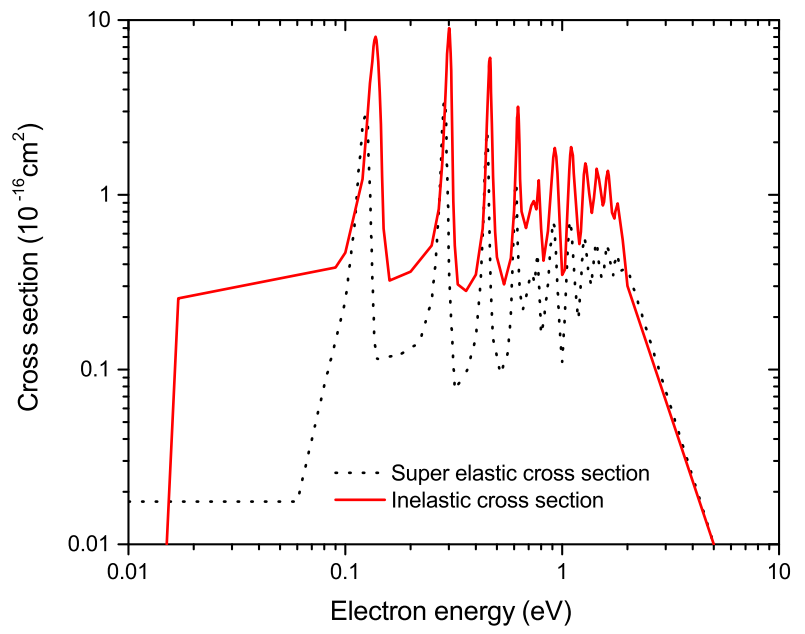

FIG. 8. Spin-orbit transition cross sections of NO at $300 \mathrm{~K}$. Solid line, inelastic cross section; dotted line, super-elastic cross section. 
includes resonance reported by Mojarrabi et al. ${ }^{37}$ peaked at $15 \mathrm{eV}$, but no appreciable effect from the resonance was observed in electron swarm parameters because of the overwhelming electronic excitation cross sections of NO in the overlapping energy range.
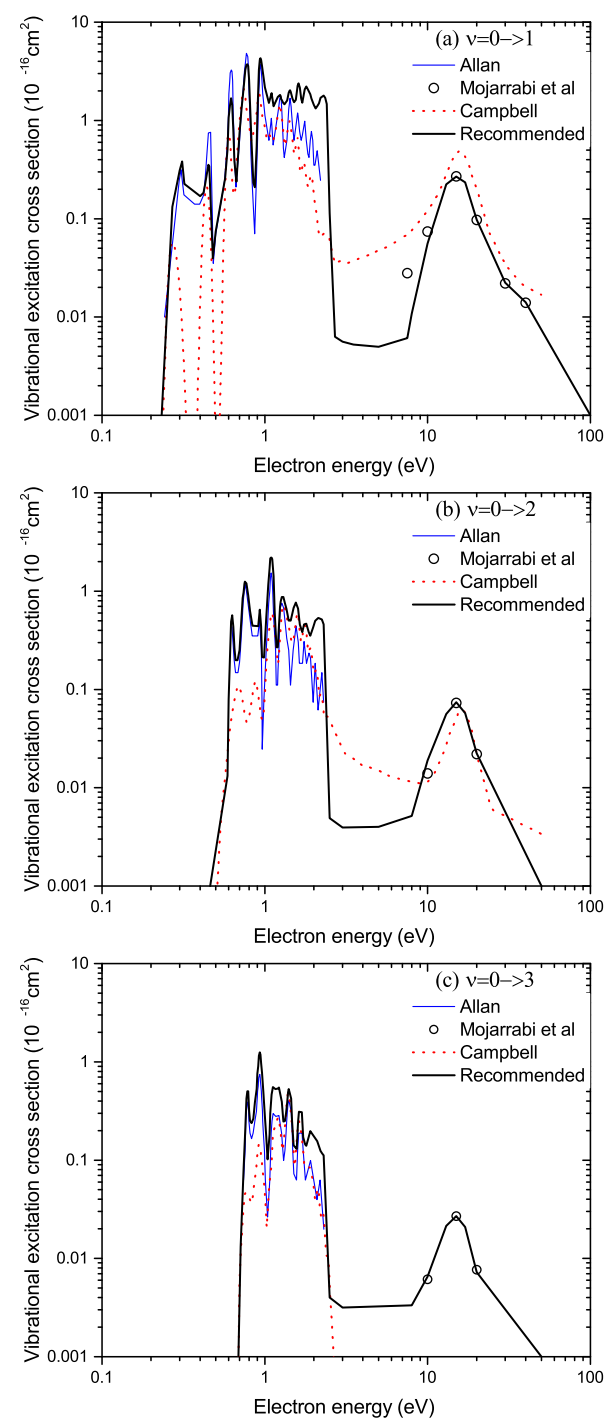

FIG. 9. Vibrational excitation cross sections for NO. Open circle, Mojarrabi et al. ${ }^{37}$; blue line, Allan'2 DCS times $4 \pi$ red dotted line, Campbell et al. ${ }^{48}$; Solid line, recommended.

\section{G. Electronic Excitation Cross Section}

Few measurements of electronic excitation in nitrogen oxides are available. For NO the only complete set of differential $^{50}$ and integral ${ }^{51}$ was given by Brunger and collaborators. Energy loss spectra at zero scattering angle, that correspond to the photoabsorption cross sections (and indicate dipole-allowed electronic excitations) were studied for all three nitroxen oxides by Brion and collaborators $^{52}$. The photoabsorption cross sections in
NO shows a rich pattern of dipole-allowed transitions with vibronic progressions, see figure 10 .

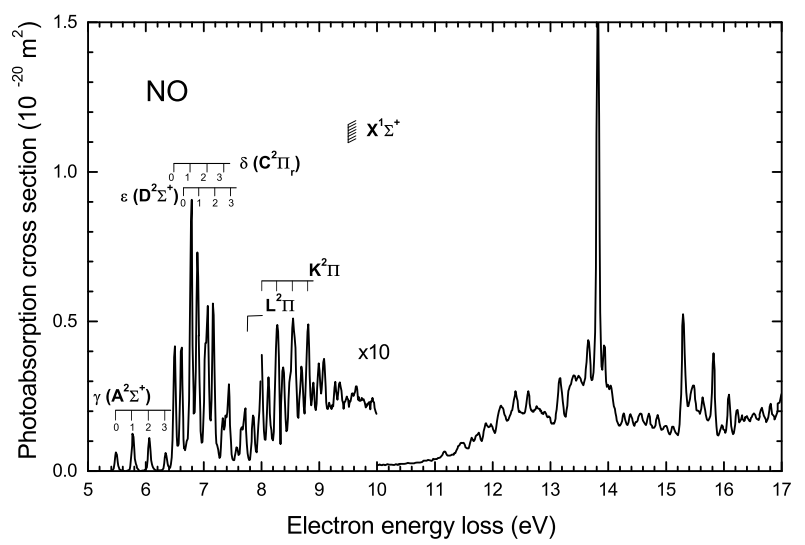

FIG. 10. Energy loss spectra in NO at $3000 \mathrm{eV}$ electron collision energy and 0 degree scattering angle, adapted from Ref. ${ }^{52}$

Electronic excitation in nitric oxide was measured by Brunger et al. ${ }^{50,51}$. In Ref. ${ }^{50}$ they reported differential cross sections obtained from energy loss measurements at $10-90^{\circ}$ scattering angles and $15,20,30,40,50 \mathrm{eV}$ collision energies. The energy resolution was $35-55 \mathrm{meV}$ (FWHM) and the spectra were recorded in the range 0.2 - $10 \mathrm{eV}$ of energy loss. Differential cross section (for the electronic excitations) were obtained via numerical procedures from the energy loss spectra; differential cross sections for elastic scattering from the same group ${ }^{37}$ were used for normalization. The estimated error was some $25 \%$ (from the uncertainty in the elastic DCSs of Mojarrabi et $a l .{ }^{37}$ and the analyzer response calibration) plus $5-100 \%$ uncertainty from the numerical deconvolution of the energy loss spectra.

Brunger et al. ${ }^{50}$ reported DCS for electron-impact excitation to the $\mathrm{A}^{2} \Sigma^{+}, \mathrm{E}^{2} \Sigma^{+}, \mathrm{S}^{2} \Sigma^{+}, \mathrm{C}^{2} \Pi_{r}, \mathrm{~K}^{2} \Pi, \mathrm{Q}^{2} \Pi$, $\mathrm{D}^{2} \Sigma^{+}, \mathrm{M}^{2} \Sigma^{+}, \mathrm{H}^{\prime}{ }^{2} \Pi, \mathrm{H}^{2} \Sigma^{+}, \mathrm{F}^{2} \Delta$ and $\mathrm{N}^{2} \Delta$ Rydberg electronic states, $\mathrm{O}^{\prime 2} \Pi+\mathrm{O}^{2} \Sigma^{+}, \mathrm{W}^{2} \Pi+\mathrm{Y}^{2} \Sigma^{+}, \mathrm{T}^{2} \Sigma^{+}$ $+\mathrm{U}^{2} \Delta+5 f$ and $\mathrm{Z}^{2} \Sigma^{+}+6 d \delta+6 f$ composite Rydberg electronic states, and a ${ }^{4} \Pi, \mathrm{b}^{4} \Sigma^{-}, \mathrm{B}^{2} \Pi, \mathrm{L}^{\prime}{ }^{2} \Phi, \mathrm{B}^{\prime}{ }^{2} \Delta$ and $L^{2} \Pi$ valence electronic states.

Differential cross sections for dipole-allowed (Rydberg) states are forward-peaked, while for the a ${ }^{4} \Pi$ and $b^{4} \Sigma^{-}$ states show maxima at $90^{\circ}$ scattering angle; the type of the $L^{\prime}{ }^{2} \Phi$ state it is unclear: for energies $20-50 \mathrm{eV}$ the DCS is forward peaked, while at $15 \mathrm{eV}$ resembles the DCS for dipole-forbidden states.

Experimental angular dependences ${ }^{50}$ for the $\mathrm{A}{ }^{2} \Sigma^{+}$, $\mathrm{C}^{2} \Pi_{r}, \mathrm{D}^{2} \Sigma^{+}$, generally agree in shape with the theory ${ }^{53}$, but absolute values of the experimental $\mathrm{DCS}^{50}$ are generally lower by a factor of two to three. Kato et al. ${ }^{54}$ measured at $100 \mathrm{eV} \mathrm{DCS}$ for the $\mathrm{A}^{2} \Sigma^{+}, \mathrm{C}^{2} \Pi_{r}, \mathrm{D}^{2} \Sigma^{+}$ at forward scattering angles $\left(4-16^{\circ}\right)$. Their DCS at $10^{\circ}$ are slightly $(15-20 \%)$ higher than DCS at the same angle and $50 \mathrm{eV}$ by Brunger et al. ${ }^{50}$.

Integral cross sections ${ }^{51}$ were obtained from the DCS ${ }^{50}$ 
TABLE V. Integral cross sections (in $10^{-19} \mathrm{~cm}^{2}$ units) for electron-impact excitation of the Rydberg and valence states of the nitric oxide, NO (from Ref. ${ }^{51}$ )

\begin{tabular}{|c|c|c|c|c|c|}
\hline $\begin{array}{l}\text { Rydberg } \\
\text { state }\end{array}$ & $\begin{array}{c}\text { energy } \\
15 \mathrm{eV}\end{array}$ & $\begin{array}{c}\text { energy } \\
20 \mathrm{eV}\end{array}$ & $\begin{array}{c}\text { energy } \\
30 \mathrm{eV}\end{array}$ & $\begin{array}{c}\text { energy } \\
40 \mathrm{eV}\end{array}$ & $\begin{array}{c}\text { energy } \\
50 \mathrm{eV}\end{array}$ \\
\hline$\overline{\mathrm{A}^{2} \Sigma^{+}}$ & 12.23 & 14.83 & 20.15 & 17.59 & 12.33 \\
\hline $\mathrm{E}^{2} \Sigma^{+}$ & 2.27 & 2.67 & 3.37 & 3.93 & 2.66 \\
\hline $\mathrm{S}^{2} \Sigma^{+}$ & 4.11 & 8.76 & 15.35 & 10.47 & 6.68 \\
\hline $\mathrm{C}^{2} \Pi_{r}$ & 23.10 & 32.74 & 41.32 & 46.77 & 32.69 \\
\hline $\mathrm{K}^{2} \Pi$ & 6.73 & 8.09 & 16.29 & 18.90 & 10.32 \\
\hline $\mathrm{Q}^{2} \Pi$ & 4.71 & 6.63 & 12.13 & 14.63 & 9.18 \\
\hline $\mathrm{D}^{2} \Sigma^{+}$ & 14.40 & 18.53 & 25.37 & 29.68 & 21.99 \\
\hline $\mathrm{M}^{2} \Sigma^{+}$ & 4.22 & 5.63 & 9.70 & 10.56 & 6.28 \\
\hline $\mathrm{H}^{\prime 2} \Pi$ & 4.22 & 5.89 & 6.92 & 9.32 & 5.90 \\
\hline $\mathrm{H}^{2} \Sigma^{+}$ & 5.75 & 8.70 & 13.80 & 13.67 & 8.38 \\
\hline $\mathrm{F}^{2} \Delta$ & 4.40 & 6.07 & 9.29 & 12.82 & 8.00 \\
\hline $\mathrm{N}^{2} \Delta$ & 2.55 & - & 5.30 & 5.84 & 5.64 \\
\hline $\mathrm{O}^{2} \Pi$ & 4.64 & 6.49 & 15.36 & 13.06 & 8.69 \\
\hline $\mathrm{W}^{2} \Pi$ & 9.43 & 13.40 & 22.70 & 21.74 & 13.36 \\
\hline $\mathrm{T}^{2} \Sigma^{+}$ & 1.53 & 2.31 & 4.72 & 4.34 & 1.74 \\
\hline $\mathrm{Z}^{2} \Sigma^{+}$ & 0.98 & 1.10 & 2.11 & 1.53 & 1.51 \\
\hline sum & 105.3 & 141.8 & 223.9 & 234.9 & 155.4 \\
\hline $\begin{array}{l}\text { Valence } \\
\text { state }\end{array}$ & $\begin{array}{l}\text { energy } \\
15 \mathrm{eV}\end{array}$ & $\begin{array}{l}\text { nergy } \\
20 \mathrm{eV}\end{array}$ & $\begin{array}{l}\text { energy } \\
30 \mathrm{eV}\end{array}$ & $\begin{array}{c}\text { energy } \\
40 \mathrm{eV}\end{array}$ & $\begin{array}{c}\text { energy } \\
50 \mathrm{eV}\end{array}$ \\
\hline $\mathrm{a}^{4} \Pi$ & $\overline{7.63}$ & 9.83 & $\overline{13.51}$ & $\overline{9.49}$ & 6.74 \\
\hline $\mathrm{b}^{4} \Sigma^{-}$ & 47.12 & 46.53 & 41.37 & 19.64 & 9.40 \\
\hline $\mathrm{B}^{2} \Pi$ & 11.86 & 14.99 & 21.26 & 14.66 & 12.39 \\
\hline $\mathrm{L}^{\prime 2} \Phi$ & 27.29 & 22.96 & 18.37 & 21.16 & 20.27 \\
\hline $\mathrm{B}^{\prime 2} \Delta$ & 32.45 & 65.26 & 84.19 & 57.76 & 21.58 \\
\hline $\mathrm{L}^{2} \Pi$ & 36.06 & 54.68 & 118.5 & 139.26 & 118.5 \\
\hline sum & 162.4 & 214.3 & 297.2 & 262.0 & 188.9 \\
\hline
\end{tabular}

by integration (and extrapolation to experimentally inaccessible angles). For Rydberg states the theoretical Born scattering amplitudes were used to extrapolate to $0^{\circ}$ scattering angle. For valence states three techniques were used: "by eye" procedure, polynomial fits and the molecular phase shift analysis.

Integral cross sections for the 16 Rydberg and 6 valence states at $15-50 \mathrm{eV}$ as obtained by Brunger et al. ${ }^{51}$ are givien by Table V. Declared errors on these data come both from uncertainties on DCS as well from extrapolation procedures; they vary from $30 \%$ for the strongest excitations to $60 \%$ for the lowest.

The sum of Rydberg states shows a maximum of $0.23 \times$ $10^{-16} \mathrm{~cm}^{2}$ at $40 \mathrm{eV}$ while for the valence states (including the $\mathrm{L}^{2} \Pi$ ) - a maximum of $0.3 \times 10^{-16} \mathrm{~cm}^{2}$ at 30 $\mathrm{eV}$. According to the experiment ${ }^{51}$ the electronic excitation into the 22 states studied would amount merely to $5 \%$ of the total cross section. In comparison, the difference between TCS and the sum of ionization and elastic cross sections is at $15-20 \mathrm{eV}$ some $2 \times 10^{-16} \mathrm{~cm}^{2}$. Experimental integral cross sections grouped by the type of excitation (Rydberg and valence) and the excitation energy are shown in Fig. 11. From this figure it is clear that excitations to the valence $\mathrm{a}^{4} \Pi$ and $\mathrm{b}^{4} \Sigma^{-}$(excitation thresholds $4.74 \mathrm{eV}$ and $5.72 \mathrm{eV}$, respectively) reach maximum at some $15-20 \mathrm{eV}$, to the valence $\mathrm{B}^{2} \Pi, \mathrm{L}^{\prime}{ }^{2} \Phi$ and $\mathrm{B}^{\prime 2} \Delta$ states $(5.64 \mathrm{eV}, 6.60 \mathrm{eV}$ and $7.44 \mathrm{eV}$ thresholds, respectively) reach maximum at $30 \mathrm{eV}$ and then drop rapidly with rising energy. Excitations to Rydberg states (and to the state identified as $\mathrm{L}^{2} \Pi$ ) reach maxima at $40 \mathrm{eV}$, see Fig. 11.

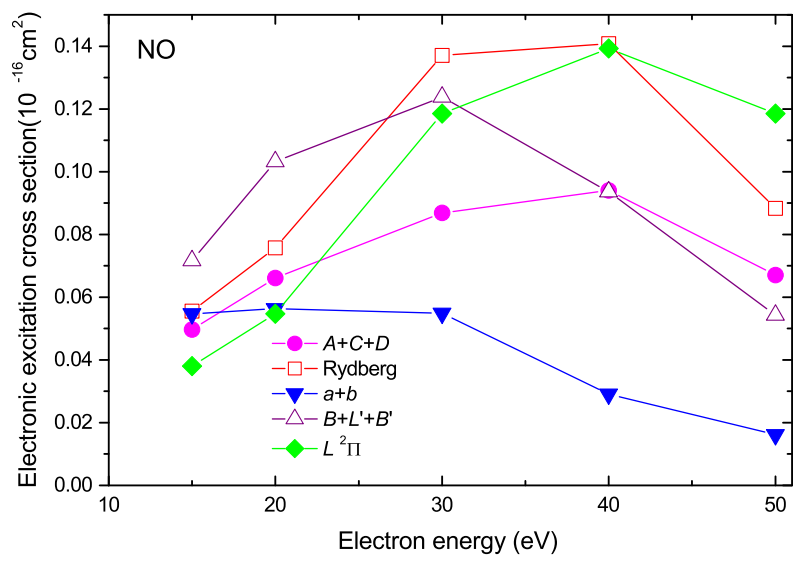

FIG. 11. Experimental ${ }^{51}$ integral cross sections for electronic excitation, grouped by the type of excitation and threshold energies. Rydberg states: circles, the sum of $\mathrm{A}^{2} \Sigma^{+}, \mathrm{C}^{2} \Pi$ and $\mathrm{D}^{2} \Sigma^{+}$states (threshold energies $5.64 \mathrm{eV}, 6.50 \mathrm{eV}, 6.61$ $\mathrm{eV}$, respectively); open squares, remaining 15 Rydberg and mixed states as measured by Brunger et al. ${ }^{51}$, starting from the $\mathrm{E}^{2} \Sigma^{+}$state (threshold $7.55 \mathrm{eV}$ ) up to the $\mathrm{Z}^{2} \Sigma^{+}$state (8.86 eV threshold). Valence states: inverted triangles, the sum of a ${ }^{4} \Pi$ and $b^{4} \Sigma^{-}$states (excitation thresholds $4.74 \mathrm{eV}$ and $5.72 \mathrm{eV}$, respectively); open triangles, the sum of valence $\mathrm{B}^{2} \Pi, \mathrm{L}^{\prime 2} \Phi$ and $\mathrm{B}^{\prime 2} \Delta$ states $(5.64 \mathrm{eV}, 6.60 \mathrm{eV}$ and $7.44 \mathrm{eV}$ thresholds); diamonds - the $\mathrm{L}^{2} \Pi$ state (7.76 eV threshold).

The agreement of Brunger et al.' $\mathrm{s}^{51}$ integral cross sections with the measurements of Skubenich et al. ${ }^{55}$ is rather poor, with discrepancies up to a factor of five. The optical emission from the $\mathrm{A}^{2} \Sigma^{+}$state was extensively studied by Schappe et al. ${ }^{56}$ up to $1000 \mathrm{eV}$ collision energy. To obtain absolute values they used normalization to the $\mathrm{N}_{2}$ emission. They concluded that despite the effects of cascades, the emission cross sections from vibronic levels are proportional to corresponding excitation cross sections. This observation yielded an absolute cross section for the excitation of the $\mathrm{A}^{2} \Sigma^{+}$state of $40 \times$ $10^{-19} \mathrm{~cm}^{2}$ at its maximum at $30 \mathrm{eV}$. This is a factor of two higher than the value reported by Brunger et al. ${ }^{51}$. Also the energy dependence measured by Schappe et al. differs from that from Ref. ${ }^{51}$, see Fig. 12.

$\mathrm{Xu}$ et $a .^{57}$ determined experimentally the generalized oscillator strength (GOS) at $1500 \mathrm{eV}$ collision energy for the $\mathrm{A}^{2} \Sigma^{+}, \mathrm{C}^{2} \Pi$ and $\mathrm{D}^{2} \Sigma^{+}$states, and performed a detailed analysis of the results obtained with other determinations (via electron scattering, photo-absorption, lifetime, calculations) giving the ranges of confidence. Using their GOS and Kim's ${ }^{58}$ Born Effective (BE) scaling model they obtained electron excitation cross sections from thresholds up to $2500 \mathrm{eV}$. For the $\mathrm{A}^{2} \Sigma^{+}$and $\mathrm{C}^{2} \Pi$ 
states the BE model agrees within experimental error bars with Brunger et al.'s measurements, see Fig. 12 for the $\mathrm{A}^{2} \Sigma^{+}$state. For the $\mathrm{D}^{2} \Sigma^{+}$state the experiment ${ }^{51}$ seems to be underestimated by a factor of 2. (Xu et al. corrected Brunger et al.'s data for vibronic populations, see their paper for details).

Olszewski and Zubek ${ }^{59}$ studied optical emission from the $\mathrm{A}^{2} \Sigma^{+}$state in the threshold region. They derived integral cross sections for excitations to the $\nu=0$ and $\nu=1$ vibronic states; threshold peaks are visible for both substates. Olszewski and Zubek, using the FranckCondon factors of Brunger et al. ${ }^{50}$, suggested that the integral cross section for the excitation of the $\mathrm{A}^{2} \Sigma^{+}$ state, as given by Brunger et al..$^{50}$, is underestimated by a factor of three at $15 \mathrm{eV}$. Note that measurements of Imami and Borst ${ }^{60}$ agree with the semi-empirical model of $\mathrm{Xu}^{57}$ giving a maximum of the emission cross section for the $\gamma$-band (i.e. the $\mathrm{A}^{2} \Sigma^{+}$) of $0.11 \times 10^{-16} \mathrm{~cm}^{2}$ at $19 \mathrm{eV}$.

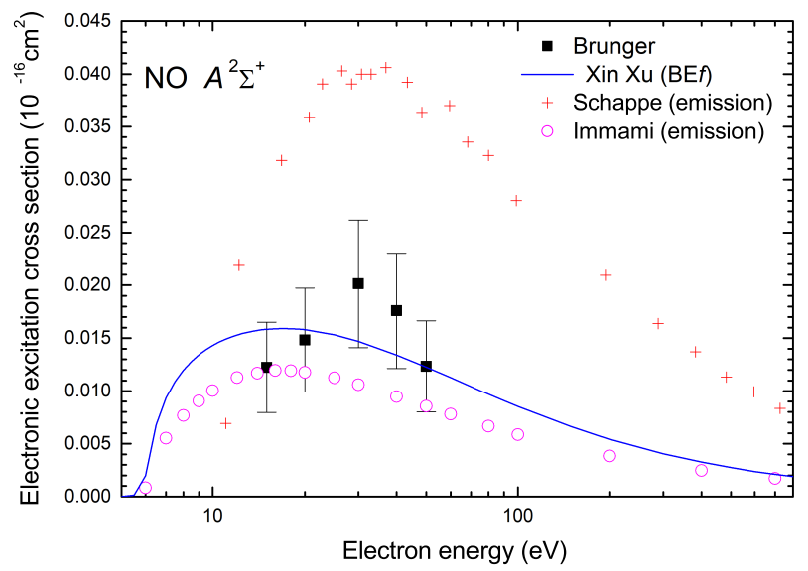

FIG. 12. Integral cross section for the excitation into $\mathrm{A}^{2} \Sigma^{+}$ state of nitric oxide NO. Squares, direct measurements of the electronic excitation via DCS from energy loss spectra ${ }^{51}$; circles, and crosses, optical emission ( $\gamma$-band) absolute cross sections calibrated to nitrogen emission cross sections ( 5 vibronic states $^{60}$ and 31 vibronic state $\left.{ }^{56}\right)$, respectively; line - Born effective-energy model (BE) with generalized optical strength directly measured. ${ }^{57}$

In conclusion, we recommend for the $A^{2} \Sigma^{+}, C^{2} \Pi$ and $D^{2} \Sigma^{+}$states the semi-empirical Born-scaled (BE) cross sections of $\mathrm{Xu}$ et al. ${ }^{57}$ see table VI. These three states cover only a part of possible electronic excitation, see the energy-loss spectra in Fig. 10. Therefore, the sum of the three states would underestimate the major energy loss of drifting electrons and overestimate ionizing events in modeling electron swarms in the gas. There is another assessment of the (total) cross section for electronic excitations using an electron swarm method. Most electronic excitation thresholds of atoms and molecules lie immediately below the ionization threshold and the electron energy losses through electronic excitations can effectively determine the overlap between the electron energy distribution function and the ionization cross section, namely, the threshold behavior of the primary ionization coefficient, one of basic parameters in gas discharge physics. The experimental procedures for the measurement of the parameter are well established and the claimed uncertainty of the primary ionization coefficient lies usually within a few percent range. Claimed uncertainty of experimental ionization cross section for atoms and molecules is also usually small. A trial-and-error procedure may be used to derive information about excitation cross sections from the primary ionization coefficient as a function of E/N. Electronic excitation thresholds of NO are substantially lower than those of argon atom and electron swarm parameters in NO-argon mixtures may also be used for that purpose (see Appendix). The resultant electronic excitation cross sections, however, should be understood as a whole only to provide realistic energy loss of electrons passing through the gas and, in fact, unique determination of individual cross sections will not be possible as long as there is no additional information. For the sum of all electronic excitation cross sections for NO we recommend values shown in Fig. 13 in order that all electron swarm data measured in pure $\mathrm{NO}$ and NO-Ar mixtures simultaneously. The present recommendation is compared with the sum of integral cross sections for 22 electronic excitations measured by Brunger et al. ${ }^{50}$ in the same figure. There is about a factor of five difference between them but the present magnitude around the peak is comparable with the difference between the present total cross section and the sum of present elastic and ionization cross sections.

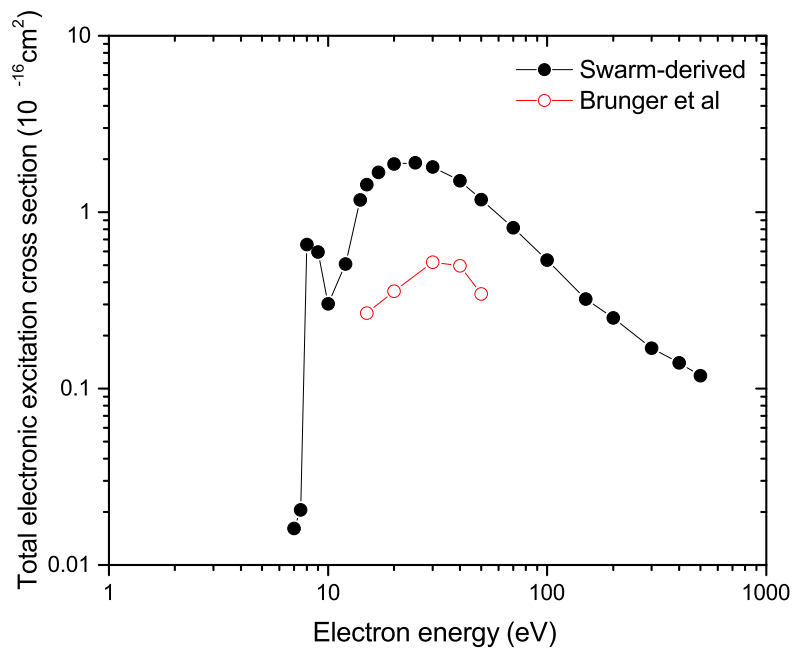

FIG. 13. The total cross section for electronic excitations. Solid circle, the present total electronic excitation cross section; open circle, the sum of 22 electronic excitation cross sections measured by Brunger et al. ${ }^{50}$ 


\section{H. Dissociation Cross Section}

Dissociation into neutral fragments was studied by LeClair et al. ${ }^{61}$ who identified two channels contributing to production of $\mathrm{O}\left({ }^{1} S\right)$, with the kinetic energy release of 3.4 and $7 \mathrm{eV}$, but no cross sections were given. VUV emission from atomic fragments was subject to numerous studies, but the agreement between different experiments is poor, see also Ref. ${ }^{62}$.

\section{Ionization Cross Section}

$\mathrm{NO}^{+}$ions are supposed to be responsible for a newly documented type of aurora ${ }^{63}$. Ionization in nitrogen oxides ( $\mathrm{NO}$ and $\mathrm{N}_{2} \mathrm{O}$ ) was already measured in the 1930s by Tate and $\mathrm{Smith}^{64}$, and in the 1960 s by Rapp and Englander-Golden ${ }^{28}$, and the latter results remain still of relevance. Rapp and collaborators used a simple geometry, with gas confined in a scattering cell (i.e. with a well determined length and gas pressure), collecting the total current of ions, i.e. measuring the so-called gross total ionization cross sections. The advantage of this method is simplicity and accuracy. A disadvantage is that multiply charged ions contribute to an overestimation of the probability for an atom/ molecule to be ionized (that is quantified by the counting ionization cross section), see a detailed discussion for $\mathrm{CH}_{4}$ by Song et al. ${ }^{1}$.

TABLE VI. Recommended cross sections for electronic excitation of NO into $\mathrm{A}^{2} \Sigma^{+}, \mathrm{C}^{2} \Pi$ and $\mathrm{D}^{2} \Sigma^{+}$states, from Born Effective scaling model ${ }^{57}$ in $10^{-18} \mathrm{~cm}^{2}$ units.

\begin{tabular}{|c|c|c|c|}
\hline 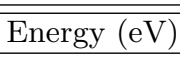 & $\mathrm{A}^{2} \Sigma^{+}\left(\nu^{\prime}=0-3\right)$ & $\mathrm{C}^{2} \Pi(\nu=0-3)^{a}$ & $\mathrm{D}^{2} \Sigma^{+}(\nu=0-3)^{b}$ \\
\hline 5.5 & 0.012 & 0 & 0 \\
\hline 6.0 & 0.196 & 0 & 0 \\
\hline 6.5 & 0.679 & 0.012 & 0 \\
\hline 7.0 & 0.934 & 0.591 & 0.352 \\
\hline 8.0 & 1.20 & 1.65 & 1.12 \\
\hline 9.0 & 1.34 & 1.97 & 1.59 \\
\hline 10 & 1.43 & 2.69 & 1.96 \\
\hline 12 & 1.53 & 3.31 & 2.51 \\
\hline 15 & 1.58 & 3.86 & 3.06 \\
\hline 20 & 1.58 & 4.28 & 3.56 \\
\hline 25 & 1.53 & 4.41 & 3.80 \\
\hline 30 & 1.47 & 4.39 & 3.89 \\
\hline 40 & 1.34 & 4.21 & 3.87 \\
\hline 50 & 1.23 & 3.97 & 3.75 \\
\hline 70 & 1.04 & 3.5 & 3.44 \\
\hline 100 & 0.853 & 2.96 & 3.01 \\
\hline 150 & 0.660 & 2.35 & 2.49 \\
\hline 200 & 0.542 & 1.96 & 2.13 \\
\hline 300 & 0.404 & 1.49 & 1.67 \\
\hline 400 & 0.325 & 1.21 & 1.38 \\
\hline 500 & 0.274 & 1.03 & 1.18 \\
\hline 700 & 0.21 & 0.794 & 0.919 \\
\hline 1000 & 0.157 & 0.601 & 0.695 \\
\hline
\end{tabular}

However, in nitrogen oxides the ionization into multiply charges ions is an insignificant part of the total counting ionization cross section: in NO the cross section for the formation of the $\mathrm{NO}^{2+}$ is less than $2 \%$ of the total counting ionization cross section ${ }^{29}$, the sum of the partial cross sections for the $\mathrm{N}^{2+}$ ion formation and for the $\mathrm{O}^{2+}$ ion formation is $0.1-0.2 \%$ of the total counting cross section ${ }^{29,65}$ and in $\mathrm{N}_{2} \mathrm{O}$ it was not measurable ${ }^{27}$.

Generally, the agreement between different measurements in NO is good: some systematic discrepancies are to be attributed to differences in experimental setups. The laboratory in Innsbruck used a double-focusing ion selector, with electrostatic plus magnetostatic field sectors $^{66}$. The extraction of ions from the interaction region was performed with a weak penetrating electric field, which did not ensure collection of ions with high residual kinetic energies. In particular, cross sections for formation of light ions, like $\mathrm{N}^{+}$or $\mathrm{O}^{+}$can be underestimated, see for example Fig. 14 in Ref. ${ }^{67}$. Cross sections were obtained via normalization to Ar ionization cross sections, via a relative-flow technique to determine gas density.

Iga et $a l .{ }^{30}$ used the method of crossed beam - electrons were intercepting the effusive gas beam at right angle; two spectrometers - a quadrupole and a time-offlight were used in a complementary manned. Cross sections were normalized to those in argon. The uncertainty on absolute values ${ }^{30}$ is $\pm 15 \%$.

Lindsay et $a .^{27,29}$ used a rather simple apparatus with a long interaction region, a time-of-flight system for extracting ions and a position-sensitive detector to determine the recoil kinetic energy of ions. The declared accuracy of absolute values is $5 \%$ for parent ionization, rising to $30 \%$ for ions with low intensities.

Lopez et al. ${ }^{31}$ used a method of crossed beams. In order to allow measurements also on radicals, they used a beam of neutral molecules, produced from a collisioninduced neutralization of previously obtained positive ions. However, the exact determination of the density of the target gas beam was not straightforward and required normalization. Experimental uncertainties were $\pm 15 \%$ on parent ionization and $\pm 18 \%$ on dissociative ionizations $^{31}$.

Nitrogen oxides were also one of first molecules on which the binary-encounter Bethe-Born model ${ }^{67}$ was applied $^{32,68,69}$. Surprisingly, NO is the molecule for which the biggest discrepancies, up to $20 \%$, are reported in the ionization from different laboratories. This, as already noted by Rapp and Englander-Golden ${ }^{28}$, and quoted recently by Itikawa ${ }^{16}$, can be due to a high reactivity of this gas and of the ions formed. However, considering the combined error bars, the agreement is still fair, see Fig. 14.

In particular, the total counting ionization by Lindsay et $a .^{29}$ agrees within the error bar with the gross total cross section by Rapp and Englander-Golden ${ }^{28}$. Counting total cross sections by Lopez et al. ${ }^{31}$ and by Igaet $a l .{ }^{30}$ are higher, but still remain within the combined er- 
ror bars. Therefore we recommend total ionization cross sections in NO by Lindsay et al. ${ }^{29}$, which agree also with the BEB model calculations of Kim and collaborators ${ }^{32}$. Recommended values are given in table VII; the uncertainty in the whole energy range is $\pm 5 \%$.

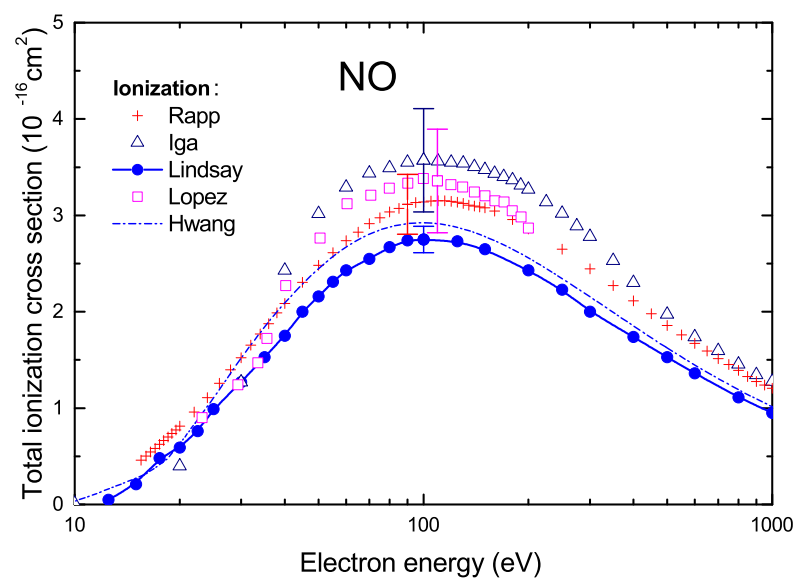

FIG. 14. Total ionization cross sections in NO: gross total Rapp and Englander-Golden ${ }^{28}$; counting total - Iga et al. ${ }^{30}$, Lindsay et $a l .{ }^{29}$, Lopez et al. ${ }^{31}$. Declared error bars are shown only in the maximum of the cross section. BEB model by Hwang et al. ${ }^{32}$. Recommended data are those by Lindsay et $a l .{ }^{29}$.

The same considerations as above on the quality of data regard partial cross sections in NO. For the parent ion $\mathrm{NO}^{+}$production, the spread among different sets is some $25 \%$, with discrepancies similar to those in the total ionization cross sections, see Fig. 15: the highest set is that by Iga et al. ${ }^{30}$, data of Kim et al. ${ }^{67}$ from Innsbruck and Lopez et al. ${ }^{31}$ are intermediate, and those by Lindsay et al. $^{29}$ are the lowest. We recommend experimental results by Lindsay et $a .^{29}$, with an uncertainty of $\pm 10 \%$.

For fragment ions from NO, good agreement is seen between the data of Iga et al. ${ }^{30}$ and Lindsay ${ }^{29}$ for $\mathrm{N}^{+}$, and somewhat worse for $\mathrm{O}^{+}$, see full symbols in Fig. 16 . For the unresolved $\left(\mathrm{N}^{+}+\mathrm{O}^{+}+\mathrm{NO}^{2+}\right)$ ionization the results of Lopez et al. ${ }^{31}$ are the highest, as they include also the $\mathrm{NO}^{2+}$ signal. As measured by Kim et al. ${ }^{67}$ and Lindsay et $a l .{ }^{29}$, this maximum for the $\mathrm{NO}^{2+}$ partial cross section is some $0.03 \times 10^{-16} \mathrm{~cm}^{2}$, see Fig. 16 .

For the reasons discussed in the description of experimental methods, for the summed $\left(\mathrm{N}^{+}+\mathrm{O}^{+}+\mathrm{NO}^{2+}\right)$, and fragment $\mathrm{N}^{+}, \mathrm{O}^{+}$, ions we recommend data of Lindsay et al. $^{29}$ with uncertainties of $\pm 5 \%, \pm 15 \%, \pm 20 \%$, respectively ${ }^{29}$. For the double ionization $\mathrm{NO}^{2+}$ we recommend data from Innsbruck ${ }^{67}$ from threshold up to $180 \mathrm{eV}$ and Lindsay et al. ${ }^{29}$ at higher energies. Recommended total and partial cross sections in NO are shown in Fig. 17 and given in table VII.

\section{J. Electron Attachment (DEA) Cross Section}

Rapp and Briglia ${ }^{70}$ measured the absolute total cross sections for negative-ion formation in NO by electron impact in a total ionization tube. The dissociative electron attachment (DEA) channel forming this negative ion is $\mathrm{O}^{-}$from NO. Orient and Chutjian ${ }^{71}$ identified three channel forming $\mathrm{O}^{-}\left({ }^{2} \mathrm{P}\right)$, but did not present the absolute cross sections. Rapp and Briglia ${ }^{70}$ is the only available measured DEA cross sections and we recommend their result as Itikawa ${ }^{16}$ did. The recommended cross sections are presented in Table VIII and Fig. 18. Please note that the units are $10^{-18} \mathrm{~cm}^{2}$. The uncertainty was estimated to be $10 \%$. For detailed discussions see Itikawa ${ }^{16}$.

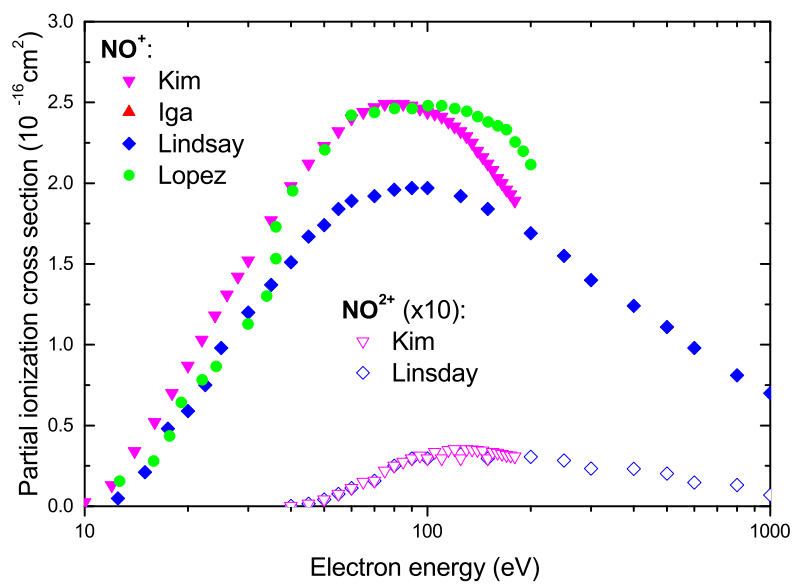

FIG. 15. Partial ionization cross sections for ionization of NO by electron impact: parent ionization $\mathrm{NO}^{+}$and doubly ionized $\mathrm{NO}^{2+}$ (multiplied by a factor of 10). Experimental data are from Kim et al. ${ }^{67}$, Iga et al. ${ }^{30}$, Lindsay et al. ${ }^{29}$, Lopez et al. ${ }^{31}$. Double ionization constitutes about $2 \%$ of the total ionization cross section in NO.

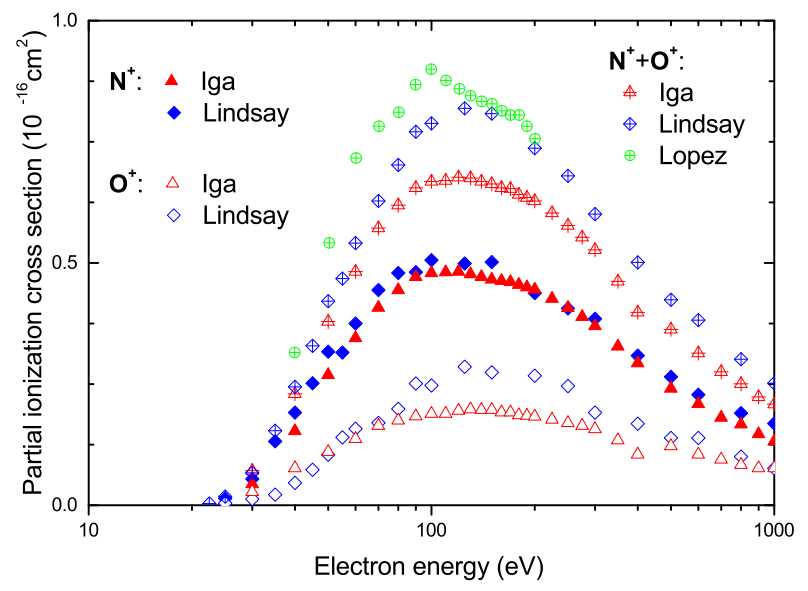

FIG. 16. Partial ionization cross sections for ionization of $\mathrm{NO}$ by electron impact: fragment $\mathrm{N}^{+}$and $\mathrm{O}^{+}$ions and the summed $\left(\mathrm{N}^{+}+\mathrm{O}^{+}+\mathrm{NO}^{2+}\right.$ ion signal unresolved in measurements of Lopez et al.). Experimental data are from Iga et $a l .{ }^{30}$, Lindsay et $a l .{ }^{29}$, Lopez et al. ${ }^{31}$. 


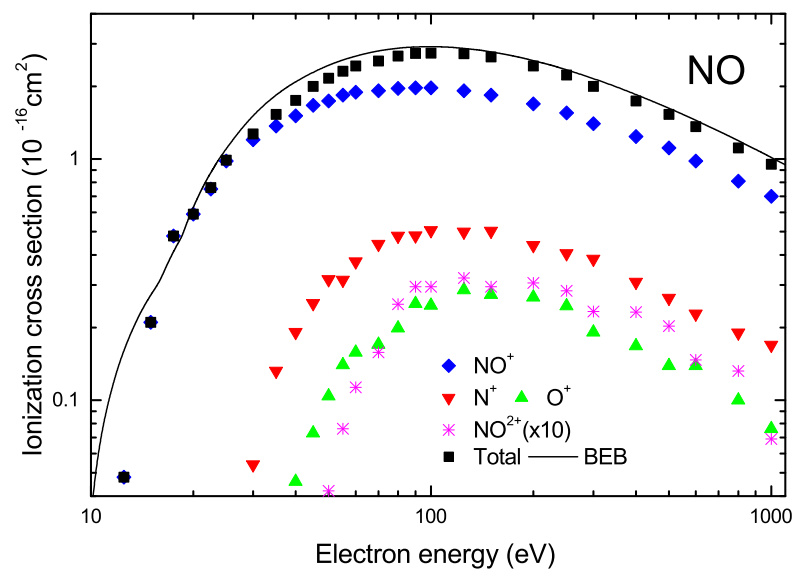

FIG. 17. Recommended total and partial cross sections for electron-impact ionization of nitric oxide, NO. Data are based on experiment by Lindsay et $\mathrm{al}_{.}{ }^{29}$ apart from $\mathrm{NO}^{2+}$ cross sections which up to $180 \mathrm{eV}$ are based on data from Innsbruck ${ }^{67}$. BEB model for total ionization by Hwang et al. ${ }^{32}$. The uncertainties are $\pm 5 \%$ on total ionization and $\mathrm{NO}^{+}, \pm 15 \%$ on $\mathrm{N}^{+}, \pm 20 \%$ on $\mathrm{O}^{+}, \pm 30 \%$ on $\mathrm{NO}^{2+}$ partial ionization cross sections $^{27}$.

TABLE VII. Recommended total and partial cross sections for electron-impact ionization of nitric oxide, $\mathrm{NO}$ in $10^{-16}$ $\mathrm{cm}^{2}$. Energy in $\mathrm{eV}$.

\begin{tabular}{|c|c|c|c|c|c|}
\hline Energy & $\mathrm{NO}^{+}$ & $\mathrm{N}^{+}$ & $\mathrm{O}^{+}$ & $\mathrm{NO}^{2+}$ & Total \\
\hline 12.5 & 0.048 & & & & 0.048 \\
\hline 15 & 0.21 & & & & 0.21 \\
\hline 17.5 & 0.48 & & & & 0.48 \\
\hline 20 & 0.59 & & & & 0.59 \\
\hline 22.5 & 0.75 & & & & 0.76 \\
\hline 25 & 0.98 & 0.014 & 0.004 & & 0.99 \\
\hline 30 & 1.20 & 0.054 & 0.013 & & 1.27 \\
\hline 35 & 1.37 & 0.132 & 0.022 & & 1.53 \\
\hline 40 & 1.51 & 0.191 & 0.046 & 0.00017 & 1.75 \\
\hline 45 & 1.67 & 0.252 & 0.073 & 0.0015 & 2.00 \\
\hline 50 & 1.74 & 0.317 & 0.104 & 0.0042 & 2.16 \\
\hline 55 & 1.84 & 0.315 & 0.140 & 0.0076 & 2.31 \\
\hline 60 & 1.89 & 0.375 & 0.158 & 0.0113 & 2.43 \\
\hline 70 & 1.92 & 0.444 & 0.170 & 0.0158 & 2.55 \\
\hline 80 & 1.96 & 0.479 & 0.199 & 0.0250 & 2.67 \\
\hline 90 & 1.97 & 0.481 & 0.251 & 0.0295 & 2.74 \\
\hline 100 & 1.97 & 0.506 & 0.247 & 0.0295 & 2.75 \\
\hline 125 & 1.92 & 0.499 & 0.286 & 0.0321 & 2.73 \\
\hline 150 & 1.84 & 0.502 & 0.274 & 0.0295 & 2.65 \\
\hline 200 & 1.69 & 0.438 & 0.267 & 0.0306 & 2.43 \\
\hline 250 & 1.55 & 0.406 & 0.246 & 0.0284 & 2.23 \\
\hline 300 & 1.40 & 0.385 & 0.191 & 0.0233 & 2.00 \\
\hline 400 & 1.24 & 0.309 & 0.168 & 0.0232 & 1.74 \\
\hline 500 & 1.11 & 0.265 & 0.139 & 0.0203 & 1.53 \\
\hline 600 & 0.98 & 0.228 & 0.139 & 0.0147 & 1.36 \\
\hline 800 & 0.81 & 0.190 & 0.100 & 0.0132 & 1.11 \\
\hline 1000 & 0.70 & 0.169 & 0.076 & 0.0069 & 0.95 \\
\hline
\end{tabular}

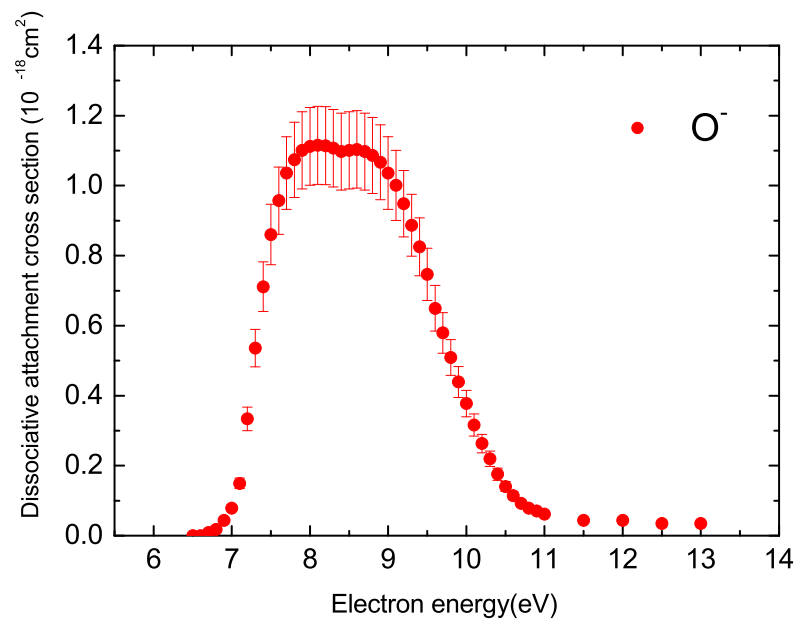

FIG. 18. Recommended dissociative attachment cross sections for the formation of $\mathrm{O}^{-}$from $\mathrm{NO}$

TABLE VIII. Recommended dissociative attachment cross sections (CS) for the formation of $\mathrm{O}^{-}$from $\mathrm{NO}$ in $10^{-18} \mathrm{~cm}^{2}$. Energy in eV.

\begin{tabular}{cccccc}
\hline \hline Energy & CS & Energy & CS & Energy & CS \\
\hline \hline 6.7 & 0.0088 & 8.3 & 1.109 & 9.9 & 0.440 \\
6.8 & 0.0176 & 8.4 & 1.100 & 10.0 & 0.378 \\
6.9 & 0.0440 & 8.5 & 1.103 & 10.1 & 0.317 \\
7.0 & 0.0792 & 8.6 & 1.106 & 10.2 & 0.264 \\
7.1 & 0.150 & 8.7 & 1.100 & 10.3 & 0.220 \\
7.2 & 0.334 & 8.8 & 1.088 & 10.4 & 0.176 \\
7.3 & 0.537 & 8.9 & 1.069 & 10.5 & 0.141 \\
7.4 & 0.713 & 9.0 & 1.040 & 10.6 & 0.114 \\
7.5 & 0.862 & 9.1 & 1.000 & 10.7 & 0.0924 \\
7.6 & 0.959 & 9.2 & 0.950 & 10.8 & 0.0792 \\
7.7 & 1.040 & 9.3 & 0.888 & 10.9 & 0.0704 \\
7.8 & 1.076 & 9.4 & 0.827 & 11.0 & 0.0616 \\
7.9 & 1.103 & 9.5 & 0.748 & 11.5 & 0.0440 \\
8.0 & 1.115 & 9.6 & 0.651 & 12.0 & 0.0440 \\
8.1 & 1.117 & 9.7 & 0.581 & 12.5 & 0.0352 \\
8.2 & 1.116 & 9.8 & 0.510 & 13.0 & 0.0352 \\
\hline \hline
\end{tabular}

\section{III. $\mathrm{N}_{2} \mathrm{O}$}

Nitrous oxide $\left(\mathrm{N}_{2} \mathrm{O}\right)$ is a closed shell, linear molecule with an $\mathrm{N}-\mathrm{N}-\mathrm{O}$ geometry.

\section{A. Total Scattering Cross Section}

Early measurements of the TCS by Ramsauer ${ }^{72}$ extended from $0.15 \mathrm{eV}$ to $1.25 \mathrm{eV}$ and were performed with an apparatus with perpendicular magnetic field and the radius of electron trajectories of $8 \mathrm{~mm}$. Those are only measurements extending below $1 \mathrm{eV}$ and showing a rise of TCS towards zero energy, as it would be predicted from the polar character of $\mathrm{N}_{2} \mathrm{O}$ molecule.

Kwan et al. ${ }^{33}$ measured TCS for electron and positron scattering between $1.25-500 \mathrm{eV}$ using a long $(109 \mathrm{~cm})$, 
curved scattering cell with a guiding magnetic field and a retarding field analyzer. Szmytkowski and collaborators measured $\mathrm{N}_{2} \mathrm{O}$ cross sections in several papers ${ }^{73-75}$. The main features of their apparatus were the same: a $127^{\circ}$ cylindrical electrostatic selector and a rather short $(30 \mathrm{~mm})$ scattering cell, resulting in a modest $\left(10^{-3} \mathrm{sr}\right)$ geometrical angular resolution.

The first series of measurements ${ }^{73,75}$ were made without a retarding field analyzer, so were possibly subject to an underestimation due to non-discrimination of inelastically scattered projectiles. In fact, remeasured values ${ }^{21}$ at energies above $10 \mathrm{eV}$ (i.e. above thresholds for electronic excitation) are higher than earlier data and agree with those by Kwan et al. ${ }^{33}$.

In the region of the low-energy ${ }^{2} \Pi$ resonance ${ }^{76,77}$ the agreement between Szmytkowski et al. ${ }^{73}$ and Kwan et al. ${ }^{33}$ is pretty good, considering that small errors in the determination of the energy scale may significantly change the TCS measured. A high (approximately $1 / 3$ of the $\mathrm{TCS}^{78}$ ) contribution comes in this resonance from the vibrational cross section. As noted subsequently by Johnstone and Newell ${ }^{79}$, the temperature of the gas, via vibrational excitation, can also influence this resonance maximum.

Xing et al. ${ }^{35}$ used a $202 \mathrm{~mm}$ long collision chamber and $70 \mathrm{~mm}$ long drift distance between the chamber and the analyzer equipped with a retarding field, obtaining an angular resolution of $6.3 \times 10^{-5} \mathrm{sr}$. Their data ${ }^{35}$ match very well with those by Kwan at al. ${ }^{33}$. This matching is confirmed also by the Bethe-Born plot, see Fig. 2 . Parameters of this plot, see eq. 1 , are $A=-75 \pm 10$ and $B=467 \pm 5$. The level of confidence on the B-B fit in $\mathrm{N}_{2} \mathrm{O}$ is higher than in NO: this is thanks to high-quality of data by Xing et al. ${ }^{35}$ extending up to $4250 \mathrm{eV}$.

Generally, after the above mentioned considerations, agreement between different sets of data ${ }^{34,35,72,73}$ is good, within $\pm 10 \%$ in the whole energy range from tenths of $\mathrm{eV}$ to $1 \mathrm{keV}$. Recommended TCS are based on Ramsauer's measurements ${ }^{72}$ at lowest energies, matching with those by Kwan et al. ${ }^{33}$ in the region of the ${ }^{2} \Pi$ resonance, then on the mean values between Kwan et al.'s and Szmytkowski et al. ${ }^{21}$ above $10 \mathrm{eV}$ and on Xing et al.'s TCS in the high energy limit. Recommended values are given in table IX they coincide with those from ref. ${ }^{13}$.

\section{B. Elastic Scattering Cross Section}

There have been many reports on the experimental measurements of elastic differential cross section (DCS) and integral cross section (ICS) for $\mathrm{N}_{2} \mathrm{O}$ (nitrous oxide) molecule. Among them, the most relevant results to this evaluation are the following. Marinkovic et al. ${ }^{74}$ reported the absolute DCS's and ICS's for the energy range from $10 \mathrm{eV}$ to $80 \mathrm{eV}$ and for the angular range of $8^{\circ}-150^{\circ}$. Later, Johnstone \& Newell ${ }^{79}$ measured the DCS's and ICS's for $5 \mathrm{eV}-80 \mathrm{eV}$ energy and $10^{\circ}-120^{\circ}$ angles. Kitajima et al. ${ }^{80}$ performed an experiment to measure DCS's

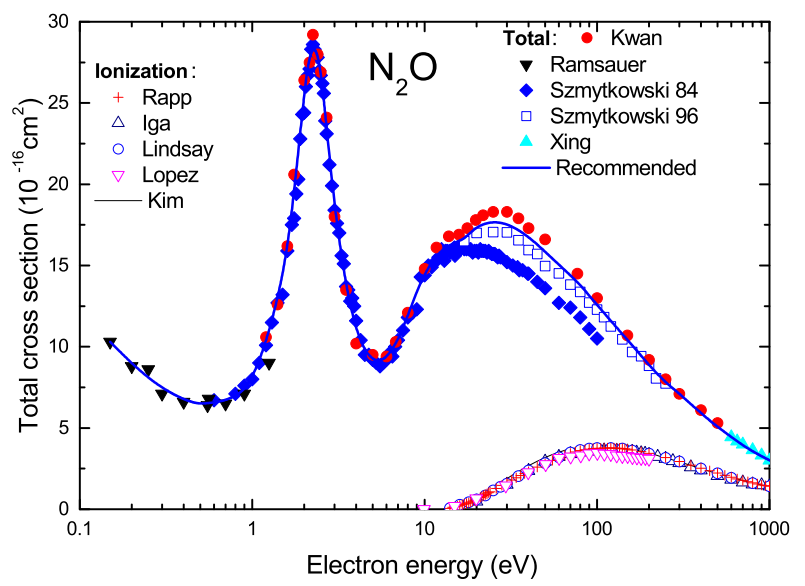

FIG. 19. Total cross sections for electron scattering on nitrous oxide, $\mathrm{N}_{2} \mathrm{O}$. Experimental absolute TCS are from ref. ${ }^{33}-$ full circles (digitalized from their figure), from ref. ${ }^{72}$ - inverted triangles, ref. ${ }^{73,75}$ - full diamonds, ref. ${ }^{21}$ - open squares, ref. ${ }^{35}$ - full triangles. The thick line represents our recommended TCS. Ionization integral cross section - experiments: Rapp and Englander-Golden ${ }^{28}$, Iga et al. ${ }^{30}$, Lindsay et al. ${ }^{27}$, Lopez et $a l .{ }^{31}$; BEB model by Kim et al. ${ }^{68}$.

TABLE IX. Recommended TCS (in $10^{-16} \mathrm{~cm}^{2}$ ) for electron scattering on nitrous oxide $\mathrm{N}_{2} \mathrm{O}$. Recommended values up to $10 \mathrm{eV}$ are based on experimental data ${ }^{33,72,73}$, at $10-250 \mathrm{eV}$ - on experimental data ${ }^{21,33}$ and on Ref. ${ }^{35}$ above $500 \mathrm{eV}$. The uncertainty in the recommended data is $\pm 10 \%$.

\begin{tabular}{cccccc}
\hline $\begin{array}{c}\text { Electron } \\
\text { energy }\end{array}$ & \multicolumn{3}{c}{$\begin{array}{c}\text { Tlectron } \\
\text { energy }\end{array}$} & $\begin{array}{c}\text { TCS } \\
\text { enectron }\end{array}$ \\
\hline \hline 0.15 & 10.3 & 2.7 & 23.5 & 60 & 15.0 \\
0.20 & 9.0 & 3.0 & 18.6 & 70 & 14.4 \\
0.25 & 8.1 & 3.5 & 13.6 & 80 & 13.8 \\
0.30 & 7.5 & 4.0 & 11.0 & 90 & 13.2 \\
0.35 & 7.1 & 4.5 & 9.73 & 100 & 12.6 \\
0.40 & 6.8 & 5.0 & 9.24 & 120 & 11.6 \\
0.45 & 6.6 & 5.5 & 9.17 & 150 & 10.4 \\
0.50 & 6.5 & 6.0 & 9.37 & 170 & 9.78 \\
0.60 & 6.6 & 7.0 & 10.4 & 200 & 8.87 \\
0.70 & 6.7 & 8.0 & 11.9 & 250 & 7.80 \\
0.80 & 7.0 & 9.0 & 13.4 & 300 & 7.12 \\
0.90 & 7.4 & 10 & 14.5 & 350 & 6.46 \\
1.00 & 8.1 & 12 & 15.9 & 400 & 5.92 \\
1.20 & 10.2 & 15 & 16.4 & 450 & 5.47 \\
1.50 & 14.3 & 17 & 16.6 & 500 & 5.08 \\
1.70 & 18.1 & 20 & 17.4 & 600 & 4.44 \\
2.00 & 25.6 & 25 & 17.7 & 700 & 3.94 \\
2.10 & 27.3 & 30 & 17.6 & 800 & 3.56 \\
2.20 & 28.2 & 35 & 17.2 & 900 & 3.26 \\
2.30 & 28.4 & 40 & 16.7 & 1000 & 3.01 \\
2.40 & 27.9 & 45 & 16.3 & & \\
2.50 & 26.9 & 50 & 15.8 & & \\
\hline \hline
\end{tabular}

for $1.5-100 \mathrm{eV}$ energy and $20^{\circ}-130^{\circ}$ angular range. Their work was supplemented by the work from Australian National University (ANU) group in the report of Kitajima et $\mathrm{al}^{81}$ which presented the cross sections 
of both Sophia University group and ANU group. ANU group measured the cross sections for the energy range of $2.0-20 \mathrm{eV}$ and the angular range of $20^{\circ}-130^{\circ}$. Finally, Lee et $\mathrm{al}^{82}$ reported the absolute DCS's and ICS's for 50 $-800 \mathrm{eV}$ and $15^{\circ}-130^{\circ}$ ranges. Excluding Marinkovic et $a l .{ }^{74}$, which shows devilations from the other results especially at high angles, we estimate recommended DCS's and ICS's values and their corresponding uncertainties for the electron impact energies at 1.5, 3.0, 5.0, 10, 15, $20,30,50,100$, and $500 \mathrm{eV}$. Numerical values of these cross sections and four representative figures for elastic DCS's are presented in Table X and Fig. 20, respectively. Similarly, the recommended ICS's are given in Table XI and Fig. 21.

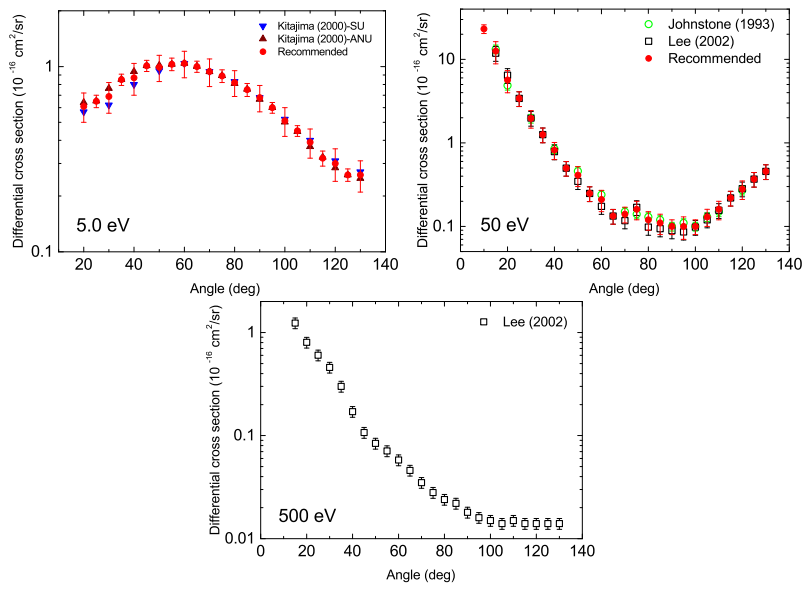

FIG. 20. Recommended elastic DCS for four representative energies.

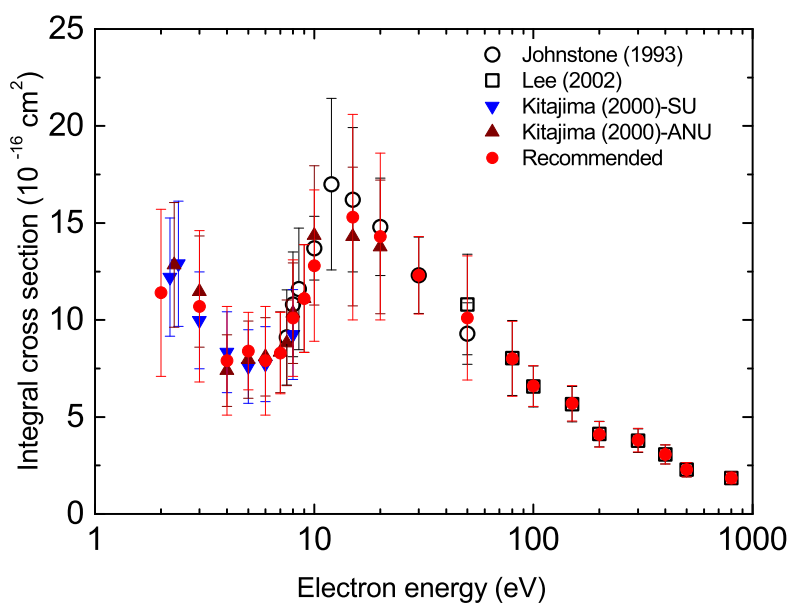

FIG. 21. Recommended elastic ICS for $\mathrm{N}_{2} \mathrm{O}$

\section{Momentum Transfer Cross Section}

Pack et $a l^{83}$ measured the drift velocity of slow electrons in pure $\mathrm{N}_{2} \mathrm{O}$ at two different gas temperatures, 195
$\mathrm{K}$ and $300 \mathrm{~K}$, and derived a momentum transfer cross section as a function of electron energy over the energy range between about 0.008 and $0.05 \mathrm{eV}$. It should also be added that they observed no appreciable dependence of the drift velocity on the gas temperature, and therefore, contribution of rotational excitation and de-excitation processes to electron swarms cannot be substantial in pure $\mathrm{N}_{2} \mathrm{O}$. Singh ${ }^{84}$ calculated momentum transfer cross section using effective-range theory ${ }^{85}$ in the energy range 0.01 to $0.1 \mathrm{eV}$. These two studies covered almost overlapping energy range and resulted in a very good agreement between them.

Marinkovic et al. ${ }^{74}$ reported the momentum transfer cross section as well as the integral elastic cross section between $10 \mathrm{eV}$ and $80 \mathrm{eV}$. Johnstone and Newell ${ }^{79}$ also determined the integral elastic and momentum transfer cross sections between $5 \mathrm{eV}$ and 80 $\mathrm{eV}$ with the claimed errors of $20 \%$ and $25 \%$, respectively. More recently, Lee et $a l .{ }^{82}$ reported a joint theoretical (combination of the Schwinger variational iterative method and the distorted-wave approximation)experimental (crossed electron beam-molecular-beam geometry) study on electron- $\mathrm{N}_{2} \mathrm{O}$ collisions over the energy range from $50 \mathrm{eV}$ to $800 \mathrm{eV}$ which gave good agreement between theory and the measurements. Experimental uncertainty estimated in the absolute DCS over the range of the scattering angles between $15^{\circ}$ and $130^{\circ}$ was $12 \%$ in the $100-800 \mathrm{eV}$ energy range and $20 \%$ elsewhere. And after accounting for extrapolation procedure the overall uncertainties in the integral elastic and momentum transfer cross sections were estimated $16 \%$ in the $100-800 \mathrm{eV}$ range and $24 \%$ elsewhere. Again agreement between theory and measurement for the integral cross sections was good. Since the above four studies reported the elastic differential cross sections which are mutually consistent well within their claimed uncertainty limits, the elastic momentum transfer cross sections derived from their differential elastic cross sections should also be reliable.

Hayashi $^{86}$ determined a set of electron collision cross sections including the momentum transfer cross section for $\mathrm{N}_{2} \mathrm{O}$ from electron swarm parameters (drift velocity, lateral diffusion coefficient, and ionization and attachment coefficients measured in pure $\mathrm{N}_{2} \mathrm{O}$ ) available at the time of compilation for electron energies up to $1000 \mathrm{eV}$. Electron swarm parameters in pure molecular gas in low and intermediate $\mathrm{E} / \mathrm{N}$ depend both on the elastic momentum and vibrational excitation cross sections and, therefore, it is not possible in principle for electron swarm study to determine both momentum and vibrational cross sections uniquely if it uses only swarm parameters measured in pure molecular gas. This is the long-standing uniqueness problem of current swarm studies. Nakamura ${ }^{87}$ determined a cross section set for the molecule after his measurements of drift velocity and longitudinal diffusion coefficient in pure $\mathrm{N}_{2} \mathrm{O}$ and also in dilute $\mathrm{N}_{2} \mathrm{O}$-Ar mixture. The sharp Ramsauer minimum in the elastic momentum cross section of the Ar atoms, which are the major constituent of the mixture, 
TABLE X. Recommended elastic DCS for $\mathrm{N}_{2} \mathrm{O}$. DCS's and uncertainties $(\delta)$ are in the units of $10^{-16} \mathrm{~cm}^{2} \mathrm{sr}^{-1}$.

\begin{tabular}{|c|c|c|c|c|c|c|c|c|c|c|c|c|c|c|c|c|c|c|c|c|}
\hline \multirow{2}{*}{$\begin{array}{c}\text { Angle } \\
\text { (deg) }\end{array}$} & \multicolumn{2}{|c|}{$1.5 \mathrm{eV}$} & \multicolumn{2}{|c|}{$3.0 \mathrm{eV}$} & \multicolumn{2}{|c|}{$\overline{5.0 \mathrm{eV}}$} & \multicolumn{2}{|c|}{$10.0 \mathrm{eV}$} & \multicolumn{2}{|c|}{$15.0 \mathrm{eV}$} & \multicolumn{2}{|c|}{$20.0 \mathrm{eV}$} & \multicolumn{2}{|c|}{$30.0 \mathrm{eV}$} & \multicolumn{2}{|c|}{$50.0 \mathrm{eV}$} & \multicolumn{2}{|c|}{$100.0 \mathrm{eV}$} & \multicolumn{2}{|c|}{$\overline{500.0 \mathrm{eV}}$} \\
\hline & $\mathrm{DC}$ & $\delta$ & $\mathrm{DC}$ & $\delta$ & $\mathrm{DC}$ & $\delta$ & $\mathrm{DC}$ & $\delta$ & DCS & $\delta$ & D & $\delta$ & $\mathrm{DC}$ & & DCS & ( & D & $\delta$ & $\mathrm{CS}$ & $\delta$ \\
\hline 10 & & & & & & & 4.43 & 0.53 & 26 & 0.99 & 33.8 & 4.05 & 29.9 & 3.6 & 23.2 & 2.78 & & & & \\
\hline 15 & & & & & & & .95 & 0.6 & .44 & 1.01 & 8.55 & 1.32 & 12.9 & 1.55 & 12.6 & 3.74 & 7.66 & 1.53 & 237 & 0.14 \\
\hline 25 & & & & & 0.65 & 0.05 & 2.41 & 0.39 & 4.12 & 0.49 & & & & & 3.41 & 0.68 & 1.62 & 0.32 & 0.603 & 0.072 \\
\hline 30 & 0.96 & 0.14 & 1.78 & 0.27 & 0.69 & .13 & 2.05 & 0.32 & .96 & 0.43 & 3.04 & 0.58 & 2.55 & 0.5 & 1.97 & 0.47 & 0.95 & 0.24 & 0.459 & 0.055 \\
\hline 35 & & & 1.75 & 0.12 & 0.85 & .06 & 1.74 & 0.25 & .68 & 0.32 & & & & & 1.26 & 0.25 & 0.55 & 0.11 & 0.3 & 0.036 \\
\hline 50 & 0.46 & 0.07 & 1.67 & 0.28 & 0.99 & 0.16 & 1.21 & 0.2 & 1.35 & 0.18 & 1.16 & 0.19 & 0.74 & 0.14 & 0.41 & 0.11 & 0.18 & 0.04 & 0.084 & 0.01 \\
\hline 55 & & & 1.54 & 0.11 & 1.03 & 0.08 & 1.11 & 0.16 & 1.27 & 0.15 & & & & & 0.25 & 0.05 & 0.15 & 0.03 & 0.071 & 0.009 \\
\hline 60 & 0.32 & 0.05 & 1.47 & 0.24 & 1.04 & 0.17 & 1.02 & 0.16 & 1.03 & 0.14 & 0.8 & 0.13 & 0.45 & 0.09 & 0.21 & 0.06 & 0.13 & 0.04 & 0.058 & 0.007 \\
\hline 65 & & & 1.32 & 0.09 & 1 & 0.07 & 0.92 & 0.15 & 0.96 & 0.12 & & & & & 0.13 & 0.03 & 0.11 & 0.02 & 0.046 & 0.006 \\
\hline 70 & 0.30 & 0.05 & 1.14 & 0.19 & 0.94 & 0.16 & 0.83 & 0.15 & 0.8 & 0.11 & 0.57 & 0.09 & 0.27 & 0.07 & 0.14 & 0.03 & 0.1 & 0.03 & 0.035 & 0.004 \\
\hline 75 & & & 1.04 & 0.07 & 0.89 & 0.07 & 0.78 & 0.12 & 0.74 & 0.09 & 0.47 & 0.06 & 0.17 & 0.02 & 0.16 & 0.04 & 0.08 & 0.02 & 0.028 & 0.003 \\
\hline 105 & & & 0.41 & 0.03 & 0. & 0.0 & 0.4 & 0.06 & 0.31 & 0.07 & 0. & 0. & 0.27 & & 0.13 & 0.03 & 0.09 & 0.02 & 14 & 0.002 \\
\hline 110 & 0.56 & 0.08 & 0.34 & 0.06 & 0.39 & 0.07 & 0.41 & 0.08 & 0.37 & 0.06 & 0.35 & 0.05 & 0.29 & 0.06 & 0.16 & 0.04 & 0.11 & 0.03 & 0.015 & 0.002 \\
\hline 115 & & & 0.31 & 0.02 & 0.32 & 0.0 & 0.45 & 0.08 & 0.5 & 0.06 & & & & & 0.22 & 0.04 & 0.12 & 0.02 & 0.014 & 0.002 \\
\hline 120 & 0.66 & 0.10 & 0.28 & 0.05 & 0.3 & 0.06 & 0.53 & 0.09 & 0.53 & 0.09 & 0.49 & 0.07 & 0.34 & 0.06 & 0.28 & 0.07 & 0.13 & 0.04 & 0.014 & 0.002 \\
\hline 125 & & & 0.28 & 0.02 & 0.26 & 0.02 & 0.63 & 0.15 & & & & & & & 0.37 & 0.07 & 0.15 & 0.03 & 0.014 & 0.002 \\
\hline 130 & 0.76 & 0.11 & 0.31 & 0.05 & 0.26 & 0.05 & 0.76 & 0.18 & 0.7 & 0.13 & 0.7 & 0.13 & 0.43 & 0.06 & 0.46 & 0.09 & 0.16 & 0.05 & 0.014 & 0.002 \\
\hline
\end{tabular}

TABLE XI. Recommended elastic ICS and uncertainties $(\delta)$ for $\mathrm{N}_{2} \mathrm{O}$ in the units of $10^{-16} \mathrm{~cm}^{2}$. Energy in $\mathrm{eV}$.

\begin{tabular}{cccccc}
\hline \hline Electron & ICS & $\delta$ & Energy & ICS & $\delta$ \\
\hline \hline 2 & 11.4 & 4.3 & 30 & 12.3 & 2.0 \\
3 & 10.7 & 3.9 & 50 & 10.1 & 3.2 \\
4 & 7.9 & 2.8 & 80 & 8.0 & 1.9 \\
5 & 8.4 & 2.0 & 100 & 6.6 & 1.1 \\
6 & 7.9 & 2.8 & 150 & 5.7 & 0.9 \\
7 & 8.3 & 2.1 & 200 & 4.1 & 0.7 \\
8 & 10.1 & 3.0 & 300 & 3.8 & 0.6 \\
9 & 11.1 & 2.8 & 400 & 3.1 & 0.5 \\
10 & 12.8 & 3.9 & 500 & 2.3 & 0.4 \\
15 & 15.3 & 5.3 & 800 & 1.9 & 0.3 \\
20 & 14.3 & 4.3 & & & \\
\hline \hline
\end{tabular}

seems to "amplify" 88 the effect of vibrational energy loss of electrons in $\mathrm{N}_{2} \mathrm{O}-\mathrm{Ar}$ mixtures and gives rise to prominent $\mathrm{E} / \mathrm{N}$ dependence in electron swarm parameters which provides a very good guide for unfolding vibrational excitation cross sections. This fact suggests simultaneous use of swarm data measured in pure molecular gas and its dilute Ar (or any of other rare gases with the Ramsauer-Townsend minimum) mixtures can help swarm study to determine the elastic momentum transfer cross section and the vibrational excitation cross sections almost separately. The momentum transfer cross sections from the two swarm methods agree well in the energy range up to $0.1 \mathrm{eV}$, where the two agree with those of Pack et al. ${ }^{83}$ and Singh ${ }^{84}$, and also in the range above $5 \mathrm{eV}$, where the two agree with data from crossed beam experiments. ${ }^{74,79,86}$ They all can be chosen as the recommended cross section in the respective energy ranges. For the remaining energy range, $0.1-5 \mathrm{eV}$, which almost exactly corresponds to the range of vibrational cross sec- tions, the momentum cross section of Nakamura is recommended. As explained above this recommended ${ }^{87}$ cross section, together with his vibrational cross sections, can reproduce swarm parameters in pure $\mathrm{N}_{2} \mathrm{O}$ and $\mathrm{N}_{2} \mathrm{O}-\mathrm{Ar}$ mixture simultaneously (see the section on the vibrational excitation cross sections below). Available momentum transfer cross sections are compared in Fig. 22. The present recommended cross section data which consists of Nakamura (up to $100 \mathrm{eV}$ ) and Hayashi (100 $1000 \mathrm{eV}$ ) are also shown in Table XII.

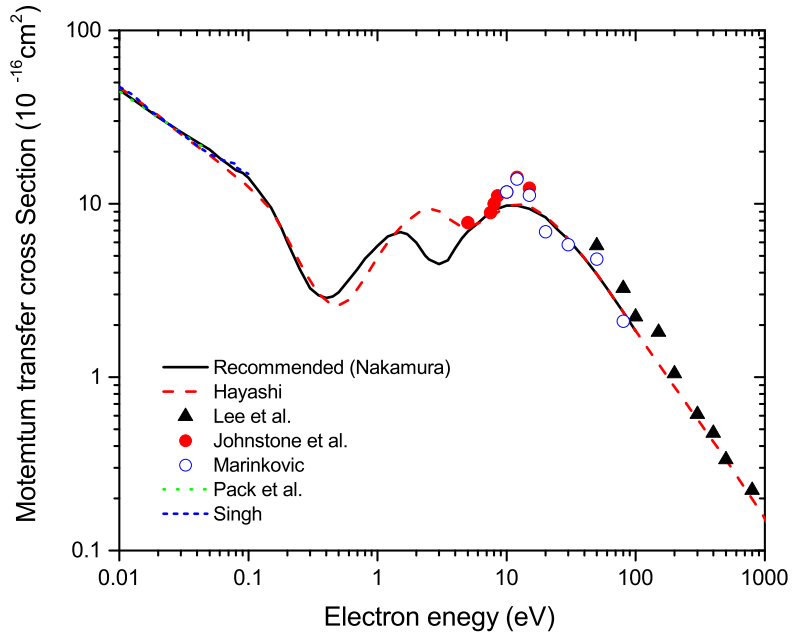

FIG. 22. Momentum transfer cross section. Dotted line, Pack, Voshall and Phelps ${ }^{83}$; short broken line, Singh ${ }^{84}$; open circle, Marinkovic et $a l^{74}$; solid circle, Johnstone and Newell ${ }^{79}$; solid triangle, Lee et al. ${ }^{82}$; broken line, Hayashi ${ }^{86}$, and solid line, Nakamura. ${ }^{87}$ 
TABLE XII. Recommended momentum transfer cross section for $\mathrm{N}_{2} \mathrm{O}$ in the units of $10^{-16} \mathrm{~cm}^{2}$. Energy in $\mathrm{eV}$.

\begin{tabular}{cccccc}
\hline $\begin{array}{c}\text { Electron } \\
\text { Energy }\end{array}$ & MT & $\begin{array}{c}\text { Electron } \\
\text { Energy }\end{array}$ & $\begin{array}{c}\text { MT } \\
\text { Electron } \\
\text { Energy }\end{array}$ & MT \\
\hline \hline 0 & 500 & 0.3 & 3.26 & 4.50 & 6.32 \\
0.001 & 139 & 0.35 & 2.96 & 5.0 & 6.92 \\
0.002 & 100 & 0.40 & 2.86 & 6.0 & 7.73 \\
0.005 & 63.1 & 0.45 & 2.92 & 7.0 & 8.60 \\
0.01 & 45.4 & 0.5 & 3.08 & 8.0 & 9.22 \\
0.02 & 31.6 & 0.6 & 3.65 & 10 & 9.75 \\
0.03 & 26.0 & 0.7 & 4.20 & 12 & 9.75 \\
0.04 & 22.7 & 0.8 & 4.83 & 15 & 9.35 \\
0.05 & 20.5 & 0.9 & 5.27 & 20 & 8.36 \\
0.06 & 18.3 & 1.0 & 5.72 & 25 & 7.06 \\
0.07 & 16.8 & 1.2 & 6.49 & 30 & 6.22 \\
0.08 & 15.6 & 1.5 & 6.87 & 40 & 4.85 \\
0.09 & 15.1 & 1.7 & 6.68 & 50 & 3.93 \\
0.10 & 14.1 & 2.0 & 5.97 & 60 & 3.25 \\
0.12 & 11.9 & 2.34 & 5.02 & 80 & 2.37 \\
0.15 & 9.48 & 2.5 & 4.77 & 100 & 1.85 \\
0.18 & 7.23 & 3.0 & 4.49 & 200 & 0.848 \\
0.20 & 6.00 & 3.5 & 4.72 & 500 & 0.306 \\
0.25 & 4.20 & 4.0 & 5.55 & 1000 & 0.130 \\
\hline \hline
\end{tabular}

\section{Rotational Excitation Cross Sections}

There are no data on rotational excitation of the $\mathrm{N}_{2} \mathrm{O}$ molecule in the literature. As part of this study we computed excitation cross sections using the UK Rmatrix $^{89,90}$ and the POLYDCS ${ }^{91}$ codes. It is worth mentioning that $a b$ initio calculations of the $\mathrm{N}_{2} \mathrm{O}$ equilibrium geometry and the electric dipole were also performed in this study. At the equilibrium geometry, the N-N and NO distances were found to be $1.122 \AA$ and $1.173 \AA$, which is similar to the experimental and previous theoretical values $^{92}$. The theoretical value of the dipole moment is about $0.38 \pm 0.04 \mathrm{D}$, with the uncertainty mainly due to the uncertainty in the equilibrium geometry. This value is much larger than the experimental value of $0.161 \mathrm{D}$, but is consistent with previous theoretical results ${ }^{92}$. The reason for the disagreement could be the following: For an accurate comparison with the experimental value, the theoretical dipole moment should be averaged over the wave function of the ground vibrational level of $\mathrm{N}_{2} \mathrm{O}$. The difference between the experimental dipole and theoretical value obtained at the equilibrium geometry, could be explained by a combined effect of a relatively strong linear dependence of the theoretical dipole as a function of internuclear distances and non-harmonicity of the $\mathrm{N}_{2} \mathrm{O}$ potential near the equilibrium. For the completeness it should also be mentioned that another experimental study $^{93}$ gave a value for the dipole of $0.52 \pm 0.45 \mathrm{D}$, which is closer to the theoretical result, but due to a large uncertainty is also consistent with the experimental value of $0.161 \mathrm{D}$ by Reinartz et al. ${ }^{94}$. For the calculation, theoretical dipole moment of $0.38 \mathrm{D}$ and the equilibrium geometry were employed. The cross sections obtained

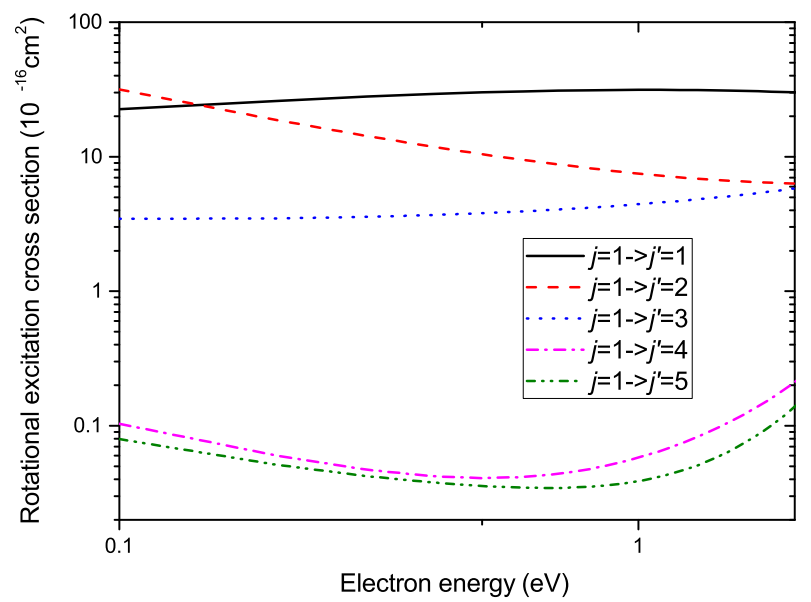

FIG. 23. Rotational excitation cross sections of the $\mathrm{N}_{2} \mathrm{O}$ molecule computed using the UK R-matrix ${ }^{89,90}$ and the POLYDCS ${ }^{91}$ codes.

are shown in Fig. 23.

\section{E. Vibrational Excitation Cross Sections}

The molecule $\mathrm{N}_{2} \mathrm{O}$ has three fundamental vibrational modes: $\nu_{1}(\mathrm{NN}$ stretch, $0.276 \mathrm{eV}), \nu_{2}$ (bend, $0.073 \mathrm{eV}$ ), and $\nu_{3}$ (NO stretch, $\left.0.159 \mathrm{eV}\right)^{95}$. Hayashi ${ }^{86}$ proposed cross sections for electron collision excitation to those three vibrational states from electron swarm parameters in pure $\mathrm{N}_{2} \mathrm{O}$. Kitajima et al. ${ }^{81}$ measured differential cross section for vibrational excitations of three fundamental modes at $2.4 \mathrm{eV}$ and $8.0 \mathrm{eV}$. Uncertainties for these differential cross sections were estimated between $30 \%$ and $50 \%$. Integral cross sections were also determined. Allan and Skalicky ${ }^{96}$ also measured absolute differential cross sections for the elastic and the vibrationally inelastic electron scattering including three fundamental modes and several other overtones. The scattering angle was fixed at $135^{\circ}$ but the measurements covered electron energy range from the threshold region up to $20 \mathrm{eV}$ including ${ }^{2} \Pi$ resonance at $2.4 \mathrm{eV}$ and a resonance at $8 \mathrm{eV}$. Each of the measured differential cross sections is multiplied by a factor $4 \pi$ and an integral cross section is estimated here. The results a compare very well with those of Kitajima et al. as shown in Fig. 24. Electron drift velocity in dilute $\mathrm{N}_{2} \mathrm{O}$-Ar mixture shows ${ }^{87}$ a peculiar E/ $\mathrm{N}$ dependence with two humps which may suggest vibrational excitation cross sections with two distinct peaks at threshold and shape resonance energies. By utilizing the differential cross sections of Allan and Skalicky ${ }^{96}$ and by following the procedure explained in the proceeding section, Nakamura derived cross sections for three vibrational excitations: $\nu_{2}$ (threshold: $\left.0.073 \mathrm{eV}\right), \nu_{3} / 2 \nu_{2}$ (unresolved, threshold: $0.145 \mathrm{eV}$ ), and $\nu_{1} / 2 \nu_{3}$ (unresolved, threshold: $0.276 \mathrm{eV})$. The resultant cross sections of the first two vibrational excitations, $\nu_{2}$ and $\nu_{3} / 2 \nu_{2}$, agree fairly well with those estimated from Allan and Skalicky, and the 

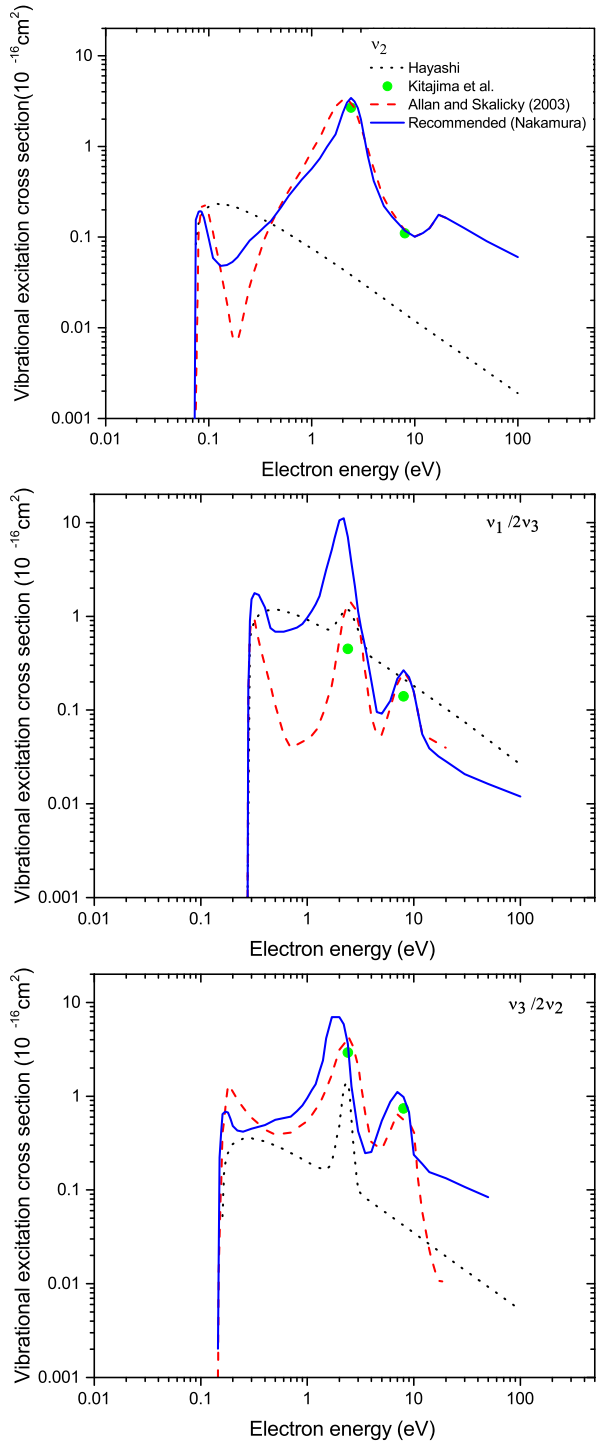

FIG. 24. Vibrational excitation cross sections. Solid circle, Kitajima et al. ${ }^{81}$; dotted curve, Hayashi ${ }^{86}$; broken curve, Allan and Skalicky ${ }^{96}$ : solid curve, Nakamura ${ }^{87}$

magnitude of the $\nu_{1} / 2 \nu_{3}$ cross section at the shape resonance is about an order of magnitude larger than that of Allan and Skalicky's. These larger cross sections, however, reproduce the experimental electron drift velocity measured in an $\mathrm{N}_{2} \mathrm{O}$-Ar mixture and also in pure $\mathrm{N}_{2} \mathrm{O}$ when combined with the recommended momentum transfer cross section discussed above. As discussed below, the magnitude of the recommended vibrational excitation cross sections and the experimental elastic integral cross section of Kitajima et al. ${ }^{81}$ can be added up to make the total cross section which is consistent with the recommended total scattering cross section around the shape resonance region, which acts to support our recommended values.

\section{F. Electronic Excitation Cross Section}

Investigations on location and assignment of electronic excitation states for the $\mathrm{N}_{2} \mathrm{O}$ molecule have been carried out through studies on optical absorption ${ }^{97}$ and electron energy loss spectrum ${ }^{98,99}$. Cubric et al. ${ }^{100}$ obtained the first high-resolution ( $30-40 \mathrm{meV}$ resolution) electron impact spectrum of $\mathrm{N}_{2} \mathrm{O}$ over the energy range from 1.5 to $21 \mathrm{eV}$ and gave detailed assignment of the observed structures, including the valence states as well as the Rydberg states. Electronic excitation in $\mathrm{N}_{2} \mathrm{O}$ (into optically allowed states), as seen in zero-degree energy-loss spectra, see Fig. 25, is dominated by two broad peaks labelled as $\mathrm{C}^{1} \Pi$ and $\mathrm{D}^{1} \Sigma^{+}$states.

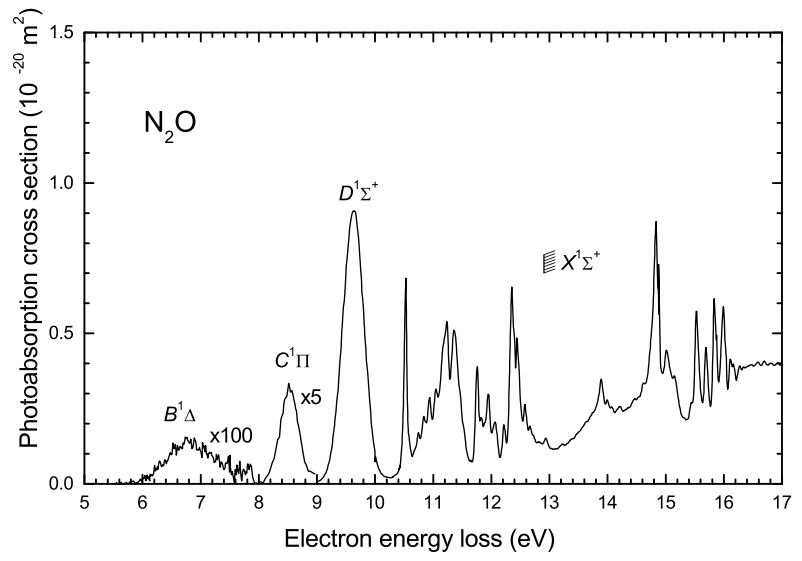

FIG. 25. Zero-angle electron-scattering energy loss spectra in $\mathrm{N}_{2} \mathrm{O}$, from experiments by Chang et al. ${ }^{52}$. The ionization threshold is $12.89 \mathrm{eV}$ for $\mathrm{N}_{2} \mathrm{O}$.

Michelin, Kroin and Lee ${ }^{101}$ reported differential and integral cross sections for electronic excitations to the $\mathrm{C}^{1} \Pi$ state and the ${ }^{3} \Pi$ state $(8.0 \mathrm{eV}$ energy loss) in the 10 to $100 \mathrm{eV}$ range by using the distorted-wave method.

Kawahara et al. ${ }^{102}$ in order to derive integral cross sections, see Fig. 26 and 27, were obtained using extrapolated differential cross sections to zero-angle scattering via generalized oscillator strength (GOS). As admitted by them, the use of GOS is not fully appropriate at low scattering energies. Therefore, they applied also a semi-empirical approach of $\mathrm{Kim}^{58}$, based on scaling of Born approximation to effective scattering energy (BE approach) and with use of GOS ( $f$-factors) from experiment (so called BE $f$ scaling). Kawahara et al.'s results for the $\mathrm{C}^{1} \Pi$ and $\mathrm{D}^{1} \Sigma^{+}$states are shown in Figs. 26 and 27. $\mathrm{BE} f$ results agree with the experiment starting from the collision energy of $50 \mathrm{eV}$.

Marinković et al. ${ }^{74}$ measured DCS for $\mathrm{C}^{1} \Pi$ and $\mathrm{D}^{1} \Sigma^{+}$ states at $0-148^{\circ}$ scattering angles and $15-80 \mathrm{eV}$ collision energy. Only for $80 \mathrm{eV}$ do they give absolute values of the DCS, via normalization to their own ${ }^{74}$ elastics DCS (that in turn were normalized to TCS). Errors on DCS were estimated as 32\%. In 1999 Marinković et 
al. ${ }^{103}$ renormalized the DCS using the generalized oscillator strength evaluated from comparison between experiments and theory: in the limit zero-scattering angle they adopted the optical oscillator strength of 0.026 and 0.375 for the $\mathrm{C}^{1} \Pi$ and $\mathrm{D}^{1} \Sigma^{+}$states, respectively.

Figs. 26 and 27 show integral cross sections for these two states obtained by multiplying the integral values given by Marinković et al. ${ }^{74}$ by the coefficients given for DCS in ref. ${ }^{103}$. This is only a rough comparison: in particular at high energies these integral cross sections can be underestimated, due to possible errors in forwardangle analysis of DCSs. In fact, the integral cross section of Marinković et al. for the $\mathrm{D}^{1} \Sigma^{+}$state at $30 \mathrm{eV}$ coincides with that of Kawahara et al. ${ }^{102}$ but at higher energies it falls much more rapidly with the energy, see fig.27.

We are not aware of experimental determinations of excitations into triplet states in $\mathrm{N}_{2} \mathrm{O}$. A recent theoretical evaluation ${ }^{104}$ using Quantemol-N R-matrix package ${ }^{90}$ gives a narrow peak with a maximum of $0.25 \times 10^{-16} \mathrm{~cm}^{2}$ at $10 \mathrm{eV}$ for the ${ }^{3} \Sigma^{+}\left({ }^{3} \mathrm{~A}_{1}\right)$ state and similarly narrow peak of $0.15 \times 10^{-16} \mathrm{~cm}^{2}$ at $14 \mathrm{eV}$ for the ${ }^{3} \Pi\left({ }^{3} \mathrm{~B}_{1}\right)$ state.

There is another assessment of the (total) cross section for electronic excitations by using an electron swarm method. Most electronic excitation thresholds of atoms and molecules lie immediately below the ionization threshold and the electron energy losses through electronic excitations can effectively determine the spread of the electron energy distribution which overlaps with the ionization cross section, namely, the threshold nature of the primary ionization coefficient. Experimental uncertainties of the ionization cross section and the primary ionization coefficient are usually low, and are both about a few per cent. A Boltzmann calculation shows small amendment to threshold part of an electronic excitation cross section can alter resultant primary ionization coefficient sensitively but only minimal change, if any, of any other swarm parameters like an electron drift velocity.

Swarm checks, see for example Ref. ${ }^{105,106}$ show that under-determination of the electronic excitation overestimates the transversal diffusion coefficient above $100 \mathrm{Td}$. The presently recommended set does not include cross sections for excitation into higher states, visible in the energy-loss spectra below the ionization threshold, see Fig. 25. Therefore, the set of recommended cross sections to be used in modeling electron swarms has to "mimic" these missing contributions. For this reason, for swarm modeling we recommend the set given in table XIII and presented in Fig. 28, that coincides also with the set used by Duplijanin et al. ${ }^{107}$, see the comparison given in Figs. 26 and 27.

Thin solid curves in Fig. 28 show the three swarmderived electronic excitation cross sections determined in order that they can reproduce the experimental primary ionization coefficient of pure $\mathrm{N}_{2} \mathrm{O}^{108}$ within a few percent. They are given realistic threshold energies but are by no means intended to be any specific excitation processes: they as a whole are only intended to pro- vide realistic energy loss of electrons passing through the gas and, in fact, unique determination of their respective cross sections was not possible. But it will be shown in the later section that the sum of these three swarm-derived cross sections, the recommended elastic cross section (Section III.B) and the recommended ionization cross section (Section III.H) agrees well with the recommended total cross section (Section III.A).

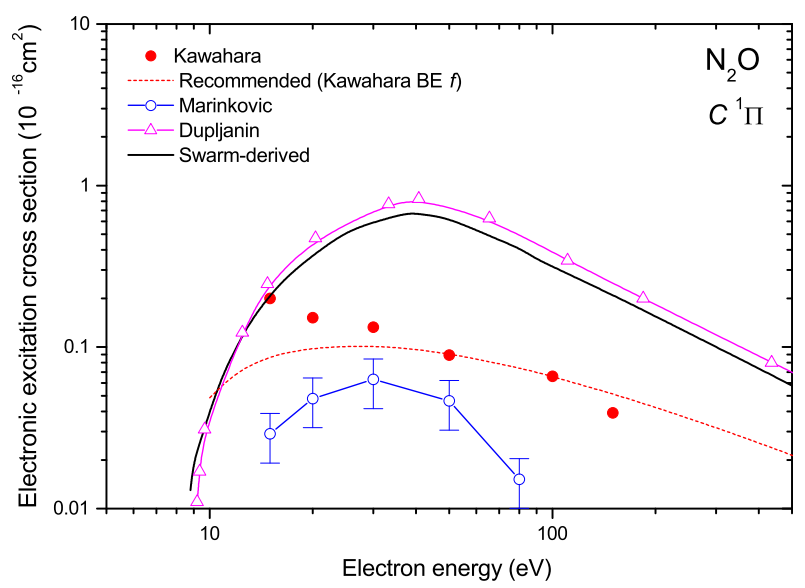

FIG. 26. Integral cross sections for the excitation of $\mathrm{N}_{2} \mathrm{O}$ into the $\mathrm{C}{ }^{1} \Pi$ state. Absolute measurements by Kawahara et $a l .{ }^{102}$ - full circles; normalized (see text) measurements by Marinković et al. ${ }^{74,103}$, open circles. Two excitation cross sections used for swarm modeling: Dupljanin et al. ${ }^{107}$ and present values ("swarm-derived") - lines with triangles and heavy chain lines, respectively. Broken lines, BE $f$ model by Kawahara et al. ${ }^{102}$.

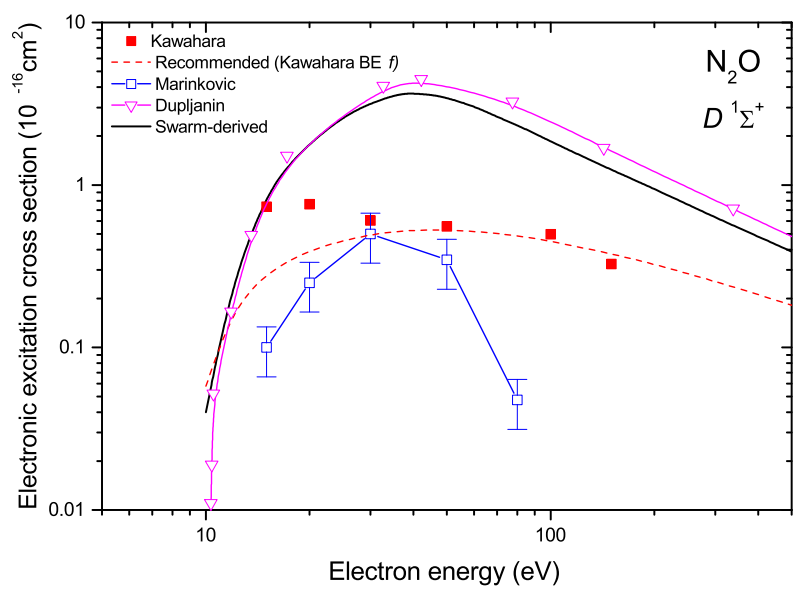

FIG. 27. Integral cross sections for the excitation of $\mathrm{N}_{2} \mathrm{O}$ into the $\mathrm{D}^{1} \Sigma^{+}$state. Absolute measurements by Kawahara et $a l .^{102}$ - full squares; normalized (see text) measurements by Marinković et $a l^{74,103}$, open squares. Two excitation cross sections used for swarm modeling: Dupljanin et al. ${ }^{107}$ and present values ("swarm-derived") - lines with triangles and heavy chain lines, respectively. Broken lines, BE $f$ model by Kawahara et al. ${ }^{102}$. 
As recommended integral cross sections for excitation to the $\mathrm{C}^{1} \Pi$ and $\mathrm{D}^{1} \Sigma^{+}$states we adopt the BE $f$ semiempirical values by Kawahara et al. ${ }^{102}$ and for the $\mathrm{B}^{1} \Delta$ state - the semi-empirical BE values of Wang et al. ${ }^{109}$, see Table XIII.

\section{G. Dissociation Cross Section}

The $\mathrm{D}^{1} \Sigma^{+}$excited state of $\mathrm{N}_{2} \mathrm{O}$ is repulsive, leading to dissociation of the molecule. Several experiments revealed dissociation of $\mathrm{N}_{2} \mathrm{O}$ into the oxygen atom in its ground state $\mathrm{O}\left({ }^{3} \mathrm{P}\right)$ and $\mathrm{N}_{2}$ molecule in electronically excited states, see Ref. ${ }^{61}$ for the discussion. Le Clair and McConkey ${ }^{61}$ studied the channel e $+\mathrm{N}_{2} \mathrm{O} \rightarrow \mathrm{e}^{\prime}+$ $\mathrm{O}\left({ }^{1} \mathrm{~S}\right)+\mathrm{N}_{2}\left(\mathrm{X}^{1} \Sigma_{g}^{+}\right)$with production of the metastable (i.e. second excited level) oxygen atom $\mathrm{O}\left({ }^{1} \mathrm{~S}\right)$. Measurements were performer via detection of optical emission from $\mathrm{XeO}^{*}$ excimer. Normalization was performed adopting the optical oscillator strength of 0.36 ; the declared uncertainty on the cross section for the oxygen atoms $\mathrm{O}\left({ }^{1} \mathrm{~S}_{0}\right)$ is $10 \%$. The maximum of the cross sections is $0.225 \times 10^{-16} \mathrm{~cm}^{2}$ at $45 \mathrm{eV}$. We note, that the cross section for production of the $\mathrm{O}\left({ }^{1} \mathrm{~S}\right)$ atom is exactly half of the excitation to the $\mathrm{D}^{1} \Sigma^{+}$state, as obtained by Kawahara et al. ${ }^{102}$ in their $\mathrm{BE} f$ model.

\section{H. Ionization Cross Section}

The agreement between different experiments ${ }^{27,28,30,31}$ in $\mathrm{N}_{2} \mathrm{O}$ is good, within $5 \%$ in the maximum of the total ionization cross section, see Fig. 29. In particular

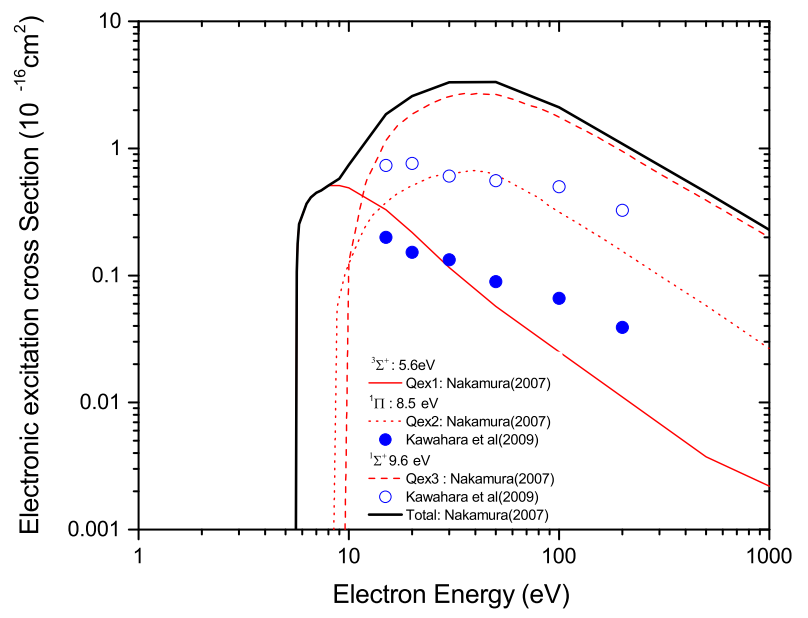

FIG. 28. Electronic excitation cross sections of $\mathrm{N}_{2} \mathrm{O}$. Closed and open circles, integral cross sections ${ }^{102}$ for excitations of $\mathrm{C}^{1} \Pi$ and $\mathrm{D}^{1} \Sigma^{+}$states respectively; three thin curves, swarmderived excitation cross sections whose excitation threshold are assumed to be $5.6 \mathrm{eV}$ (the value assigned to ${ }^{3} \Sigma^{+}$), $8.5 \mathrm{eV}$ $\left(\mathrm{C}^{1} \Pi\right)$ and $9.6 \mathrm{eV}\left(\mathrm{D}^{1} \Sigma^{+}\right)$, respectively; thick solid curve, sum of the swarm-derived cross sections.
TABLE XIII. Recommended cross sections for electronic excitation of $\mathrm{N}_{2} \mathrm{O}$ into $\mathrm{B}^{1} \Delta, \mathrm{C}^{1} \Pi$, and $\mathrm{D}^{1} \Sigma$ states, from Born Effective scaling model ${ }^{102}$ in $10^{-18} \mathrm{~cm}^{2}$ units. Uncertainty of this determination is $\pm 20 \%$. The last column is the sum of electronic excitations, as needed to reproduce swam coefficients (present work). The latter data are much higher than the sum of the three states: the swarm-derive cross sections account for the total energy loss due to electronic excitation, so they comprise also dipole-forbidden states; further, the account also for the "effective" energy loss, i.e. for excitations into vibronic series.

\begin{tabular}{|c|c|c|c|c|}
\hline $\begin{array}{c}\text { Energy } \\
(\mathrm{eV})\end{array}$ & $\mathrm{B}^{1} \Delta$ & $\mathrm{C}^{1}{ }^{1} \Pi$ & $\mathrm{D}^{1} \Sigma$ & $\begin{array}{l}\text { Swarm-derived } \\
\text { Sum }\end{array}$ \\
\hline 5.65 & & & & 10.7 \\
\hline 5.70 & & & & 17.8 \\
\hline 5.8 & & & & 25.4 \\
\hline 6.0 & & & & 29.7 \\
\hline 6.3 & & & & 36.7 \\
\hline 6.6 & 0 & 0 & 0 & 41.1 \\
\hline 7.0 & 0.712 & 0 & 0 & 44.8 \\
\hline 7.4 & 1.48 & 0 & 0 & 46.7 \\
\hline 7.8 & 1.92 & 0 & 0 & \\
\hline 8.0 & & & & 50.9 \\
\hline 8.2 & 2.23 & 0 & 0 & \\
\hline 8.6 & 2.47 & 0.636 & 0 & \\
\hline 9.0 & 2.66 & 2.41 & 0 & 57.6 \\
\hline 9.4 & 2.81 & 3.35 & 0 & \\
\hline 10 & 2.98 & 4.35 & 4.79 & 74 \\
\hline 11 & 3.19 & 5.57 & 11.2 & \\
\hline 12 & 3.31 & 6.44 & 16.0 & \\
\hline 15 & 3.41 & 8.00 & 27.1 & 185.7 \\
\hline 20 & 3.27 & 8.98 & 38.5 & \\
\hline 25 & 3.04 & 9.18 & 44.9 & \\
\hline 30 & 2.82 & 9.08 & 48.5 & 331.7 \\
\hline 40 & 2.43 & 8.58 & 51.3 & \\
\hline 50 & 2.13 & 8.00 & 51.5 & 333.3 \\
\hline 70 & 1.71 & 6.96 & 49.0 & \\
\hline 100 & 1.32 & 5.8 & 44.0 & 210.1 \\
\hline 150 & 0.965 & 4.54 & 37.0 & \\
\hline 200 & 0.762 & 3.76 & 31.8 & \\
\hline 300 & 0.54 & 2.82 & 25.0 & \\
\hline 400 & 0.42 & 2.27 & 20.8 & \\
\hline 500 & 0.344 & 1.92 & 17.9 & 45.2 \\
\hline 600 & 0.292 & 1.66 & 15.7 & \\
\hline 700 & 0.254 & 1.47 & 14.1 & \\
\hline 800 & 0.225 & 1.32 & 12.8 & \\
\hline 900 & 0.203 & 1.2 & 11.7 & \\
\hline 1000 & 0.184 & 1.1 & 10.8 & 22.9 \\
\hline
\end{tabular}

the most recent experiment by Lindsay et al. ${ }^{27}$ coincides with that by Rapp, Englander-Golden ,and Briglia ${ }^{110}$; some differences exist in the low-energy part: data of Lopez $^{31}$ are higher than other sets, and measurements of Iga ${ }^{30}$ are lower in the threshold region. More significant differences are to be noted for the parent $\mathrm{N}_{2} \mathrm{O}^{+}$ion yield, see Fig. 30. Somewhat akin to the parent ion in ionization of NO, the data of Iga et al. ${ }^{30}$ and Lopez ${ }^{31}$ for $\mathrm{N}_{2} \mathrm{O}^{+}$are higher than those by Lindsay et al. ${ }^{27}$. The experiment from Innsbruck ${ }^{66}$, using normalization to $\mathrm{Ar}^{+}$, agrees with Lindsay et al.. Note also that the shape of the 


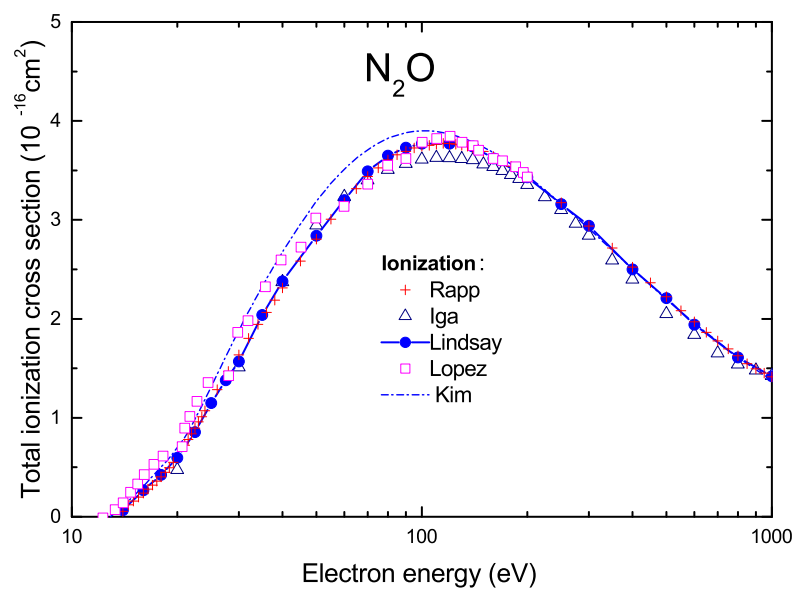

FIG. 29. Total ionization cross sections in $\mathrm{N}_{2} \mathrm{O}$ : gross total - Rapp, Englander-Golden ${ }^{28}$; counting total - Iga et al. ${ }^{30}$, Lindsay et al. ${ }^{27}$, Lopez et al. ${ }^{31}$. Normalized data of Adamczyk et $a l .{ }^{111}$ coincide with ref. ${ }^{110}$. BEB model by Kim et al. ${ }^{68}$. Recommended data are those by Lindsay et al. ${ }^{27}$.

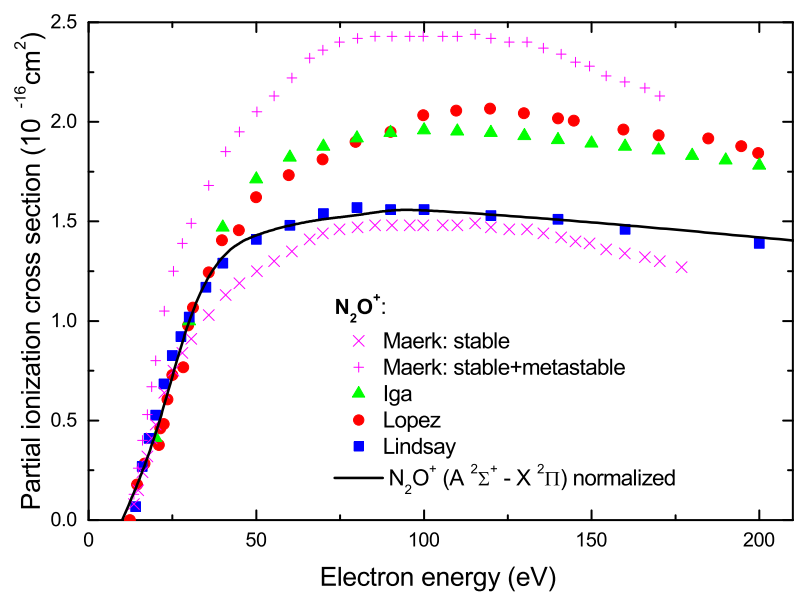

FIG. 30. Experimental ${ }^{27,30,31,66}$ partial ionization for the parent ion $\mathrm{N}_{2} \mathrm{O}^{+}$. The optical emission for $\mathrm{A}^{2} \Sigma^{+} \rightarrow \mathrm{X}^{2} \Pi$ transition $^{112}$ (normalized by a factor of 4 to Lindsay et al.' $\mathrm{s}^{27}$ $\mathrm{N}_{2} \mathrm{O}^{+}$signal at $100 \mathrm{eV}$ ) is also shown

optical emission curve ${ }^{112}$ from the $\mathrm{A}^{2} \Sigma^{+}$excited state of $\mathrm{N}_{2} \mathrm{O}$ coincides with the $\mathrm{N}_{2} \mathrm{O}^{+}$yield by Lindsay et al. ${ }^{27}$, see Fig. 30. The difference in $\mathrm{N}_{2} \mathrm{O}^{+}$formation seems to be "compensated" in partial cross sections for $\mathrm{N}^{+}$and $\mathrm{O}^{+}$formation, where data by Linsday et $a .^{27}$ are at the maximum higher by a factor of 2 than those by Iga et $a l .{ }^{30}$ and Lopez et al. ${ }^{31}$, see Fig. 31. A hint for resolving this discrepancy could come from early measurements by Märk et al. ${ }^{66}$, with a long, double E-M mass selector. In that experiment the elapsed time between the instant of ionization and detection was longer than $14 \mu \mathrm{s}$. Märk et al. noticed that normalization of their data to the $\mathrm{Ar}^{+}$ signal of Rapp and Englander-Golden ${ }^{110}$ gave the $\mathrm{N}_{2} \mathrm{O}^{+}$ cross section lower by some $40 \%$ than normalization to the dissociative ionization ${ }^{110}$. By changing ion optics,

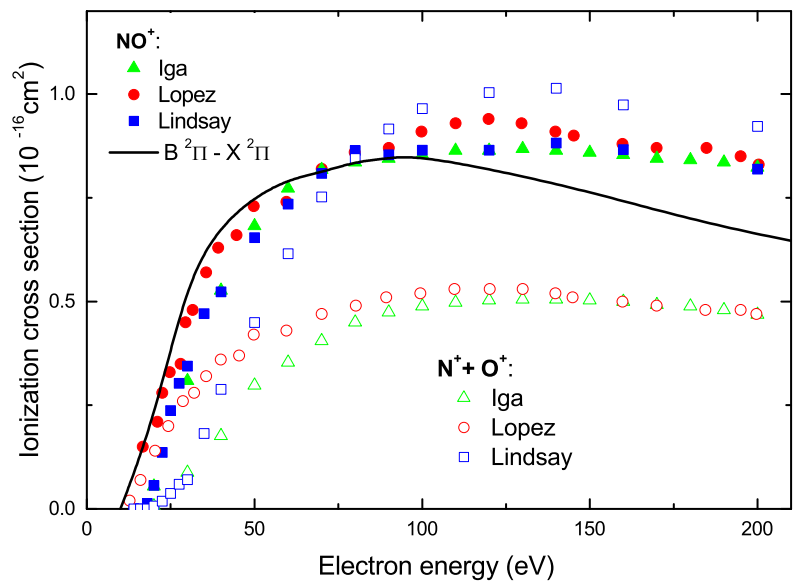

FIG. 31. Partial ionization of $\mathrm{N}_{2} \mathrm{O}$ into $\mathrm{NO}^{+}$and $\left(\mathrm{N}^{+}+\mathrm{O}^{+}\right)$. Experimental data from ref. ${ }^{27,30,31}$. The optical emission from $\mathrm{NO}^{+}$for $\mathrm{B}^{2} \Pi \rightarrow \mathrm{X}^{2} \Pi$ transition ${ }^{112}$ (normalized by a factor of 40 to Lindsay et al.'s ${ }^{27} \mathrm{NO}^{+}$signal at $70 \mathrm{eV}$ ) is also shown.

Märk et al. evaluated the metastable $\mathrm{N}_{2} \mathrm{O}^{+*}$ to $\mathrm{N}_{2} \mathrm{O}^{+}$ ratio as $11 \%$. Thus, using Märk et al.'s reasoning, the difference between the two groups of data for $\mathrm{N}_{2} \mathrm{O}^{+}$production is due to fragmentation of the metastable $\mathrm{N}_{2} \mathrm{O}^{+*}$ ion. This in turn, is not validated by the discussion of Lindsay et $a .^{27}$ : in their experiment the time elapsed between the ionization and detection of $\mathrm{N}_{2} \mathrm{O}^{+}$is $1.3 \mu \mathrm{s}$ and the time between the electron pulse and extraction pulse is 200 ns. According to Newton and Sciammana ${ }^{113}$ the fragmentation time of $\mathrm{N}_{2} \mathrm{O}^{+*}$ is only 90 ns. NIST spectra ${ }^{114}$ (4:1 ratio between $\mathrm{N}_{2} \mathrm{O}^{+}$and $\mathrm{NO}^{+}$ions) at $70 \mathrm{eV}$ would support results of Iga et al. ${ }^{30}$ and Lopez et $a l .{ }^{31}$. An updated evaluation of $\mathrm{N}_{2} \mathrm{O}^{+*}$ metastable yield is needed to resolve this issue. Recommended ionization cross sections for $\mathrm{N}_{2} \mathrm{O}$, see Fig. 32 and table XIV, are based on data of Lindsay et al. ${ }^{27}$ and coincide with those given by Lindsay and Mangan in their review ${ }^{27}$ : this is a self consistent set and summed partial cross sections agree with determinations of total ionization from other experiments ${ }^{30,31,110}$.

\section{Electron Attachment (DEA) Cross Section}

Rapp and Briglia ${ }^{70}$ measured the absolute total cross sections for negative-ion formation in $\mathrm{N}_{2} \mathrm{O}$ and some other gases by electron impact in a total ionization tube. Both dissociative attachment and ion-pair formation were measured, with careful attention paid to complete collection of the negative ions up to $50 \mathrm{eV}$ electron energy. Their results showed a single peak at 2.2 $\mathrm{eV}$ and the total cross section for negative-ion formation at that energy was $9.78 \times 10^{-2} \pi \mathrm{a}_{0}^{2}$. In this experiment, negative-ion formed is believed to be mostly $\mathrm{O}^{-}$from $\mathrm{N}_{2} \mathrm{O}$, inferred from the investigations of other studies such as Krishnakumar et al. ${ }^{115}$. Krishnakumar et al. measured the cross sections for the production of 


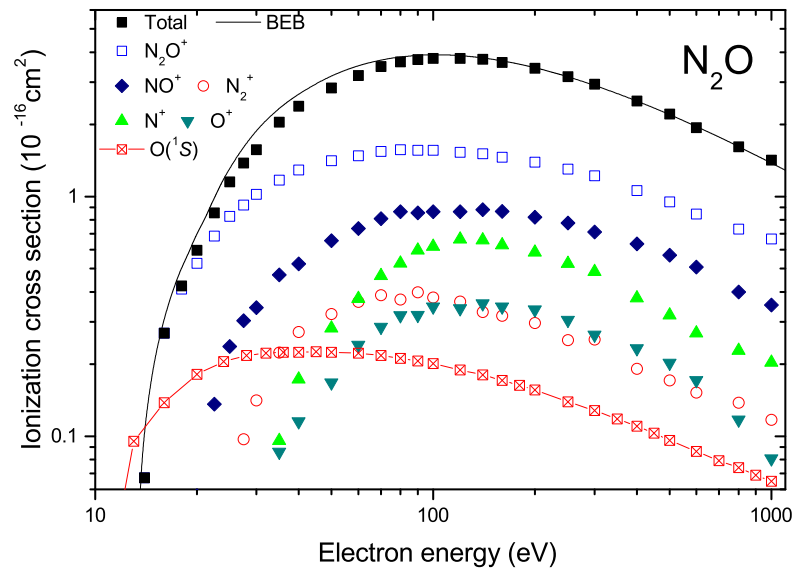

FIG. 32. Recommended cross sections for ionization of $\mathrm{N}_{2} \mathrm{O}$ are based on Lindsay et l. $^{27}$ measurements and are the same as given by Lindsay and Mangan in their review ${ }^{27}$. The cross section for the formation of a neutral oxygen atom $\mathrm{O}$ in ${ }^{1} S_{0}$ electronic state measured by LeClair et al. ${ }^{61}$ is also given: this comparison makes clear that the formation of the $\mathrm{O}$ atom is not a "co-product" of ionization. BEB model by Kim et al. ${ }^{68}$. The uncertainties are $\pm 5 \%$ on total ionization and $\mathrm{N}_{2} \mathrm{O}^{+}$, $\pm 10 \%$ on $\mathrm{NO}^{+}$and $\mathrm{N}^{+}$, and $\pm 15 \%$ on $\mathrm{N}_{2}^{+}$and $\mathrm{O}^{+}$partial ionization cross sections ${ }^{27}$.

TABLE XIV. Recommended cross sections for ionization of $\mathrm{N}_{2} \mathrm{O}$ are based on Lindsay et al. ${ }^{27}$ measurements and are the same as given by Lindsay and Mangan in their review ${ }^{27}$ in the units of $10^{-16} \mathrm{~cm}^{2}$. Energy in $\mathrm{eV}$.

\begin{tabular}{|c|c|c|c|c|c|c|}
\hline electron & CS & CS & $\mathrm{CS}$ & CS & CS & CS \\
\hline Energy & $\mathrm{N}_{2} \mathrm{O}^{+}$ & $\mathrm{N}_{2}^{+}$ & $\mathrm{NO}^{+}$ & $\mathrm{N}^{+}$ & $\mathrm{O}^{+}$ & Total \\
\hline 14 & 0.067 & & & & & 0.067 \\
\hline 16 & 0.269 & & & & & 0.269 \\
\hline 18 & 0.411 & & 0.0131 & & & 0.424 \\
\hline 20 & 0.527 & 0.0066 & 0.0564 & & 0.0066 & 0.597 \\
\hline 22.5 & 0.684 & 0.017 & 0.136 & 0.0023 & 0.0163 & 0.855 \\
\hline 25 & 0.827 & 0.047 & 0.237 & 0.0059 & 0.0315 & 1.15 \\
\hline 27.5 & 0.922 & 0.097 & 0.303 & 0.0187 & 0.0407 & 1.38 \\
\hline 30 & 1.02 & 0.141 & 0.344 & 0.0237 & 0.0466 & 1.57 \\
\hline 35 & 1.17 & 0.223 & 0.471 & 0.0958 & 0.086 & 2.04 \\
\hline 40 & 1.29 & 0.272 & 0.523 & 0.173 & 0.115 & 2.38 \\
\hline 50 & 1.41 & 0.323 & 0.654 & 0.282 & 0.167 & 2.84 \\
\hline 60 & 1.48 & 0.363 & 0.735 & 0.375 & 0.240 & 3.20 \\
\hline 70 & 1.54 & 0.387 & 0.809 & 0.467 & 0.285 & 3.49 \\
\hline 80 & 1.57 & 0.372 & 0.864 & 0.526 & 0.319 & 3.65 \\
\hline 90 & 1.56 & 0.398 & 0.854 & 0.596 & 0.320 & 3.73 \\
\hline 100 & 1.56 & 0.379 & 0.865 & 0.618 & 0.347 & 3.77 \\
\hline 120 & 1.53 & 0.365 & 0.865 & 0.663 & 0.341 & 3.77 \\
\hline 140 & 1.51 & 0.33 & 0.882 & 0.657 & 0.357 & 3.74 \\
\hline 160 & 1.46 & 0.318 & 0.866 & 0.627 & 0.347 & 3.62 \\
\hline 200 & 1.39 & 0.297 & 0.819 & 0.585 & 0.337 & 3.43 \\
\hline 250 & 1.30 & 0.252 & 0.775 & 0.525 & 0.305 & 3.16 \\
\hline 300 & 1.22 & 0.253 & 0.712 & 0.486 & 0.265 & 2.94 \\
\hline 400 & 1.06 & 0.191 & 0.634 & 0.377 & 0.232 & 2.50 \\
\hline 500 & 0.95 & 0.171 & 0.569 & 0.320 & 0.202 & 2.21 \\
\hline 600 & 0.844 & 0.152 & 0.507 & 0.269 & 0.171 & 1.94 \\
\hline 800 & 0.731 & 0.138 & 0.400 & 0.228 & 0.117 & 1.61 \\
\hline 1000 & 0.666 & 0.117 & 0.353 & 0.203 & 0.0807 & 1.42 \\
\hline
\end{tabular}

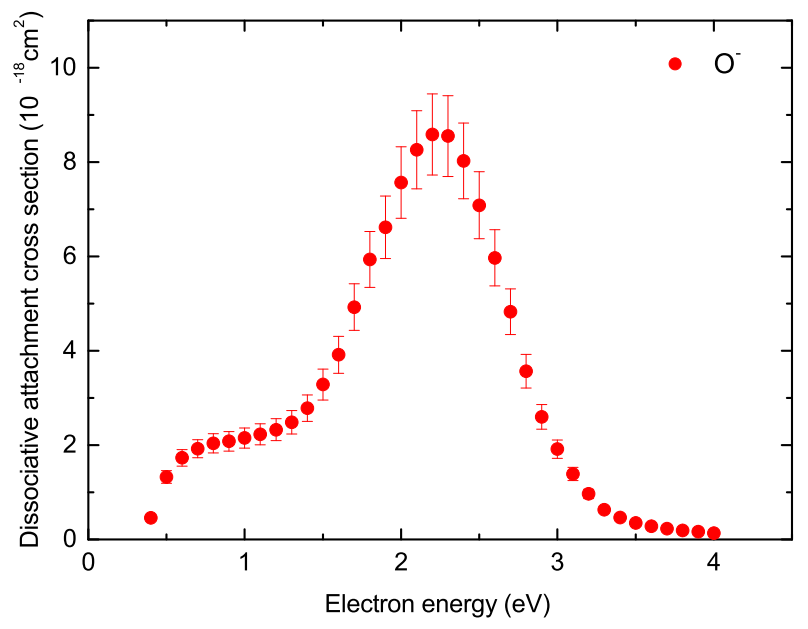

FIG. 33. Recommended cross sections for the formation of $\mathrm{O}^{-}$from $\mathrm{N}_{2} \mathrm{O}$.

$\mathrm{O}^{-}$from $\mathrm{N}_{2} \mathrm{O}$ by the process of DEA for electron-impact energies ranging from 0 to $50 \mathrm{eV}$. Three new $\mathrm{O}^{-}$peaks at $5.4,8.1$, and $13.2 \mathrm{eV}$ were observed, and their data above $4 \mathrm{eV}$ electron-impact energy differ from Rapp and Briglia. ${ }^{70}$ The cross sections between about 1.5 and 4 eV agree well with Rapp and Briglia, but disagreements appeared again below about $1.5 \mathrm{eV}$. Krishnakumar ${ }^{116}$ believes that one reason for their higher cross sections compared with Rapp and Briglia ${ }^{70}$ below $1.6 \mathrm{eV}$ may be due to heating of the gas by the magnetic coil they used inside the vacuum chamber. DEA in $\mathrm{N}_{2} \mathrm{O}$ has a strong temperature dependence as was shown by Chantry ${ }^{117}$. Meanwhile, the problem with Rapp and Briglia's data is above $4 \mathrm{eV}$, where Krishnakumar et al. ${ }^{115}$ saw three smaller clean peaks. Instead, Rapp found a broad peak at about $10 \mathrm{eV}$, and this might have been due to some impurities in the gas they used ${ }^{116}$. Also, the Krishnakumar group have confirmed the peaks when they did the velocity map imaging experiments as shown in Nandi et $a l .{ }^{118}$. Therefore, we recommend the cross sections of Rapp and Briglia ${ }^{70}$ in the energy region between $1.6 \mathrm{eV}$ and $4 \mathrm{eV}$. The uncertainty is given to be $15 \%$. Our DEA cross sections are presented in Table XV and Fig. 33, respectively. Above $4 \mathrm{eV}$, the results of Krishnakumar et al. ${ }^{115}$ could be recommended, but they are very noisy, wiggly and also blown up $40 \sim 70$ times. So it is very difficult to extract precise numerical data by digitizing and no numerical values are available from the original authors.

\section{IV. $\mathrm{NO}_{2}$}

Nitrogen dioxide $\left(\mathrm{NO}_{2}\right)$ is free radical with one unpaired electron. Its $\mathrm{X}{ }^{2} \mathrm{~A}_{1}$ electronic ground state has a bent structure. There are less data available for $\mathrm{NO}_{2}$ than $\mathrm{NO}$ or $\mathrm{N}_{2} \mathrm{O}$; this situation could be due to the difficulty with handling $\mathrm{NO}_{2}$ molecules. $\mathrm{NO}_{2}$ is corrosive 
TABLE XV. Recommended dissociative attachment cross sections (CS) for the formation of $\mathrm{O}^{-}$from $\mathrm{N}_{2} \mathrm{O}$ in the units of $10^{-18} \mathrm{~cm}^{2}$. Energy in $\mathrm{eV}$.

\begin{tabular}{cccc}
\hline \hline Energy & CS & Energy & CS \\
\hline 0.4 & 0.46 & 2.3 & 8.55 \\
0.5 & 1.33 & 2.4 & 8.02 \\
0.6 & 1.73 & 2.5 & 7.09 \\
0.7 & 1.92 & 2.6 & 5.97 \\
0.8 & 2.04 & 2.7 & 4.83 \\
0.9 & 2.08 & 2.8 & 3.56 \\
1.0 & 2.15 & 2.9 & 2.60 \\
1.1 & 2.23 & 3.0 & 1.91 \\
1.2 & 2.33 & 3.1 & 1.39 \\
1.3 & 2.48 & 3.2 & 0.97 \\
1.4 & 2.78 & 3.3 & 0.63 \\
1.5 & 3.28 & 3.4 & 0.47 \\
1.6 & 3.92 & 3.5 & 0.35 \\
1.7 & 4.93 & 3.6 & 0.28 \\
1.8 & 5.94 & 3.7 & 0.23 \\
1.9 & 6.62 & 3.8 & 0.19 \\
2.0 & 7.57 & 3.9 & 0.17 \\
2.1 & 8.26 & 4.0 & 0.13 \\
2.2 & 8.59 & & \\
\hline \hline
\end{tabular}

and poisonous, and in the gas phase exists in equilibrium with $\mathrm{N}_{2} \mathrm{O}_{4}$ (dinitrogen tetroxide), which could cause a problem when performing experiments.

\section{A. Total Scattering Cross Section}

Only few experiments have been performed on TCS in $\mathrm{NO}_{2}$ due to the highly corrosive character of this gas. Szmytkowski and collaborators corrected ${ }^{119}$ their earlier data $^{120}$ for the error due to collecting inelastically scattered electrons. The differences are similar to those in $\mathrm{N}_{2} \mathrm{O}$. However, corrected ${ }^{119}$ data are higher than the measurements by Zecca et al. ${ }^{36}$ in the high-energy limit. The reason for this discrepancy is unclear. Therefore, the recommended values at $100-350 \mathrm{eV}$ are based on mean values from the three experiments ${ }^{21,36,120}$; at 7 $100 \mathrm{eV}$ on the newer measurements of Szmytkowski and Możejko $^{21}$, and on older ones ${ }^{120}$ below $7 \mathrm{eV}$. The overall uncertainty on these data is to be estimated as $\pm 15 \%$. Theoretical calculations of total cross sections were performed by Gupta et al. ${ }^{121}$ who used the R-Matrix method as implemented in the Quantemol-N package ${ }^{90}$ below 15 $\mathrm{eV}$ and spherical complex optical potential. Above 50 $\mathrm{eV}$ these calculations agree very well with recommended data. Below $10 \mathrm{eV}$ the R-Matrix method shows presence of two narrow resonances, that were not visible in the experiments, see Fig. 34. Calculations show a steeper rise of the cross sections in the limit of zero energy than it is measured: a similar observation was made for another weakly polar molecule, $\mathrm{NF}_{3}$, see ${ }^{3}$. For $\mathrm{NO}_{2}$ the BetheBorn plot is of poor quality, as data by Zecca et al. ${ }^{36}$ are underestimated above $1400 \mathrm{eV}$. A regression line would coincide with that for $\mathrm{N}_{2} \mathrm{O}$.

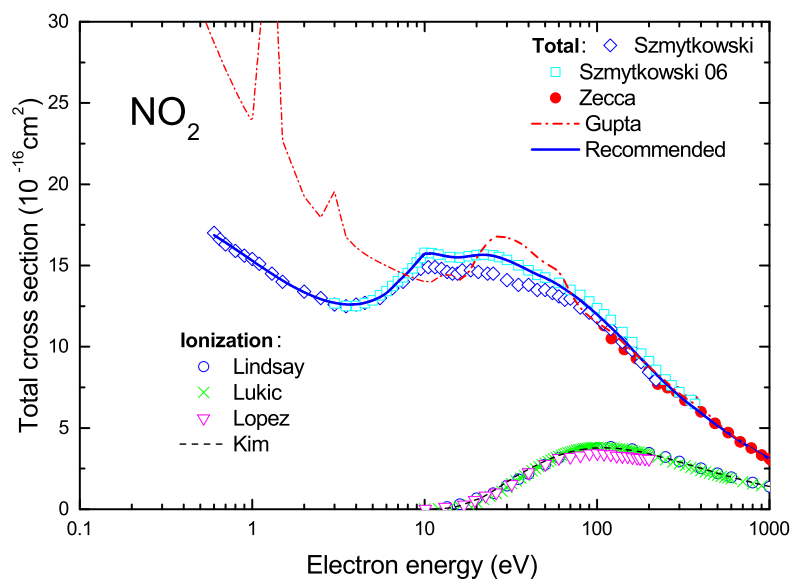

FIG. 34. Total cross sections for electron scattering on nitrogen dioxide, $\mathrm{NO}_{2}$. Experimental absolute TCS are from Szmytkowski et al. ${ }^{120}$ - diamonds, from Szmytkowski and Możejko ${ }^{34}$ - open squares, from ref. ${ }^{36}$ - full circles. Theoretical total ${ }^{121}$ : Quantemol package below $15 \mathrm{eV}$ and optical model at higher energies. Thick line is present recommended TCS. Ionization integral cross section - experiments: Lindsay et $a l .{ }^{29}$, Lukić et al. ${ }^{122}$, Lopez et al. ${ }^{31}$; BEB model by Kim et $a l .{ }^{68}$.

TABLE XVI. Recommended TCS (in $10^{-16} \mathrm{~cm}^{2}$ units) for electron scattering on nitrogen dioxide $\mathrm{NO}_{2}$. Recommended values up to $7 \mathrm{eV}$ are based on experimental data by Szmytkowski et al. ${ }^{120}$, at $7-100 \mathrm{eV}$ on the remeasurements by Szmytkowski and Możejko ${ }^{119}$, at $100-350 \mathrm{eV}$ - on the nonweighted average from the three experiments ${ }^{36,119,120}$ and on ref. $^{36}$ above $350 \mathrm{eV}$. The uncertainty on recommended data is $\pm 15 \%$.

\begin{tabular}{ccccll}
\hline $\begin{array}{c}\text { Electron } \\
\text { energy }\end{array}$ & $\begin{array}{c}\text { TCS } \\
\text { electron } \\
\text { energy }\end{array}$ & $\begin{array}{c}\text { TCS } \\
\text { energy }\end{array}$ \\
\hline \hline 0.6 & 16.9 & 8 & 14.5 & 90 & 12.4 \\
0.7 & 16.4 & 9 & 15.2 & 100 & 12.0 \\
0.8 & 16.0 & 10 & 15.8 & 120 & 11.2 \\
0.9 & 15.6 & 11 & 15.7 & 150 & 10.2 \\
1.0 & 15.3 & 12 & 15.7 & 170 & 9.50 \\
1.2 & 14.7 & 14 & 15.5 & 200 & 8.80 \\
1.5 & 14.1 & 16 & 15.5 & 220 & 8.30 \\
1.7 & 13.7 & 18 & 15.7 & 250 & 7.75 \\
2.0 & 13.3 & 20 & 15.6 & 300 & 6.97 \\
2.5 & 12.9 & 22 & 15.7 & 350 & 6.40 \\
3.0 & 12.7 & 25 & 15.6 & 400 & 5.92 \\
3.5 & 12.6 & 30 & 15.4 & 450 & 5.50 \\
3.7 & 12.6 & 35 & 15.0 & 500 & 5.14 \\
4.0 & 12.6 & 40 & 14.7 & 600 & 4.55 \\
4.2 & 12.6 & 45 & 14.4 & 700 & 4.07 \\
4.5 & 12.7 & 50 & 14.3 & 800 & 3.69 \\
5.0 & 12.8 & 60 & 13.8 & 900 & 3.37 \\
6.0 & 13.2 & 70 & 13.3 & 1000 & 3.11 \\
7.0 & 14.0 & 80 & 12.9 & & \\
\hline \hline
\end{tabular}


TABLE XVII. Recommended elastic ICS and uncertainties $(\delta)$ for $\mathrm{NO}_{2}$ in the units of $10^{-16} \mathrm{~cm}^{2}$. Energy in $\mathrm{eV}$.

\begin{tabular}{cccc}
\hline Electron & ICS & Energy & ICS \\
\hline \hline 30 & 9.47 & 300 & 2.46 \\
40 & 7.17 & 400 & 1.96 \\
50 & 6.21 & 500 & 1.68 \\
60 & 5.39 & 600 & 1.54 \\
70 & 4.85 & 700 & 1.43 \\
80 & 4.62 & 800 & 1.34 \\
90 & 4.47 & 900 & 1.27 \\
100 & 4.33 & 1000 & 1.20 \\
200 & 3.11 & 2000 & 0.77 \\
\hline \hline
\end{tabular}

\section{B. Elastic Scattering Cross Section}

There are no experimental elastic DCS and/or ICS for $\mathrm{NO}_{2}$ (nitrogen dioxide) known to these authors at the time of evaluation. Therefore, we decided to recommend theoretical ICS's. There are several theoretical reports on elastic ICS's of $\mathrm{NO}_{2}$. Mentioning a few relevant recent result, they are Joshipura et $\mathrm{l}^{123}$, Munjal et al. ${ }^{124}$, and Gupta et al. ${ }^{121}$. In Fig. 35, Joshipura et al. ${ }^{123}$ and Gupta et al. ${ }^{121}$ are presented. Also shown is the total cross section (TCS) of Szmytkowski et al. ${ }^{120}$ to compare with the elastic ICS's. The two theoretical results diverge as the electron energies get smaller. Considering that the TCS measurements are generally more reliable than the other cross section measurements and that the uncertainty of the TCS of Szmytkowski et al. ${ }^{120}$ in the range of $5-30$ $\mathrm{eV}$ is $3 \%$, the calculation of Gupta et al. seems to be overestimated, especially in this energy range. Therefore, we recommend Joshipura et al. ${ }^{123}$ and the recommended ICS values are tabulated in Table XVII.

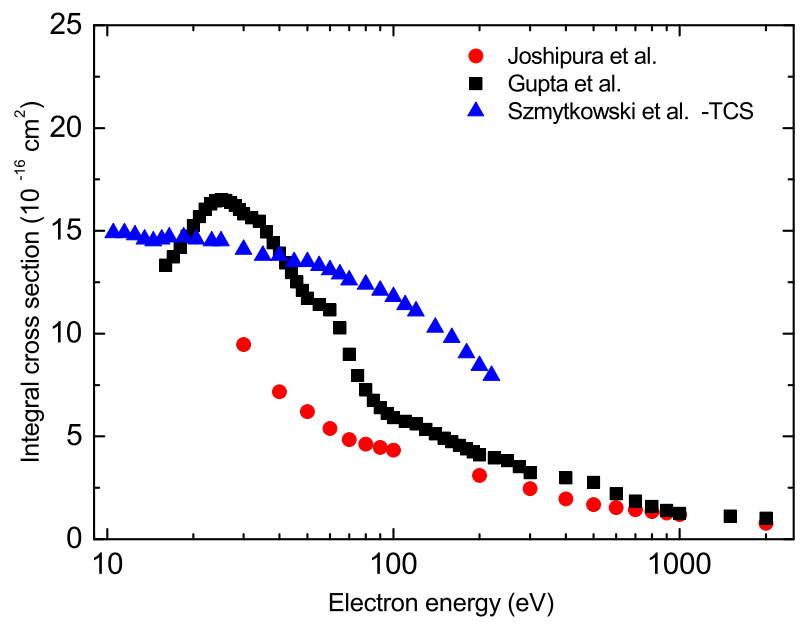

FIG. 35. Recommended elastic ICS of Joshipura et al ${ }^{123}$ compared with the values computed by Gupta et al. ${ }^{121}$ and TCS measured by Szmytkowski et al. ${ }^{120}$.

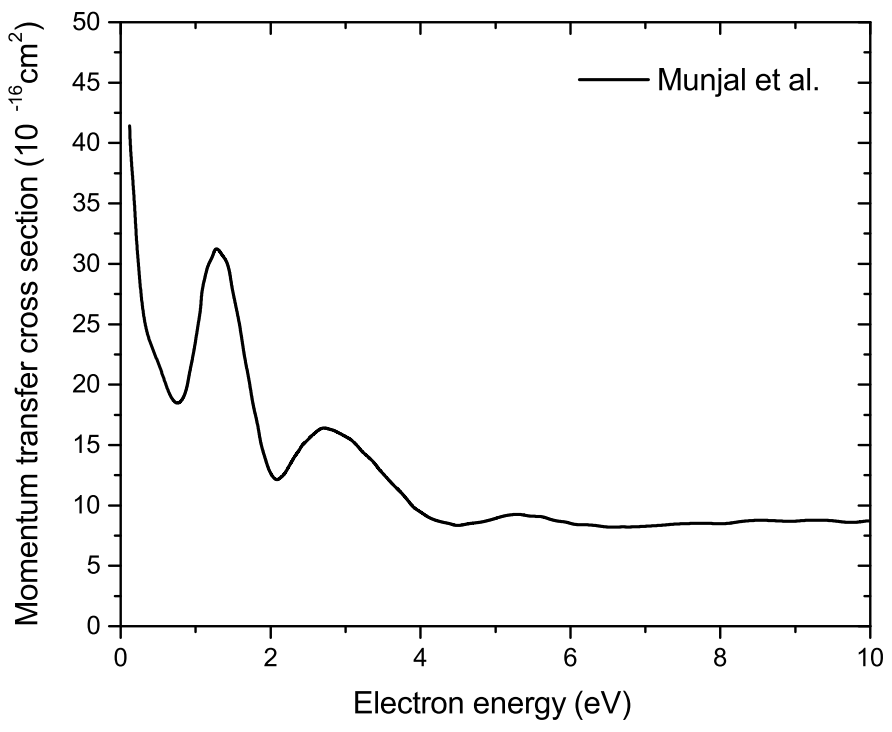

FIG. 36. Momentum transfer cross section of $\mathrm{NO}_{2}$ molecule computed using the R-matrix method by Munjal et al. ${ }^{124}$.

\section{Momentum Transfer Cross Section}

Momentum transfer cross section for the $\mathrm{NO}_{2}$ molecule were computed by Munjal et al. ${ }^{124}$ using the R-matrix method $^{89}$ and POLYDCS ${ }^{91}$. Munjal et al.'s calculations are based on a 21-state close coupling expansion and suggest that the electron $-\mathrm{NO}_{2}$ system supports a large number of resonance as might be expected given the open shell nature of the target and the presence of several lowlying electronic states. The momentum transfer cross sections computed by Munjal et al., see Fig. 36 show significant structure due to these resonances. At present these are the only momentum transfer cross section available for $\mathrm{NO}_{2}$ but they must be considered somewhat uncertain.

\section{Rotational Excitation Cross Sections}

There are no experimental data on rotational excitation of the $\mathrm{NO}_{2}$ molecule, but the theoretical study by Munjal et al. ${ }^{124}$ reported differential cross sections at one energy of $4 \mathrm{eV}$. That study used a somewhat large, compared to the experimental value, dipole moment of 0.738 D. Because the reported data is given only for one energy and the employed dipole moment was not accurate in Ref. ${ }^{124}$, in this study basic $a b$ initio structure and electron-scattering calculations, similar to those made for $\mathrm{N}_{2} \mathrm{O}$, were also performed for $\mathrm{NO}_{2}$. The calculations using the Molpro suite, the MRCI method, and the cc-pVTZ basis produced $\mathrm{NO}_{2}$ properties that are in good agreement with experimental values: The molecule has the $C_{2 v}$ geometry with the theoretical NO bond length of $1.184 \AA$ and the bond angle of $134.4^{\circ}$. The experimental values $^{125}$ are $1.193 \AA$ and $134.1^{\circ}$ correspondingly. Theo- 


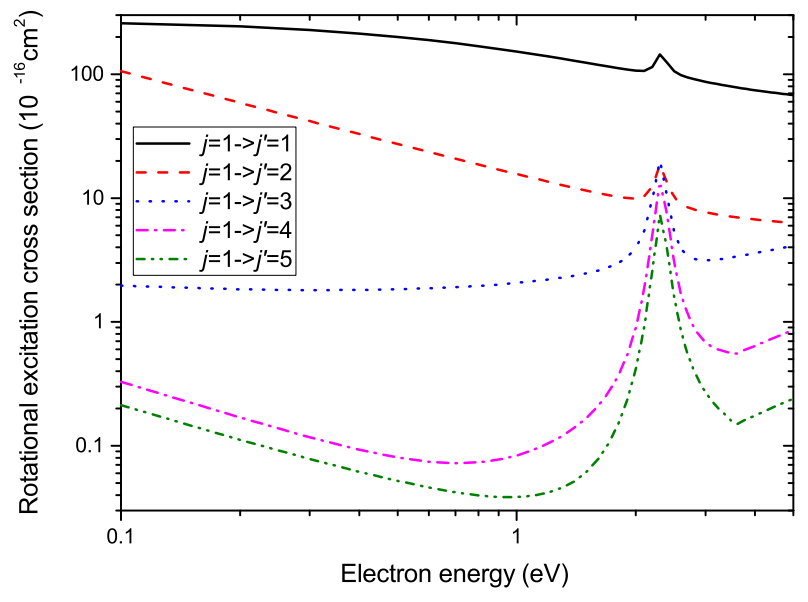

FIG. 37. Rotational excitation cross sections of the $\mathrm{NO}_{2}$ molecule computed in this study.

retical rotational constants at the equilibrium geometry are $0.413,8.08$, and $0.435 \mathrm{~cm}^{-1}$. The dipole moment is $0.302 \mathrm{D}$, while reported experimental values are ranging in the interval $0.254-0.316 \mathrm{D}$, see Ref. ${ }^{126}$ and references therein, with the positive charge displaced towards to the nitrogen atom corresponding to the polarity $\mathrm{O}^{-} \mathrm{N}^{+} \mathrm{O}^{-}$. The electron-scattering calculations were performed using the theoretical values for the dipole moment and the equilibium geometry. Previous experience suggests that it is safe to neglect the spin angular momentum when considering rotational excitation of molecules with no overall orbital angular momentum ${ }^{127}$. The spin unresolved cross sections were computed using the UK Rmatrix ${ }^{89,90}$ and the POLYDCS ${ }^{91}$ codes and are shown in Fig. 37 .

\section{E. Vibrational Excitation Cross Sections}

There is no measured or theoretical data on vibrational excitation of the $\mathrm{NO}_{2}$ molecule by an electron impact. While experimental measurements of cross sections for the process could be long and expensive, a theoretical determination with a reasonable uncertainty seems to be a relatively straightforward problem for theorists working in the area of electron-molecule scattering.

\section{F. Electronic Excitation Cross Section}

Measurements of electron scattering at 0 angle ${ }^{128}$, that correspond to the photoabsorption cross section, yielded a broad band centered at $3.12 \mathrm{eV}$, and attributed to the $4 \mathrm{~b}_{2} \rightarrow 6 \mathrm{a}_{1}\left({ }^{2} \mathrm{~A}_{1} \rightarrow{ }^{2} \mathrm{~B}_{2}\right)$ and $6 \mathrm{a}_{1} \rightarrow 2 \mathrm{~b}_{1}\left({ }^{2} \mathrm{~A}_{1} \rightarrow{ }^{2} \mathrm{~B}_{1}\right)$ transitions.

A second broad band with a maximum of the photoabsorption cross section amounting to $0.13 \times 10^{-16} \mathrm{~cm}^{2}$ (a factor 2 higher than for the $\mathrm{C}^{1} \Pi$ state in $\mathrm{N}_{2} \mathrm{O}$ ) extending from 6.3 to $9.4 \mathrm{eV}$ results from excitation of the unpaired electron in the $6 \mathrm{a}_{1}$ orbital to the $5 \mathrm{~b}_{2}$ virtual valence and the $3 \mathrm{~s} \sigma, 3 \mathrm{p} \sigma$ and $3 \pi$ Rydberg orbitals ${ }^{128}$ at $8 \mathrm{eV}$ and attributed to $4 \mathrm{~b}_{2} \rightarrow 7 \mathrm{a}_{1}\left({ }^{2} \mathrm{~A}_{1} \rightarrow{ }^{2} \mathrm{~B}_{2}\right)$ and $1 \mathrm{a}_{2} \rightarrow 2 \mathrm{~b}_{1}\left({ }^{2} \mathrm{~A}_{1}\right.$ $\rightarrow{ }^{2} \mathrm{~B}_{1}$ ) transitions.

A sharp maximum of the photoabsorption cross section with the value of $0.44 \times 10^{-16} \mathrm{~cm}^{2}$ is centered at $9.7 \mathrm{eV}$ see Fig. 38.

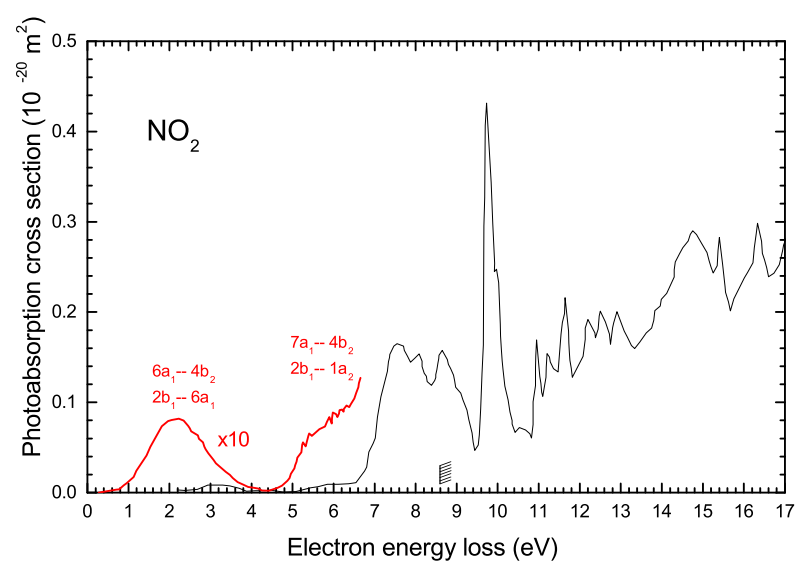

FIG. 38. Zero-angle electron-scattering energy loss spectra in $\mathrm{NO}_{2}$, from experiments by $\mathrm{Au}$ et al. ${ }^{128}$. Ionization threshold is $9.586 \pm 0.002 \mathrm{eV}$ for $\mathrm{NO}_{2}$.

We are not aware of measurements of electronic excitations either to optically allowed or forbidden states. Mundjal et al. ${ }^{124}$ and Gupta et al. ${ }^{121}$ used the molecular R-matrix codes ${ }^{89}$, in the latter case through Quantemol$\mathrm{N}$ interface ${ }^{90}$, to obtain low-energy elastic and electronic excitation cross sections. According to Gupta et al. integral cross section for the excitation $\mathrm{X}^{1} A_{1} \rightarrow{ }^{2} B_{1}(3.0 \mathrm{eV}$ excitation energy) shows a sharp peak of $1.0 \times 10^{-16} \mathrm{~cm}^{2}$ just above threshold. The nature of the peak is unclear.

As part of this study we performed electron-scattering calculations for electronic excitation using the UK Rmatrix code. We used the same basis and orbital sets, the same equilibrium geometry as in the rotational excitation calculations described above. Our computed cross sections are shown in Fig. 39. The cross sections were calculated for one single geometry, no Franck-Condon overlap between initial and final vibrational levels of the electric states was accounted for. Such results could be viewed as an approximation for the cross sections where a sum over possible final vibrational levels and an average over initial levels are evaluated. The excitation thresholds in the obtained results are vertical transition energies, which should also be interpreted as approximate values of excitation energies for vibronic transitions with the most favorable Franck-Condon factors.

\section{G. Dissociation Cross Section}

There is no measured or theoretical data on neutral dissociation of the $\mathrm{NO}_{2}$ molecule by an electron impact. 


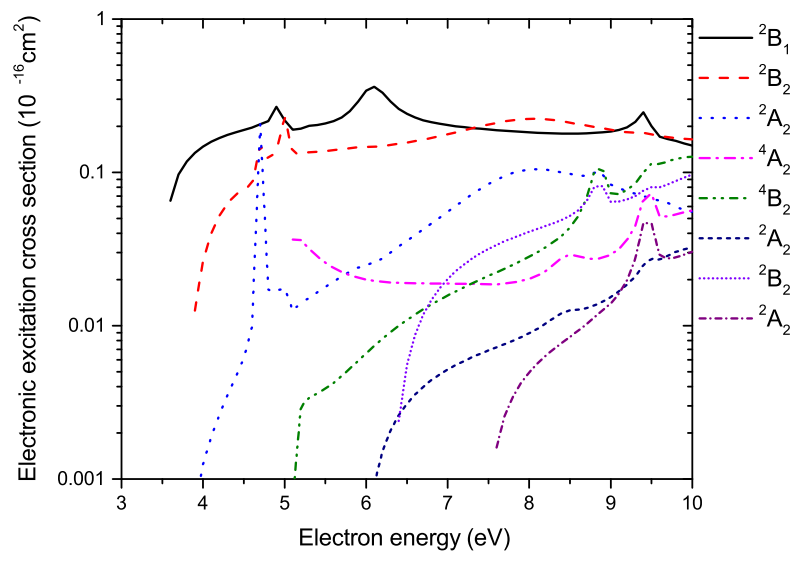

FIG. 39. Suggested cross sections electronic excitation excitation of the $\mathrm{NO}_{2}$ molecule from the ground state $X^{2} A_{1}$ into a few first excited states. Obtained in this study using the UK R-matrix ${ }^{89,90}$ code.

\section{H. Ionization Cross Section}

In spite of the importance of $\mathrm{NO}_{2}$ in technological plasmas and its role as a precursor of the pollutant ozone formation in urban smog, ionization cross sections were studied in detail only in this century. Lukic̀ et al. ${ }^{122}$ used a parallel plate ionization chamber. Thanks to a precise determination of the pressure in the scattering chamber, the gross total ionization cross section was measured up to $1000 \mathrm{eV}$ with $\pm 5 \%$ precision. Jiao et al. ${ }^{129}$ used a Fourier-transform mass spectrometer, with a cubic trapping cell ( $5 \mathrm{~cm}$ on a side); the uncertainty on the absolute data was $\pm 18 \%$. They evaluated a fraction of doubly charged ions as less than $0.2 \%$ of the total ion population; they also proved that $\mathrm{NO}_{2}^{+}$and $\mathrm{NO}^{+}$ ion are produced with thermal kinetic energies while recoil energies of $\mathrm{O}^{+}$and $\mathrm{N}^{+}$ions are less than $4.6 \mathrm{eV}$. All measurements ${ }^{29,31,122,129}$ agree within the declared error bar; in particular, those by Lindsay et al. ${ }^{29}$ agree with Lukic̀ et $a .^{122}$ (and with BEB model ${ }^{68}$ ) within $5 \%$, in the whole energy range between $50-1000 \mathrm{eV}$, see Fig. 40. Relatively good agreements exist also for partial cross sections. The dominant channel is formation of the $\mathrm{NO}^{+}$dissociated ion, see Fig. 41. The three recent experiments $^{29,31,129}$ agree within combined error bars, both for the formation of $\mathrm{NO}_{2}^{+}$and $\mathrm{NO}^{+}$. Experimental $\mathrm{NO}_{2}^{+}$cross sections from Innsbruck ${ }^{65}$ are lower by factor of two than other experimental sets and are not shown in Fig. 41. Stephan et al. ${ }^{65}$ reported also the formation of $\mathrm{NO}_{2}^{2+}$ ions, with the cross section three orders of magnitude lower than $\mathrm{NO}_{2}^{+}$. Also partial cross sections for formation of atomic ion fragments, $\mathrm{O}^{+}$(dominating) and $\mathrm{N}^{+}$from Lindsay et al. ${ }^{29}$ and Jiao et $a l .{ }^{129}$ agree well, within combined error bars (that are $15 \%$ and $20 \%$, for the two ions, respectively, in the experiment of Lindsay et al.). The uncertainty on the combined $\left(\mathrm{N}^{+}+\mathrm{O}^{+}\right)$yield is only $5 \%$ in that ${ }^{29}$ experiment; unresolved results of Lopez et $a l .{ }^{31}$ and summed results of Jiao et $a l .{ }^{129}$ agree

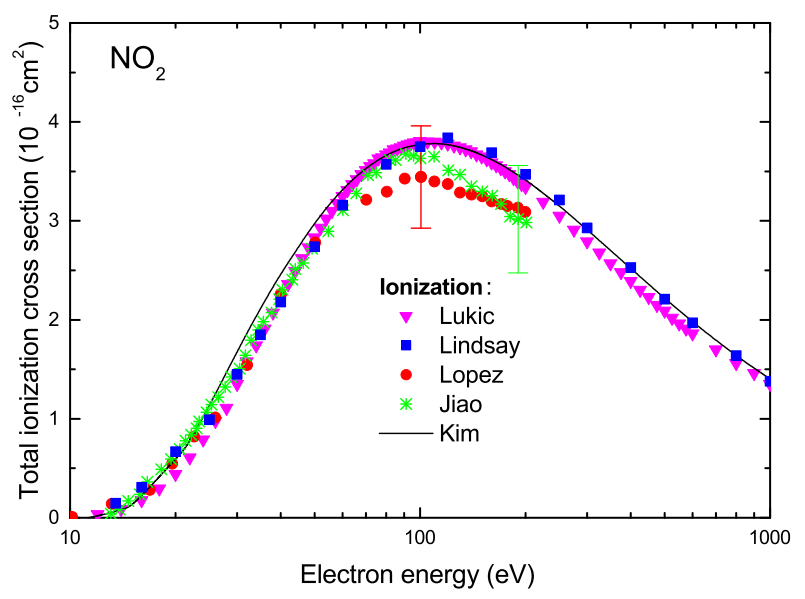

FIG. 40. Total ionization cross section in $\mathrm{NO}_{2}$ : gross total Lukic̀ et al. ${ }^{122}$, counting total - Jiao et al. ${ }^{129}$, Lindsay et al. ${ }^{29}$, Lopez et al. ${ }^{31}$. BEB model by Kim et al. ${ }^{68}$. Recommended data are those by Lindsay et al. ${ }^{29}$.

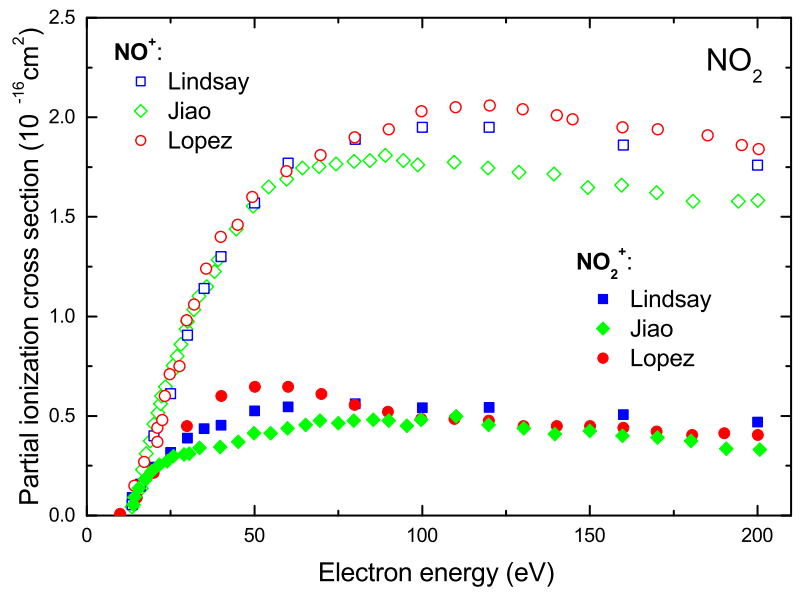

FIG. 41. Partial ionization cross sections in $\mathrm{NO}_{2}$ : lower, full points - formation of the $\mathrm{NO}_{2}^{+}$parent ion; upper, open points - formation of the $\mathrm{NO}^{+}$dissociated ion. Experiments by Jiao et $a l .{ }^{129}$, Lindsay et $a l .{ }^{29}$, Lopez et al. ${ }^{31}$. Recommended data are those by Lindsay et $\mathrm{al}^{29}$.

within error bars with Lindsay et al., see Fig. 42. Our recommended set of $\mathrm{NO}_{2}$ ionization coincides with that from the review by Lindsay and Mangan ${ }^{27}$, and are based on measurements by Lindsay et al. ${ }^{29}$, see table XVIII.

\section{Electron Attachment (DEA) Cross Section}

Rangwala et $\mathrm{al}^{130}$ is the only report which present the absolute DEA cross sections to $\mathrm{NO}_{2}$ molecule. In their experiment, a magnetically collimated and pulsed electron beam of variable energy is crossed with an effusive molecular beam producing negative ions. They reported the absolute cross section for the formation of $\mathrm{O}^{-}$from $\mathrm{NO}_{2}$ by DEA in the energy range from $0.0 \mathrm{eV}$ and 5.4 


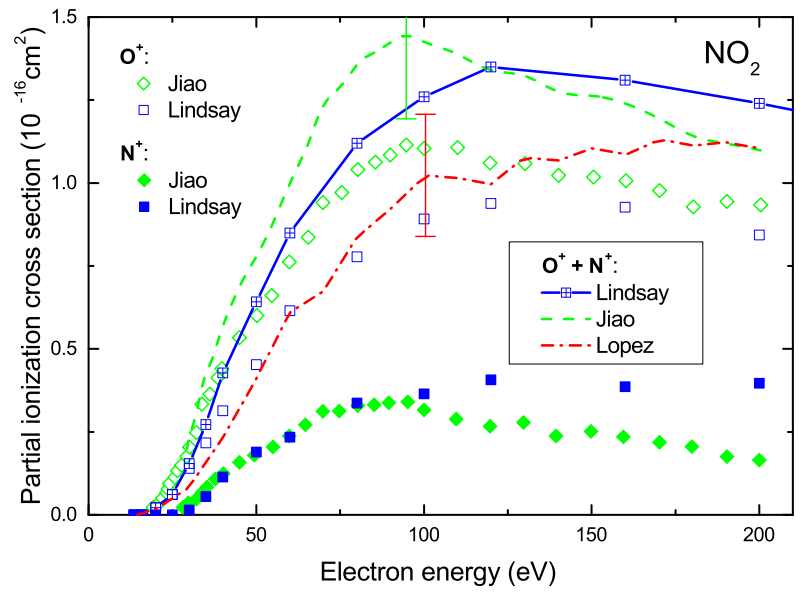

FIG. 42. Partial ionization of $\mathrm{NO}_{2}$ into $\mathrm{N}^{+}$(lower, full points), $\mathrm{O}^{+}$(upper, open points), and non-resolved $\left(\mathrm{N}^{+}+\right.$ $\left.\mathrm{O}^{+}\right)$- lines. Experimental data from ref. ${ }^{29,31,129}$.

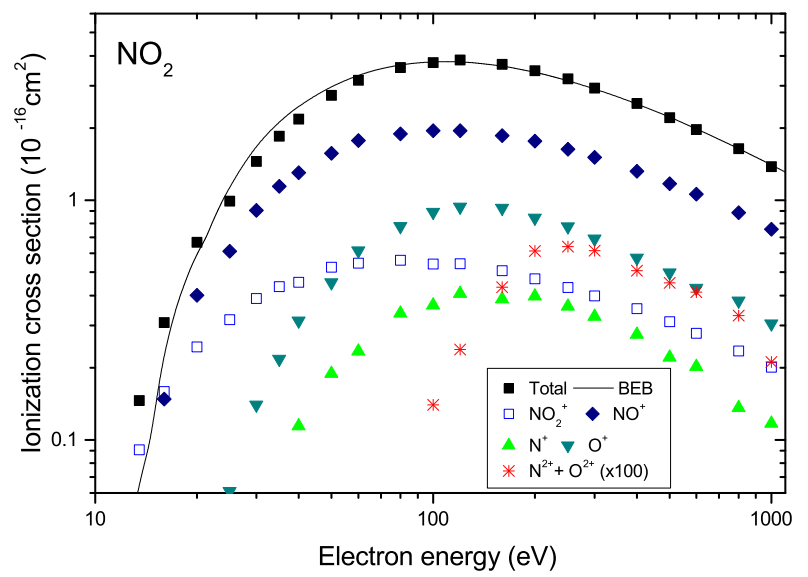

FIG. 43. Recommended cross sections for ionization of $\mathrm{NO}_{2}$ are based on Lindsay et al. $^{29}$ measurements and are the same as given by Lindsay and Mangan in their review ${ }^{27}$. BEB model by Kim et al. ${ }^{68}$. The uncertainties are $\pm 5 \%$ on total ionization, $\mathrm{NO}_{2}^{+}, \mathrm{NO}^{+}$and combined $\left(\mathrm{N}^{+}+\mathrm{O}^{+}\right)$partial ionization cross sections, and $\pm 20 \%, \pm 15 \%$ and $\pm 12 \%$ on $\mathrm{N}^{+}, \mathrm{O}^{+}$and combined $\left(\mathrm{N}^{2+}+\mathrm{O}^{2+}\right)$ partial ionizations, respectively $^{27}$.

$\mathrm{eV}$. The resonance peaks were observed at the incident electron energies of 1.4, 3.1, $8.3 \mathrm{eV}$. The numerical and graphical form of the cross sections are given in Table XIX and Fig. 44, respectively. $1 \sigma$ uncertainty at the peak cross section is $13 \%$. Earlier than this, Abouf et $\mathrm{al}^{131}$ studied ions produced by dissociative attachment in $\mathrm{NO}_{2}$ using a trochoidal monochromator as electron gun. $\mathrm{O}^{-}, \mathrm{O}_{2}^{-}$, and $\mathrm{NO}^{-}$were observed. $\mathrm{O}^{-}$production was much more dominant over $\mathrm{O}_{2}^{-}$and $\mathrm{NO}^{-}$ions. For $\mathrm{O}^{-}$ production, three peaks were observed with their maxima near $1.8 \mathrm{eV}, 3.5 \mathrm{eV}$ and $8.5 \mathrm{eV}$, and the $1.8 \mathrm{eV}$ peak is the most intense. These facts agree reasonably well with the result of Rangwala et al ${ }^{130}$. But, Abouf et al ${ }^{131}$ did not report the absolute cross sections and did the
TABLE XVIII. Recommended cross sections for ionization of $\mathrm{NO}_{2}$ are based on Lindsay et al. $^{29}$ measurements and are the same as given by Lindsay and Mangan in their review ${ }^{27}$ in the units of $10^{-16} \mathrm{~cm}^{2}$. Energy in $\mathrm{eV}$.

\begin{tabular}{|c|c|c|c|c|c|c|}
\hline $\begin{array}{c}\text { electron } \\
\text { Energy } \\
\end{array}$ & $\begin{array}{c}\mathrm{CS} \\
\mathrm{NO}_{2}^{+} \\
\end{array}$ & $\begin{array}{c}\mathrm{CS} \\
\mathrm{NO}^{+} \\
\end{array}$ & $\begin{array}{l}\mathrm{CS} \\
\mathrm{N}^{+} \\
\end{array}$ & $\begin{array}{l}\mathrm{CS} \\
\mathrm{O}^{+} \\
\end{array}$ & $\begin{array}{c}\mathrm{CS} \\
\mathrm{N}^{2+}+\mathrm{O}^{2+} \\
\end{array}$ & $\begin{array}{c}\text { CS } \\
\text { Total } \\
\end{array}$ \\
\hline 13.5 & 0.0909 & 0.055 & 0 & 0 & 0 & 0.146 \\
\hline 16 & .159 & 0.148 & 0 & 0 & 0 & 0.308 \\
\hline 20 & .244 & 0.401 & 0 & 0.02 & 0 & 0.667 \\
\hline 25 & 317 & 0.612 & 0 & .061 & 0 & 0.990 \\
\hline 30 & 389 & 0.906 & 0.015 & 0.140 & 0 & 1.45 \\
\hline 35 & .436 & 1.14 & 0.055 & 0.217 & 0 & 1.85 \\
\hline 40 & 454 & 1.30 & 0.1 & 0 & 0 & 2.18 \\
\hline 50 & 25 & 1.57 & 0.189 & 0 & 0 & 2.74 \\
\hline 60 & 546 & 1.77 & 0.234 & 0.615 & 0 & 3.16 \\
\hline 80 & 561 & 1.89 & 0.337 & 0.778 & 0 & 3.57 \\
\hline 10 & 542 & 1.95 & 0.3 & 0.892 & 0.001 & 3.75 \\
\hline 1 & 43 & 1.95 & 07 & 0.938 & 0 & 3.84 \\
\hline 160 & 507 & 1.86 & 0.386 & 0.927 & & 3.69 \\
\hline 200 & 470 & 1.76 & 0.397 & 0.843 & 0.00 & 3.47 \\
\hline 25 & 432 & 1.63 & 0.360 & 0.776 & 0.00 & 3.21 \\
\hline 300 & 399 & 1.51 & 0.327 & 0.690 & 0 & 2.93 \\
\hline 400 & 353 & 1.32 & 0.275 & 0.574 & 0.00 & 2.53 \\
\hline 500 & 0.311 & 1.17 & 0.221 & 0.498 & 0.00452 & 2.21 \\
\hline 60 & 278 & 1.06 & 0.202 & 0.429 & & 1.97 \\
\hline & 0.235 & 0.886 & 0.136 & 0.380 & & 1.64 \\
\hline 1000 & 0.201 & 0.756 & 0.117 & 0.305 & 0.00211 & 1.38 \\
\hline
\end{tabular}

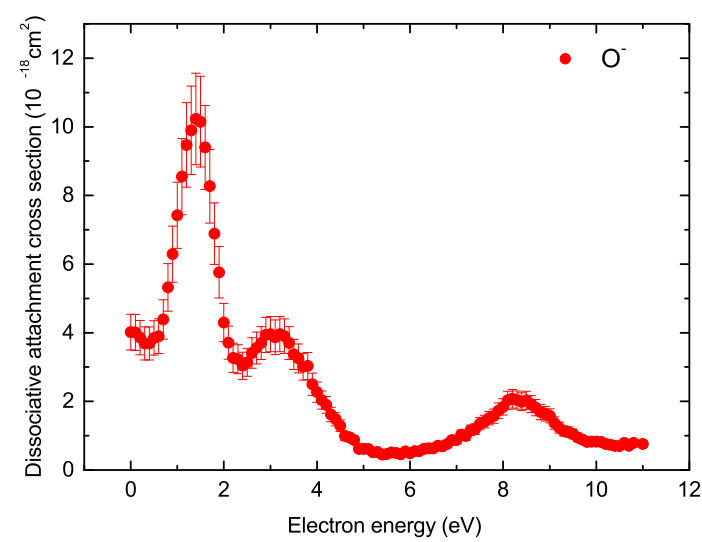

FIG. 44. Recommended cross sections for the formation of $\mathrm{O}^{-}$from $\mathrm{NO}_{2}$.

measurements only in the limited electron-energy range.

\section{SUMMARY}

In spite of being constituted of the same two elements, oxygen nitrides show significantly different features, as seen in electron scattering. Biologically, $\mathrm{NO}, \mathrm{N}_{2} \mathrm{O}$ and $\mathrm{NO}_{2}$ are drastically different. NO, which is formed in nostrils during breathing, contributes to better oxygenation of the blood; $\mathrm{N}_{2} \mathrm{O}$ is slightly anesthetic while $\mathrm{NO}_{2}$ is poisonous. 
TABLE XIX. Recommended dissociative attachment cross sections (CS) for the formation of $\mathrm{O}^{-}$from $\mathrm{NO}_{2}$ in the units of $10^{-18} \mathrm{~cm}^{2}$. Energy in $\mathrm{eV}$.

\begin{tabular}{cccc}
\hline \hline Energy & CS & Energy & CS \\
\hline \hline 0.0 & 4.02 & 5.6 & 0.51 \\
0.2 & 3.86 & 5.8 & 0.46 \\
0.4 & 3.69 & 6.0 & 0.49 \\
0.6 & 3.90 & 6.2 & 0.55 \\
0.8 & 5.32 & 6.4 & 0.63 \\
1.0 & 7.42 & 6.6 & 0.71 \\
1.2 & 9.47 & 6.8 & 0.76 \\
1.4 & 10.20 & 7.0 & 0.87 \\
1.6 & 9.40 & 7.2 & 0.99 \\
1.8 & 6.89 & 7.4 & 1.19 \\
2.0 & 4.30 & 7.6 & 1.41 \\
2.2 & 3.27 & 7.8 & 1.57 \\
2.4 & 3.04 & 8.0 & 1.84 \\
2.6 & 3.41 & 8.2 & 2.08 \\
2.8 & 3.70 & 8.4 & 1.99 \\
3.0 & 3.96 & 8.6 & 1.92 \\
3.2 & 3.96 & 8.8 & 1.69 \\
3.4 & 3.70 & 9.0 & 1.58 \\
3.6 & 3.25 & 9.2 & 1.24 \\
3.8 & 3.03 & 9.4 & 1.11 \\
4.0 & 2.27 & 9.6 & 0.95 \\
4.2 & 1.90 & 9.8 & 0.82 \\
4.4 & 1.48 & 10.0 & 0.83 \\
4.6 & 0.99 & 10.2 & 0.76 \\
4.8 & 0.87 & 10.4 & 0.71 \\
5.0 & 0.62 & 10.6 & 0.79 \\
5.2 & 0.52 & 10.8 & 0.79 \\
5.4 & 0.45 & 11.0 & 0.76 \\
\hline \hline & & &
\end{tabular}

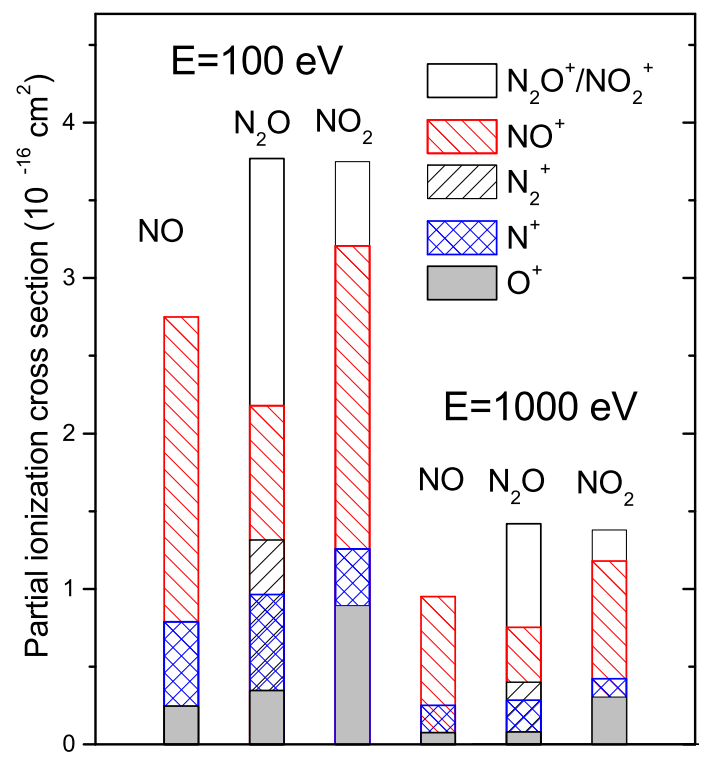

FIG. 45. Partial ionization cross sections in $\mathrm{NO}, \mathrm{N}_{2} \mathrm{O}$ and $\mathrm{NO}_{2}$. Data are from recommended sets, see text.

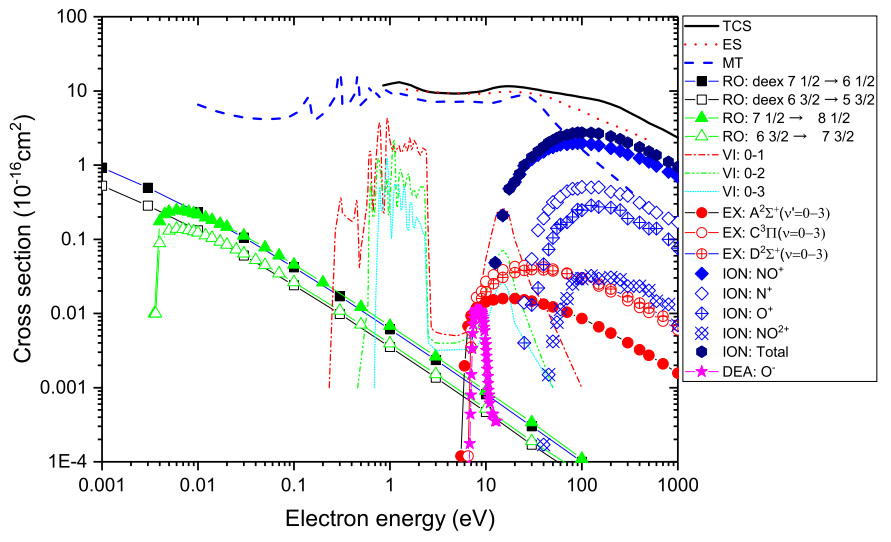

FIG. 46. Summary of recommended cross section for electron collisions with NO. TCS - total scattering, ES - elastic scattering, MT - momentum transfer, ION - ionization, VI vibrational excitation, RO - rotational excitation, EX - electronic excitation, DEA - dissociative electron attachment.

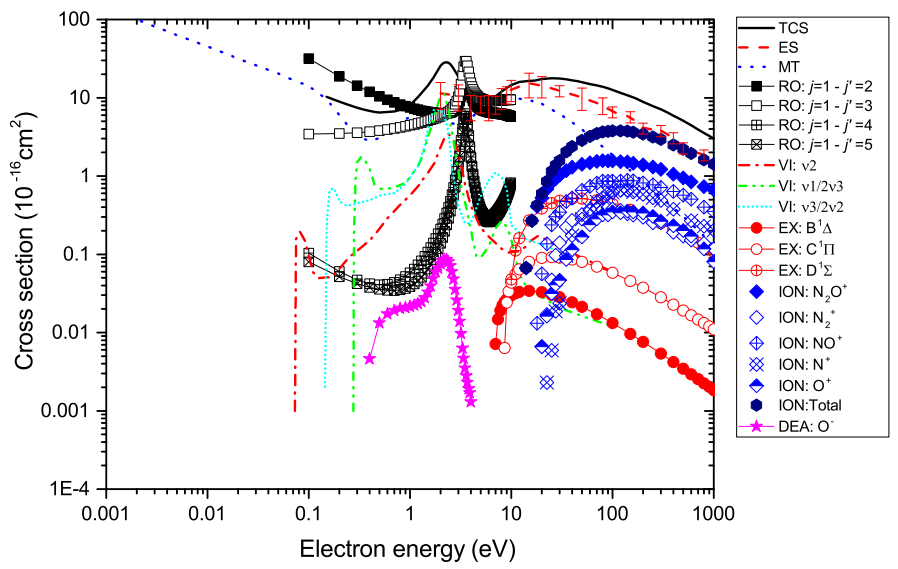

FIG. 47. Summary of recommended cross section for electron collisions with $\mathrm{N}_{2} \mathrm{O}$. TCS - total scattering, ES - elastic scattering, MT - momentum transfer, ION - ionization, VI vibrational excitation, RO - rotational excitation, EX - electronic excitation, DEA - dissociative electron attachment.

Figs. 46, 47 and 48 summarize our recommended electron collision cross sections for $\mathrm{NO}, \mathrm{N}_{2} \mathrm{O}$ and $\mathrm{NO}_{2}$, respectively. The most prominent feature for $\mathrm{NO}$ at $1 \mathrm{eV}$ and below are two overlapping resonances, giving rise to a structure visible in TCS as a series of sharp peaks: in this the NO molecule resembles $\mathrm{O}_{2}{ }^{13}$. The TCS in $\mathrm{N}_{2} \mathrm{O}$ shows a broad resonant peak, which in the vibrational channel constitutes one-third of the TCS at $2.3 \mathrm{eV}$, see Fig. 47.

In the recommended total cross sections, the rotational structure is not resolved. Therefore, the recommended total cross sections should be understood as summed over all possible final rotational states and averaged over initial states of the target molecule for the energy distribu- 


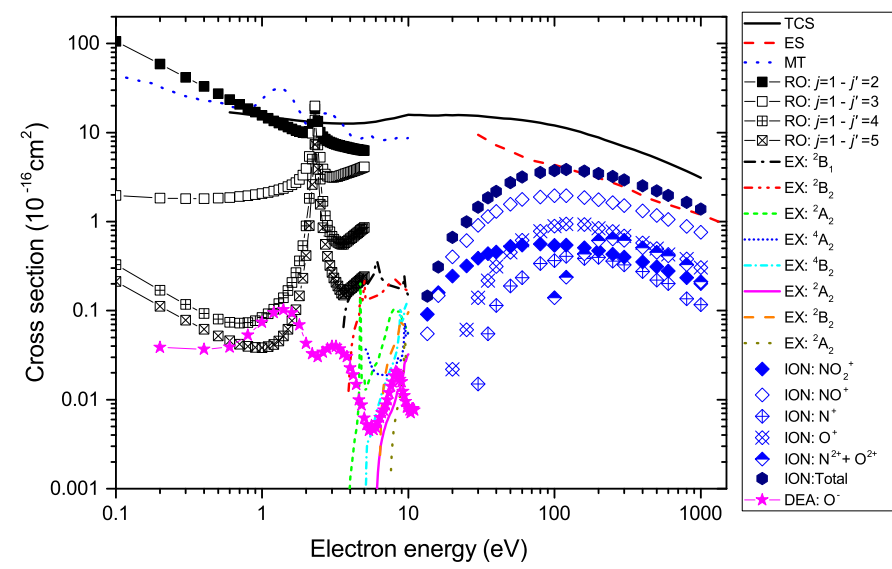

FIG. 48. Summary of recommended cross section for electron collisions with $\mathrm{NO}_{2}$. TCS - total scattering, ES - elastic scattering, MT - momentum transfer, ION - ionization, RO rotational excitation, EX - electronic excitation, DEA - dissociative electron attachment.

tion of the experiments in which the cross sections were measured. For example, the rotational excitation cross sections shown in Figs. 47 and 48 are state-selective and could be larger for certain transitions than the total cross sections with unresolved rotational structure.

In $\mathrm{NO}_{2}$, which is also a "prototype" system showing similar features to ozone, theory ${ }^{124}$ predicts two narrow resonances at $1-3 \mathrm{eV}$, see Fig. 36. They are clearly visible in the dissociative attachment channel and as an enhancement of the rotational-excitation cross sections at about $2.2 \mathrm{eV}$ as predicted by the present theory, see Fig. 37.

Electronic excitation in the open shell NO molecule shows a number of partially overlapping states, starting from some $4.75 \mathrm{eV}$; in $\mathrm{N}_{2} \mathrm{O}$ it is dominated by two dipoleallowed states, visible as broad peaks, centered at $8.5 \mathrm{eV}$ and $9.5 \mathrm{eV}$ in the energy-loss spectra. In their maxima, the electronic excitation cross sections amount to about $3 \%$ of the TCS. A similar proportion is predicted by the present R-matrix calculation for $\mathrm{NO}_{2}$ in the energy range $9-10 \mathrm{eV}$, see Fig. 39.

Comparing the ionization cross sections for the three nitrogen oxides, the total ionization cross sections scale roughly with molecular dipole polarizabilities ${ }^{132}$. The total ionization cross sections in $\mathrm{NO}_{2}$ and $\mathrm{N}_{2} \mathrm{O}$ practically coincide, amounting in their maxima, respectively to 3.84 and $3.77 \times 10^{-16} \mathrm{~cm}^{2}$ (with respective polarizabilities, 2.91 and $2.998 \times 10^{-30} \mathrm{~m}^{2}$, see Table I). Total ionization cross sections are well reproduced by BEB model ${ }^{32,68}$, for all three nitrogen oxides. The optical potential model ${ }^{123}$ overestimates slightly (10-15\%) the total ionization cross sections for all three targets. Fig. 45 compares partitioning into different channels of ionization at $100 \mathrm{eV}$ and $1000 \mathrm{eV}$. For neither $\mathrm{N}_{2} \mathrm{O}$ nor $\mathrm{NO}_{2}$ is the parent ion the dominant product (i.e. constitutes over $50 \%$ of the ionization events) at energies where other channels are available. The $\mathrm{NO}^{+}$dissociated ion is the main ion in the ionization of $\mathrm{NO}_{2}$ and constitutes about $\frac{1}{4}$ of ionization events in of $\mathrm{N}_{2} \mathrm{O}$. The $\mathrm{N}^{+}$ion is formed with roughly double the probability of the $\mathrm{O}^{+}$ion in $\mathrm{NO}$ and $\mathrm{N}_{2} \mathrm{O}$; in $\mathrm{NO}_{2}$ the $\mathrm{O}^{+}$ion prevails over $\mathrm{N}^{+}$, see Fig. 45 .

In summary, the main differences between the three nitrogen oxides are visible in the low energy range (below 5 $\mathrm{eV}$ ) where the cross sections display the existence of different resonances. This energy region is the one for which biological processes are influenced the most. Experimental (and theoretical) studies are still needed. In particular, our knowledge on electron scattering is broadly satisfactory for $\mathrm{NO}$ and $\mathrm{N}_{2} \mathrm{O}$ but it has many gaps for $\mathrm{NO}_{2}$ : for example we are not aware of measurements of the vibrational or electronic-excitation cross sections. For NO and $\mathrm{NO}_{2}$ we also lack measurements of dissociation into neutrals.

\section{Acknowledgments}

We thank Tom Meltzer for providing the data for figure 1. This work was supported by R\&D Program of 'Plasma BigData ICT Convergence Technology Research Project' through the National Fusion Research Institute of Korea (NFRI) funded by the Government funds. Also this work was partly supported by the Technology Innovation Program (20003641, Development and Dissemination on National Standard Reference Data) funded By the Ministry of Trade, Industry \& Energy(MOTIE, Korea). VK acknowledges the support by the National Science Foundation Grant No. PHY-1806915. 


\section{APPENDIX: ELECTRON SWARM PARAMETERS IN PURE NO AND NO-AR MIXTURES}

The drift velocity and the product of the gas number density and the longitudinal diffusion coefficient $\left(\mathrm{ND}_{L}\right)$ in pure $\mathrm{NO}$ and in the $4.99 \% \mathrm{NO}-\mathrm{Ar}$ mixture were measured by Takeuchi and Nakamura ${ }^{43}$, and re-analyzed here. These swarm parameter were determined differentially from arrival-time distributions (ATDs) of an isolated electron pulse observed at several drift distances from the cathode at each $\mathrm{E} / \mathrm{N}$ ( $\mathrm{E}$ is the electric field strength and $\mathrm{N}$ the gas number density, $1 \mathrm{Td}=14$ $\left.\times 10^{-17} \mathrm{Vcm}^{2}\right)$ by using the double shutter electron drift tube with variable drift distance $(1-10 \mathrm{~cm})$. The purity of NO was $99.99 \%$ and the mix-ratio was measured by a gas-chromatograph of the gas company. At low $\mathrm{E} / \mathrm{N}(<10 \mathrm{Td})$ in pure NO the ATD of electrons decays rapidly with the distance due to the three-body attachment process in $\mathrm{NO}^{133}$. The ATD also has increase at its later time showing there are delayed electron component, which possibly are electrons autodetached from unstable negative ions. This increase deteriorates observed ATD substantially and gives rise to apparent gasdensity dependence of the swarm parameters, especially seriously of $\mathrm{ND}_{L}$. The gas density-independent drift velocity was estimated through the extrapolation to $\mathrm{N}=0$. This probably is the reason of scattering results of earlier drift velocity measurements ${ }^{134,135}$. In NO-Ar mixture, on the other hand, the ATD at high E/N (> 50 Td) shows strong growth with drift distance, probably due to the Penning ionization, and it was not possible to determine swarm parameters properly. The magnitude of the drift velocity around the maximum $(2.5 \mathrm{Td})$ and the minimum $(10 \mathrm{Td})$ depends respectively on the magnitude of vibrational cross sections and the threshold magnitude of the electron excitation cross section. The magnitude and width of the prominent peak structure seen in the $\mathrm{ND}_{L}$ depends on the depth and width of the minimum of the inelastic cross section of NO over $2.5-$ $7 \mathrm{eV}$ range. Lakshminarasimha and Lucas ${ }^{136}$ measured the ionization coefficient in $\mathrm{NO}$ over the $\mathrm{E} / \mathrm{N}$ range 56 - $1412 \mathrm{Td}$ with the accuracy of $\pm 3 \%$. In order that the measured ionization coefficient can be reproduced within the claimed accuracy by a Boltzmann equation analysis, the sum of the electronic excitation cross sections should be larger than the sum of Brunger et al..$^{50}$ by a factor of about 5 as shown in Fig. 13.

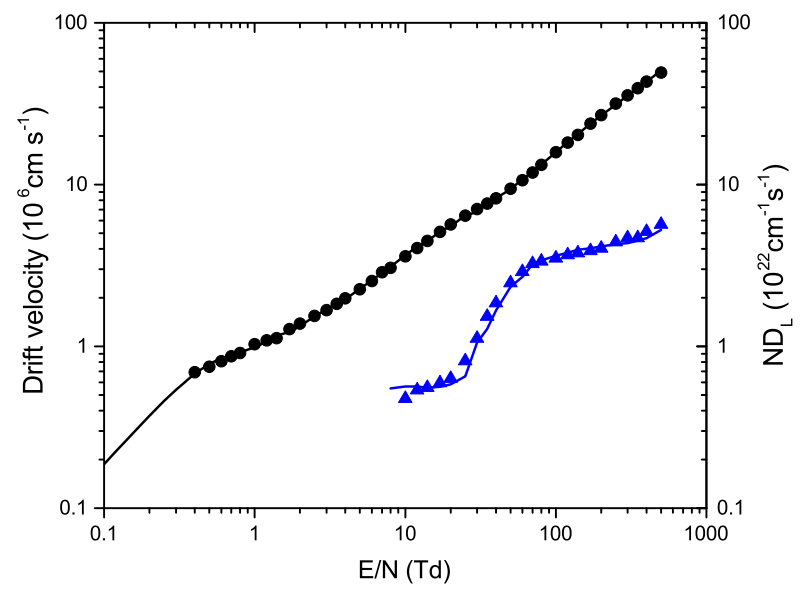

FIG. 49. The drift velocity and $\mathrm{ND}_{L}$ of electrons in pure NO. Solid circle, electron drift velocity; solid triangle, $\mathrm{ND}_{L}$, ; solid line, Boltzmann equation calculation using the present recommended cross section set of NO.

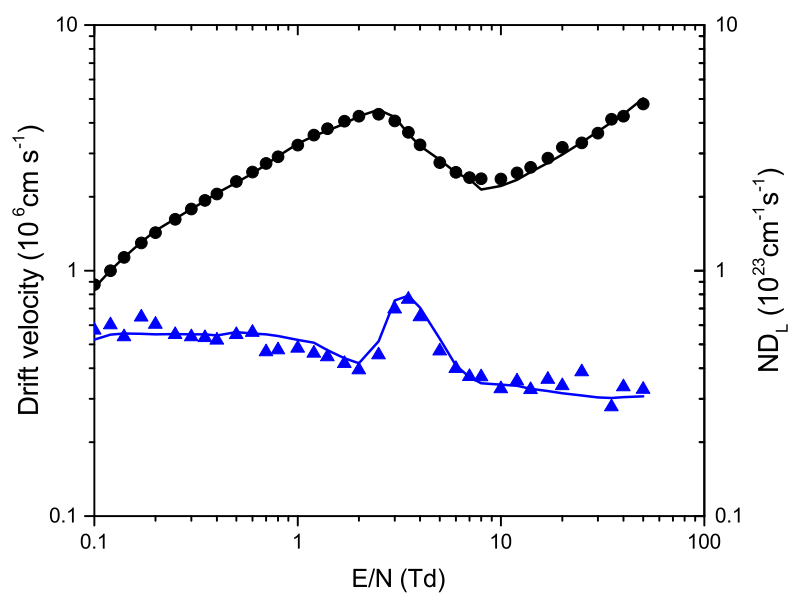

FIG. 50. The drift velocity and $\mathrm{ND}_{L}$ of electrons in the $4.99 \%$ NO-Ar mixture. Solid circle, electron drift velocity; solid triangle, $\mathrm{ND}_{L}$, ; solid line, Boltzmann equation calculation using the present recommended cross section set of NO.

\section{REFERENCES}

${ }^{1}$ M.-Y. Song, J. S. Yoon, H. Cho, Y. Itikawa, G. P. Karwasz, V. Kokoouline, Y. Nakamura, and J. Tennyson, "Cross sections for electron collisions with methane," J. Phys. Chem. Ref. Data 44, 023101 (2015).

${ }^{2}$ M.-Y. Song, J.-S. Yoon, H. Cho, G. P. Karwasz, V. Kokoouline, Y. Nakamura, and J. Tennyson, "Cross sections for electron collisions with acetylene," J. Phys. Chem. Ref. Data 46, 013106 (2017).

${ }^{3}$ M.-Y. Song, J.-S. Yoon, H. Cho, G. P. Karwasz, V. Kokoouline, Y. Nakamura, J. R. Hamilton, and J. Tennyson, "Cross sections for electron collisions with $\mathrm{NF}_{3}$," J. Phys. Chem. Ref. Data 46, 043104 (2017).

${ }^{4}$ R. Zhang, A. Faure, and J. Tennyson, "Electron and positron collisions with polar molecules: studies with the benchmark water molecule," Phss. Scr. 80, 015301 (2009).

${ }^{5}$ R. J. Hargreaves, I. E. Gordon, L. S. Rothman, S. A. Tashkun, V. I. Perevalov, A. A. Lukashevskaya, S. N. Yurchenko, J. Ten- 


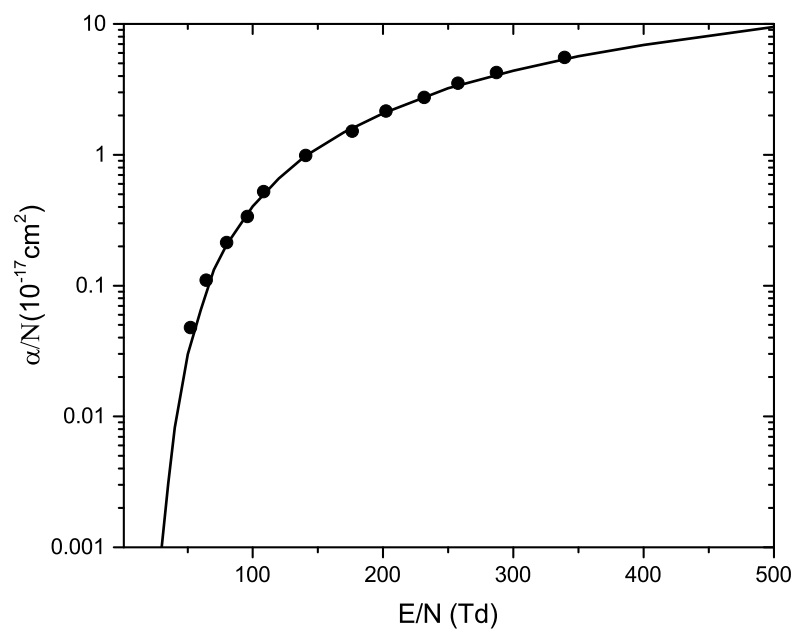

FIG. 51. The ionization coefficient of NO. Solid circle, experimental result; solid line, Boltzmann equation calculation using the present recommended cross section set of NO.

nyson, and H. S. Müller, "Spectroscopic line parameters of no, no2, and n2o for the hitemp database," Journal of Quantitative Spectroscopy and Radiative Transfer 232, 35 - 53 (2019).

${ }^{6}$ R. D. Nelson Jr., D. R. Lide, and A. A. Maryott, Selected Values of electric dipole moments for molecules in the gas phase, NSRDS-NBS10 (U.S. Department of Commerce, National Bureau Standards, 1967).

${ }^{7}$ T. N. Olney, N. Cann, G. Cooper, and C. Brion, "Absolute scale determination for photoabsorption spectra and the calculation of molecular properties using dipole sum-rules," Chem. Phys. 223, 59 - 98 (1997).

${ }^{8}$ M. J. Travers, D. C. Cowles, and G. Ellison, "Reinvestigation of the electron affinities of $\mathrm{O}_{2}$ and NO," Chem. Phys. Letts. 164, 449 - 455 (1989).

${ }^{9}$ E. S. Kryachko, C. Vinckier, and M. T. Nguyen, "Another look at the electron attachment to nitrous oxide," J. Chem. Phys. 114, 7911-7917 (2001), https://doi.org/10.1063/1.1364679.

${ }^{10} \mathrm{~K}$. M. Ervin, J. Ho, and W. C. Lineberger, "Ultraviolet photoelectron spectrum of nitrite anion," The Journal of Physical Chemistry 92, 5405-5412 (1988), https://doi.org/10.1021/j100330a017.

${ }^{11}$ W. M. Haynes, ed., CRC Handbook of Chemistry and Physics, 96 th Edition, 96 (CRC Press, 2015).

${ }^{12}$ A. Wong, S. N. Yurchenko, P. Bernath, H. S. P. Mueller, S. McConkey, and J. Tennyson, "ExoMol Line List XXI: Nitric Oxide (NO)," Mon. Not. R. Astron. Soc. 470, 882-897 (2017).

${ }^{13}$ G. P. Karwasz, R. S. Brusa, and A. Zecca, 6.1 Total scattering cross sections: Datasheet from Landolt-Börnstein - Group I Elementary Particles, Nuclei and Atoms . Volume 17C: Interactions of Photons and Electrons with Molecules, edited by Y. Itikawa, C, Vol. 17 (Springer-Verlag Berlin Heidelberg, 2003) copyright 2003 Springer-Verlag Berlin Heidelberg.

${ }^{14}$ K. Anzai, H. Kato, M. Hoshino, H. Tanaka, Y. Itikawa, L. Campbell, M. J. Brunger, S. J. Buckman, H. Cho, F. Blanco, G. Garcia, P. Limão-Vieira, and O. Ingólfsson, "Cross section data sets for electron collisions with $\mathrm{H}_{2}, \mathrm{O}_{2}, \mathrm{CO}, \mathrm{CO}_{2}, \mathrm{~N}_{2} \mathrm{O}$ and $\mathrm{H}_{2} \mathrm{O}$," Eur. Phys. J. D 66, 36 (2012).

${ }^{15}$ A. Zecca, G. P. Karwasz, R. S. Brusa, and T. Wroblewski, "Low-energy electron collisions in nitrogen oxides: a comparative study," Int. J. Mass Spectrom. 223-224, 205 - 215 (2003).

${ }^{16}$ Y. Itikawa, "Cross sections for electron collisions with nitric oxide," J. Phys. Chem. Ref. Data 45, 033106 (2016).

${ }^{17}$ E. Brüche, "Wirkungsquerschnitt und Molekülbau," Ann. Phys. 388, 1065 - 1128 (1927).
${ }^{18}$ A. Zecca, I. Lazzizzera, M. Krauss, and C. E. Kuyatt, "Electron scattering from $\mathrm{NO}$ and $\mathrm{N}_{2} \mathrm{O}$ below $10 \mathrm{eV}$," J. Chem. Phys. 61, 4560 - 4566 (1974)

${ }^{19}$ G. Dalba, P. Fornasini, R. Grisenti, G. Ranieri, and A. Zecca, "Absolute total cross section measurements for intermediate energy electron scattering. II. $\mathrm{N}_{2}, \mathrm{O}_{2}$ and NO," J. Phys. B: At. Mol. Phys. 13, 4695 - 4701 (1980).

${ }^{20}$ C. Szmytkowski and K. Maciag, "Total cross section for electron impact on nitrogen monoxide," J. Phys. B 24, 4273 - 4279 (1991).

${ }^{21}$ C. Szmytkowski, K. Maciag, and G. Karwasz, "Absolute electron scattering total cross section measurements for noble gas atoms and diatomic molecules," Phys. Scr. 54, 271 - 280 (1996).

${ }^{22}$ D. T. Alle, M. J. Brennan, and S. J. Buckman, "Low-energy total electron scattering cross section and electron affinity for NO," J. Phys. B: At., Mol. Opt. Phys. 29, L277 - L282 (1996).

${ }^{23} \mathrm{M}$. Allan, "Transitions Between the ${ }^{2} \Pi_{1 / 2}$ and ${ }^{2} \Pi_{3 / 2}$ Spin-Orbit Components of NO Induced by Impact of Slow Electrons," Phys. Rev. Lett. 93, 063201 (2004).

${ }^{24} \mathrm{M}$. Allan, "Electron collisions with NO: elastic scattering, vibrational excitation and ${ }^{2} \Pi_{1 / 2} \rightleftharpoons{ }^{2} \Pi_{1 / 2}$ transitions," J. Phys. B: At., Mol. Opt. Phys. 38, $603-614$ (2005).

${ }^{25}$ L. Josić, T. Wróblewski, Z. L. Petrović, J. Mechlińska-Drewko, and G. Karwasz, "Influence of resonant scattering on electronswarm parameters in NO," Chem. Phys. Lett. 350, 318 - 324 (2001).

${ }^{26}$ G. Karwasz, R. Brusa, A. Gasparoli, and A. Zecca, "Total cross-section measurements for e - CO scattering: 80-4000 eV," Chem. Phys. Lett. 211, $529-533$ (1993).

${ }^{27}$ B. G. Lindsay and M. A. Mangan, "Interactions of Photons and Electrons with Molecules - 5.1 Ionization: Datasheet from Landolt-Börnstein - Group I Elementary Particles, Nuclei and Atoms · Volume 17C: Interactions of Photons and Electrons with Molecules," Landolt-Börnstein (2003), copyright 2003 SpringerVerlag Berlin Heidelberg.

${ }^{28}$ D. Rapp and P. Englander-Golden, "Total Cross Sections for Ionization and Attachment in Gases by Electron Impact. I. Positive Ionization," J. Chem. Phys. 43, $1464-1479$ (1965).

${ }^{29}$ B. G. Lindsay, M. A. Mangan, H. C. Straub, and R. F. Stebbings, "Absolute partial cross sections for electron-impact ionization of $\mathrm{NO}$ and $\mathrm{NO}_{2}$ from threshold to $1000 \mathrm{eV}$," J. Chem. Phys. 112, $9404-9410$ (2000).

${ }^{30}$ I. Iga, M. V. V. S. Rao, and S. K. Srivastava, "Absolute electron impact ionization cross sections for $\mathrm{N}_{2} \mathrm{O}$ and $\mathrm{NO}$ from threshold up to $1000 \mathrm{eV}$," J. Geophys. Res. E 101, 9261 - 9266 (1996).

${ }^{31}$ J. Lopez, V. Tarnovsky, M. Gutkin, and K. Becker, "Electronimpact ionization of $\mathrm{NO}, \mathrm{NO}_{2}$, and $\mathrm{N}_{2} \mathrm{O}$," Intern. J. Mass Spectrom. 225, $25-37$ (2003).

${ }^{32}$ W. Hwang, Y. Kim, and M. E. Rudd, "New model for electronimpact ionization cross sections of molecules," J. Chem. Phys. 104, 2956-2966 (1996).

${ }^{33}$ C. K. Kwan, Y. F. Hsieh, W. E. Kauppila, S. J. Smith, T. S. Stein, M. N. Uddin, and M. S. Dababneh, "Total-Scattering Measurements and Comparisons for Collisions of Electrons and Positrons with $\mathrm{N}_{2} \mathrm{O}$," Phys. Rev. Lett. 52, 1417-1420 (1984).

${ }^{34}$ C. Szmytkowski, P. Możejko, and G. Kasperski, "Electron scattering on triatomic molecules: $\mathrm{SO}_{2}$, OCS and $\mathrm{N}_{2} \mathrm{O}$," in Proc. XVIII International Symposium on Physics of Ionized Gases, edited by B. Vujicic and S. Djurovic, Kotor, Yugoslavia (Faculty of Sciences, Institute of Physics Novi Sad, 1996) pp. $66-69$.

${ }^{35}$ X. Shilin, Z. Fang, Y. Liqiang, Y. Changqing, and X. Kezun, "Absolute total cross section measurement for electron scattering on $\mathrm{N}_{2} \mathrm{O}$ in the energy range $600-4250 \mathrm{eV}$," J. Phys. B: At., Mol. Opt. Phys. 30, $2867-2871$ (1997).

${ }^{36}$ A. Zecca, J. C. Nogueira, G. P. Karwasz, and R. S. Brusa, "Total cross sections for electron scattering on $\mathrm{NO}_{2}, \mathrm{OCS}, \mathrm{SO}_{2}$ at intermediate energies," J. Phys. B: At. Mol. Opt. Phys. 28, $477-486$ (1995).

${ }^{37}$ B. Mojarrabi, R. J. Gulley, A. G. Middleton, D. C. Cartwright, P. J. O. Teubner, S. J. Buckman, and M. J. Brunger, "Electron 
collisions with NO: elastic scattering and rovibrational ( 0 to 1 , 2, 3, 4) excitation cross sections," J. Phys. B: At. Mol. Opt. Phys. 28, 487 - 504 (1995).

${ }^{38}$ M. Jelisavcic, R. Panajotovic, and S. J. Buckman, "Absolute Collision Cross Sections for Low Energy Electron Scattering from NO: The Role of Resonances in Elastic Scattering and Vibrational Excitation," Phys. Rev. Lett. 90, 203201 (2003).

${ }^{39}$ M. J. Brunger, L. Campbell, D. C. Cartwright, A. G. Middleton, B. Mojarrabi, and P. J. O. Teubner, "Electron-impact excitation of Rydberg and valence electronic states of nitric oxide: II. Integral cross sections," J. Phys. B: At. Mol. Opt. Phys. 33, 809 -819 (2000).

${ }^{40}$ M. M. Fujimoto and M. T. Lee, "Elastic and absorption cross sections for electron-nitric oxide collisions," J. Phys. B: At. Mol. Opt. Phys. 33, 4759 - 4768 (2000).

${ }^{41}$ Y. Itikawa, "Momentum-transfer cross sections for electron collisions with atoms and molecules," Atomic Data and Nuclear Data Tables 14, 1 - 10 (1974).

${ }^{42}$ A. V. Phelps, Compilation of Electron Cross Sections, edited by JILA (Univ. Colorado, 1995).

${ }^{43} \mathrm{~T}$. Takeuchi and Y. Nakamura, "Electron collision cross section set for NO molecules via electron swarm study," IEE Japan ED-02-95, 53 - 57 (2002).

${ }^{44} \mathrm{Y}$. Itikawa and N. Mason, "Rotational excitation of molecules by electron collisions," Phys. Rep. 414, 1 - 41 (2005).

${ }^{45} \mathrm{~K}$. Takayanagi, "Rotational and vibrational excitation of polar molecules by slow electrons," J. Phys. Soc. Jpn. 21, 507 - 514 (1966).

${ }^{46}$ D. E. Stogryn and A. P. Stogryn, "Molecular multipole moments," Mol. Phys. 11, 371 - 393 (1966).

${ }^{47} \mathrm{~T}$. Takeuchi and Y. Nakamura, "Measurements of electron transport coefficients in pure NO and in NO-Ar mixtures," T. IEE Japan 121-A, $481-486$ (2001).

${ }^{48}$ L. Campbell, M. J. Brunger, Z. L. Petrovic, M. Jelisavcic, R. Panajotovic, and S. J. Buckman, "Infrared auroral emissions driven by resonant electron impact excitation of NO molecules," Geophys. Res. Lett. 31, L10103 (2004).

${ }^{49}$ L. C. Pitchford, L. L. Alves, K. Bartschat, S. F. Biagi, M.-C. Bordage, I. Bray, C. E. Brion, M. J. Brunger, L. Campbell, A. Chachereau, B. Chaudhury, L. G. Christophorou, E. Carbone, N. A. Dyatko, C. M. Franck, D. V. Fursa, R. K. Gangwar, V. Guerra, P. Haefliger, G. J. M. Hagelaar, A. Hoesl, Y. Itikawa, I. V. Kochetov, R. P. McEachran, W. L. Morgan, A. P. Napartovich, V. Puech, M. Rabie, L. Sharma, R. Srivastava, A. D. Stauffer, J. Tennyson, J. de Urquijo, J. van Dijk, L. A. Viehland, M. C. Zammit, O. Zatsarinny, and S. Pancheshnyi, "LXCat: an Open-Access, Web-Based Platform for Data Needed for Modeling Low Temperature Plasmas," Plasma Proc. Polymers 14, 1600098 (2017).

${ }^{50}$ M. J. Brunger, L. Campbell, D. C. Cartwright, A. G. Middleton, B. Mojarrabi, and P. J. O. Teubner, "Electron-impact excitation of rydberg and valence electronic states of nitric oxide: I. differential cross sections," J. Phys. B: At., Mol. Opt. Phys. 33, $783-808$ (2000).

${ }^{51}$ M. J. Brunger, L. Campbell, D. C. Cartwright, A. G. Middleton, B. Mojarrabi, and P. J. O. Teubner, "Electron-impact excitation of rydberg and valence electronic states of nitric oxide: II. integral cross sections," J. Phys. B: At., Mol. Opt. Phys. 33, $809-819$ (2000).

${ }^{52}$ W. F. Chang, G. Cooper, and C. E. Brion, "Absolute optical oscillator strengths for the photoabsorption of nitric oxide (5-30 eV) at high resolution," Chem. Phys. 170, $111-121$ (1993).

${ }^{53}$ L. E. Machado, A. L. Monzani, M.-T. Lee, and M. M. Fujimoto, "Proc. Int. Symp. on Electron- and Photon- Molecule Collisions and Swarms," (Berkeley, CA: Lawrence Livermore Pres, 1995) p. H32.

${ }^{54}$ H. Kato, H. Kawahara, M. Hoshino, H. Tanaka, and M. J. Brunger, "Excitation of the $A^{2} \Sigma^{+}, C^{2} \Pi$ and $D^{2} \Sigma^{+}$Rydbergelectronic states in NO by $100 \mathrm{eV}$ electrons," Chem. Phys. Lett. 444, $34-38$ (2007).
${ }^{55}$ V. V. Skubenik, M. M. Povch, and I. P. Zapesochnyi, High Energy Chem. (USSR) 11, 92 - 95 (1977).

${ }^{56}$ R. S. Schappe, R. J. Edgell, and E. Urban, "Electron-impact excitation of nitric oxide $\left(A^{2} \Sigma^{+}-X^{2} \Pi\right)$," Phys. Rev. A 65, 042701 (2002).

${ }^{57}$ X. Xu, L.-Q. Xu, T. Xiong, T. Chen, Y.-W. Liu, and L.-F. Zhu, "Oscillator strengths and integral cross sections for the valenceshell excitations of nitric oxide studied by fast electron impact," J. Chem. Phys. 148, 044311 (2018).

${ }^{58}$ Y.-K. Kim, "Scaling of plane-wave Born cross sections for electron-impact excitation of neutral atoms," Phys. Rev. A 64, 032713 (2001).

${ }^{59} \mathrm{R}$. Olszewski and M. Zubek, "A study of electron impact excitation of the $A^{2} \Sigma^{+}$state of nitric oxide in the near-threshold energy range," Chem. Phys. Lett. 340, 249 - 255 (2001).

${ }^{60} \mathrm{M}$. Imami and W. L. Borst, "Electron impact excitation of the gamma bands of nitric oxide," J. Chem. Phys. 63, 3602-3605 (1975).

${ }^{61} \mathrm{~L}$. R. LeClair and J. W. McConkey, "Selective detection of $\mathrm{O}\left({ }^{1} S_{0}\right)$ following electron impact dissociation of $\mathrm{O}_{2}$ and $\mathrm{N}_{2} \mathrm{O}$ using a $\mathrm{XeO}^{*}$ conversion technique," J. Chem. Phys. 99, 4566 -4577 (1993).

${ }^{62}$ J. W. McConkey, C. P. Malone, P. V. Johnson, C. Winstead, V. McKoy, and I. Kanik, "Electron impact dissociation of oxygen-containing molecules-A critical review," Phys. Rep. 466, $1-103$ (2008)

${ }^{63}$ E. A. MacDonald, E. Donovan, Y. Nishimura, N. A. Case, D. M. Gillies, B. Gallardo-Lacourt, W. E. Archer, E. L. Spanswick, N. Bourassa, M. Connors, M. Heavner, B. Jackel, B. Kosar, D. J. Knudsen, C. Ratzlaff, and I. Schofield, "New science in plain sight: Citizen scientists lead to the discovery of optical structure in the upper atmosphere," Sci. Adv. 4, eaaq0030 (2018).

${ }^{64}$ J. T. Tate and P. T. Smith, "The efficiencies of ionization and ionization potentials of various gases under electron impact," Phys. Rev. 39, 270-277 (1932).

${ }^{65}$ K. Stephan, H. Helm, Y. B. Kim, G. Seykora, J. Ramler, M. Grössl, E. Märk, and T. D. Märk, "Single and double ionization of nitrogen dioxide by electron impact from threshold up to $180 \mathrm{eV}$," J. Chem. Phys. 73, $303-308$ (1980).

${ }^{66}$ E. Märk, T. D. Märk, Y. B. Kim, and K. Stephan, "Absolute electron impact ionization cross section from threshold up to 180 $\mathrm{eV}$ for $\mathrm{N}_{2} \mathrm{O}+\mathrm{e} \rightarrow \mathrm{N}_{2} \mathrm{O}^{+}+2 \mathrm{e}$ and the metastable and collision induced dissociation of $\mathrm{N}_{2} \mathrm{O}^{+}$," J. Chem. Phys. 75, $4446-4453$ (1981).

${ }^{67}$ Y. B. Kim, K. Stephan, E. Märk, and T. D. Märk, "Single and double ionization of nitric oxide by electron impact from threshold up to $180 \mathrm{eV}$," J. Chem. Phys. 74, $6771-6776$ (1981).

${ }^{68}$ Y.-K. Kim, W. Hwang, N. M. Weinberger, M. A. Ali, and M. E. Rudd, "Electron-impact ionization cross sections of atmospheric molecules," J. Chem. Phys. 106, 1026-1033 (1997), https://doi.org/10.1063/1.473186.

${ }^{69}$ M. Kumar, Y. Kumar Kumar, N. Tiwari, and S. Tomar, "Total ionization cross sections of $\mathrm{NO}_{2}, \mathrm{CO}$ and CS molecules due to electron impact," J. At. Mol. Sci 4, 30 - 40 (2013).

${ }^{70}$ D. Rapp and D. D. Briglia, "Total cross sections for ionization and attachment in gases by electron impact. ii. negative ion formation," J. Chem. Phys. 43, 1480 - 1489 (1965), https://doi.org/10.1063/1.1696958.

${ }^{71}$ O. J. Orient and A. Chutjian, "Detection of New Dissociative Electron Attachment Channels in NO," Phys. Rev. Lett. 74, 5017-5019 (1995)

${ }^{72}$ C. Ramsauer and R. Kollath, "Über den Wirkungsquerschnitt der Gasmolekule Gegenüber Elektronen unterhalb 1 Volt," Nachtrag, Ann. Phys. (Leipzig) 7, 176-182 (1930).

${ }^{73}$ C. Szmytkowski, G. Karwasz, and K. Maciag, "Absolute total electron-scattering cross sections of $\mathrm{N}_{2} \mathrm{O}$ and OCS in the lowenergy region," Chem. Phys. Lett. 107, 481 - 484 (1984).

${ }^{74}$ B. Marinkovic, C. Szmytkowski, V. Pejcev, D. Filipovic, and L. Vuskovic, "Differential cross sections for elastic and inelastic scattering of electrons by $\mathrm{N}_{2} \mathrm{O}$ in the range from 10 to $80 \mathrm{eV}$," 
J. Phys. B: At., Mol. Opt. Phys. 19, 2365 - 2375 (1986).

${ }^{75}$ C. Szmytkowski, K. Maciag, G. Karwasz, and D. Filipovic, "Total absolute cross section measurements for electron scattering on $\mathrm{NH}_{3}$, OCS and $\mathrm{N}_{2} \mathrm{O}$," J. Phys. B: At., Mol. Opt. Phys. 22, $525-530$ (1989).

${ }^{76}$ L. A. Morgan, C. J. Gillan, J. Tennyson, and X. Chen, "Rmatrix calculations for polyatomic molecules: electron scattering by $\mathrm{N}_{2} \mathrm{O}$," J. Phys. B: At. Mol. Opt. Phys. 30, 4087-4096 (1997).

${ }^{77} \mathrm{C}$. Winstead and V. McKoy, "Electron collisions with nitrous oxide," Phys. Rev. A 57, 3589-3597 (1998).

${ }^{78}$ G. P. Karwasz, T. Wróblewski, R. S. Brusa, and E. Illenberger, "Electron scattering on triatomic molecules: The need for data," Jpn. J. Appl. Phys. 45, $8192-8196$ (2006).

${ }^{79}$ W. M. Johnstone and W. R. Newell, "Absolute elastic cross sections for electron scattering from $\mathrm{N}_{2} \mathrm{O}$," J. Phys. B: At., Mol. Opt. Phys. 26, 129 - 138 (1993).

${ }^{80}$ M. Kitajima, Y. Sakamoto, S. Watanabe, T. Suzuki, T. Ishikawa, H. Tanaka, and M. Kimura, "Absolute elastic differential cross-sections for electron scattering by $\mathrm{N}_{2} \mathrm{O}$ at $1.5-100$ eV," Chem. Phys. Letts. 309, $414-420$ (1999).

${ }^{81}$ M. Kitajima, Y. Sakamoto, R. J. Gulley, M. Hoshino, J. C. Gibson, H. Tanaka, and S. J. Buckman, "Electron scattering from $\mathrm{N}_{2} \mathrm{O}$ : absolute elastic scattering and vibrational excitation," J. Phys. B: At. Mol. Opt. Phys. 33, 1687 - 1702 (2000).

${ }^{82}$ M.-T. Lee, I. Iga, M. G. P. Homem, L. E. Machado, and L. M. Brescansin, "Elastic and absorption cross sections for electronnitrous oxide collisions," Phys. Rev. A 65, 062702 (2002).

${ }^{83}$ J. L. Pack, R. E. Voshall, and A. V. Phelps, "Drift velocities of slow electrons in krypton, xenon, deuterium, carbon monoxide, carbon dioxide, water vapor, nitrous oxide, and ammonia," Phys. Rev. 127, 2084-2089 (1962).

${ }^{84}$ Y. Singh, "Scattering cross sections for slow electrons in polyatomic gases," J. Phys. B: At. Mol. Phys. 3, 1222-1231 (1970).

${ }^{85}$ F. T. O'Malley, "Extrapolation of electron-rare gas atom cross sections to zero energy," Phys. Rev. 130, 1020-1029 (1963).

${ }^{86}$ M. Hayashi, Handbook on Plasma Material Science, p759 (Ohmsha, Tokyo, 1992).

${ }^{87} \mathrm{Y}$. Nakamura, ed., Electron swarm parameters in pure $\mathrm{N}_{2} \mathrm{O}$ and in dilute $\mathrm{N}_{2} \mathrm{O}-\mathrm{Ar}$ mixtures and electron collision cross sections of $\mathrm{N}_{2} \mathrm{O}$ molecule, Proc. 28th ICPIG (Prague, Czech Republic, 2007).

${ }^{88}$ J. F. Nolan and A. V. Phelps, "Measurement of cesium excitation cross section near threshold by a swarm technique," Phys. Rev. 140, A792-A799 (1965).

${ }^{89}$ J. Carr, P. Galiatsatos, J. Gorfinkiel, A. Harvey, M. Lysaght, D. Madden, Z. Mašín, M. Plummer, J. Tennyson, and H. Varambhia, "UKRmol: a low-energy electron- and positronmolecule scattering suite," Euro. Phys. J. D 66, 58 (2012).

${ }^{90}$ J. Tennyson, D. B. Brown, J. J. Munro, I. Rozum, H. N. Varambhia, and N. Vinci, "Quantemol-n: an expert system for performing electron molecule collision calculations using the r-matrix method," J. Phys. Conf. Series 86, 012001 (2007).

${ }^{91}$ N. Sanna and F. A. Gianturco, "Differential cross sections for electron/positron scattering from polyatomic molecules," Comput. Phys. Commun. 114, 142 (1998).

${ }^{92} \mathrm{~K}$. Mogi, T. Komine, and K. Hirao, "A theoretical study on the dipole moment of $\mathrm{N}_{2} \mathrm{O}$ and the weakly bound complexes formed by $\mathrm{N}_{2} \mathrm{O}$," J. Chem. Phys. 95, 8999-9008 (1991).

${ }^{93}$ H. Jalink, D. H. Parker, and S. Stolte, "Experimentalverification of the sign of the electric-dipole moment of $\mathrm{N}_{2} \mathrm{O}$," J. Molec. Spectrosc. 121, 236-237 (1987).

${ }^{94}$ J. M. L. J. Reinartz, W. L. Meerts, and A. Dymanus, "Hyperfine-structure, electric and magnetic-properties of ${ }^{14} \mathrm{~N}_{2}{ }^{16} \mathrm{O}$ in ground and 1 st excited bending vibrationalstate," Chem. Phys. 31, 19-29 (1978).

${ }^{95}$ T. Shimanouchi, Tables of Molecular Vibrational Frequencies, 39, Vol. Consolidated Volume I, (Nat. Stand. Ref. Data Ser, 1972).
${ }^{96}$ M. Allan and T. Skalickỳ, "Structures in elastic, vibrational, and dissociative electron attachment cross sections in $\mathrm{N}_{2} \mathrm{O}$ near threshold," J. Phys. B: At., Mol. Opt. Phys. 36, 3397 - 3409 (2003).

${ }^{97}$ S. P. McGlynn, J. W. Rabalais, J. R. McDonald, and V. M. Scherr, "Electronic spectoscopy of isoelectronic molecules. ii. linear triatomic groupings containing sixteen valence electrons," Chem. Rev. 71, 73-108 (1971).

${ }^{98}$ R. I. Hall, A. Chutjian, and S. Trajmar, "Electron impact excitation and assignment of the low-lying electronic states of $\mathrm{N}_{2} \mathrm{O}$," Journal of Physics B: Atomic and Molecular Physics 6, L365L368 (1973).

${ }^{99}$ D. F. Dance and I. C. Walker, "Electron energy loss spectrum of nitrous oxide," J. Chem. Soc., Faraday Trans. II 72, 2105 2107 (1976).

${ }^{100}$ D. Cubric, D. Cvejanovic, J. Jureta, S. Cvejanovic, P. Hammond, G. C. King, and F. H. Read, "Threshold electron impact spectrum of $\mathrm{N}_{2} \mathrm{O}$," J. Phys. B: At. Mol. Phys. 19, 4225-4239 (1986).

${ }^{101}$ S. E. Michelin, T. Kroin, and M. T. Lee, "Elastic and excitation cross sections for electron - nitrous oxide collisions," J. Phys. B: At. Mol. Opt. Phys. 29, 2115-2125 (1996).

${ }^{102}$ H. Kawahara, D. Suzuki, H. Kato, M. Hoshino, H. Tanaka, O. Ingólfsson, L. Campbell, and M. J. Brunger, "Cross sections for electron impact excitation of the $\mathrm{c} 1$ and $\mathrm{d} 1+$ electronic states in n2o," The Journal of Chemical Physics 131, 114307 (2009), https://doi.org/10.1063/1.3230150.

${ }^{103}$ B. Marinkovic, R. Panajotovic, Z. Pesic, D. M Filipovic, Z. Felfli, and A. Z. Msezane, "Normalization of the measured relative electron differential cross sections for $2^{1} \Sigma^{+}$and $1^{\Pi}$ states of $\mathrm{N}_{2} \mathrm{O}$," J. Phys. B: At. Mol. Opt. Phys. 32, $1949-$ 1957 (1999).

${ }^{104} \mathrm{M}$. Vinodkumar and M. Barot, "Scattering of $\mathrm{N}_{2} \mathrm{O}$ on electron impact over an extensive energy range $(0.1 \mathrm{eV}-2000 \mathrm{eV}), " \mathrm{~J}$. Chem. Phys. 137, 074311 (2012).

${ }^{105}$ T. Wróblewski, G. P. Karwasz, H. Nowakowska, J. MechlińskaDrewko, V. T. Novaković, and Z. L. Petrović, "Semiempirical analysis of electron scattering cross sections in $\mathrm{N}_{2} \mathrm{O}$ and $\mathrm{CO}_{2}$," Czech. J. Phys. 54, C742 (2004).

${ }^{106}$ J. Mechlińska-Drewko, T. Wróblewski, Z. L. Petrović, V. Novaković, and G. P. Karwasz, "Electron scattering on $\mathrm{n}_{2} \mathrm{O}$-from cross sections to diffusion coefficients," Radiat. Phys. Chem. 68, 205 - 209 (2003), proceedings of the 2nd Conference on Elementary Processess in Atomic Systems, CEPAS 2002. Gdansk, Poland, 2-6 September 2002.

${ }^{107}$ S. Dupljanin, J. de Urquijo, O. Šašić, E. Basurto, A. M. Juárez, J. L. Hernández-Ávila, S. Dujko, and Z. L. Petrović, "Transport coefficients and cross sections for electrons in $\mathrm{N}_{2} \mathrm{O}$ and $\mathrm{N}_{2} \mathrm{O} / \mathrm{N}_{2}$ mixtures," Plasma Sources Sci. Tech. 19, 025005 (2010).

${ }^{108}$ M. Hayashi, "private communication," (1986).

${ }^{109}$ Y.-Y. Wang, J.-M. Sun, and L.-F. Zhu, "Cross sections for the valence shell excitations of nitrous oxide studied by fast electron impact," J. Chem. Phys. 132, 124301 (2010).

${ }^{110}$ D. Rapp, P. Englander-Golden, and D. D. Briglia, "Cross sections for dissociative ionization of molecules by electron impact," J. Chem. Phys. 42, $4081-4085$ (1965).

${ }^{111}$ B. Adamczyk, K. Bederski, L. Wójcik, T. Stański, B. Adamczyk, K. Bederski, L. Wojcik, and T. Stanski, "Folio Scientatis Scientiarum Lublinensis Mat," Fiz. Chem. 18, 217 (1976).

${ }^{112}$ H. A. van Sprang, G. R. Mohlmann, and F. J. De Heer, "Emission of radiation due to ionization and dissociation of $\mathrm{N}_{2} \mathrm{O}$ by electron impact," Chem. Phys. 33, 65 - 72 (1978).

${ }^{113}$ A. S. Newton and A. Sciamanna, "Metastable peaks in the mass spectra of $\mathrm{N}_{2} \mathrm{O}$ and $\mathrm{NO}_{2}$. II," J. Chem. Phys. 52, $327-336$ (1970).

${ }^{114}$ NIST, "Experimental polarizabilities," (2018).

${ }^{115}$ E. Krishnakumar and S. K. Srivastava, "Dissociative attachment of electrons to $\mathrm{N}_{2} \mathrm{O}$," Phys. Rev. A 41, 2445-2452 (1990).

${ }^{116}$ E. Krishnakumar, "private communication," (2016). 
${ }^{117} \mathrm{P}$. J. Chantry, "Temperature dependence of dissociative attachment in $\mathrm{n}_{2} \mathrm{O}$," J. Chem. Phys. 51, 3369-3379 (1969), https://doi.org/10.1063/1.1672521.

${ }^{118}$ D. Nandi, V. S. Prabhudesai, and E. Krishnakumar, "Dissociative electron attachment to $\mathrm{N}_{2} \mathrm{O}$ using velocity slice imaging," Phys. Chem. Chem. Phys. 16, 3955-3963 (2014).

${ }^{119}$ C. Szmytkowski and P. Możejko, "Electron-scattering total cross sections for triatomic molecules: $\mathrm{NO}_{2}$ and $\mathrm{H}_{2} \mathrm{O}$," Optica Applicata 36, 543 (2006).

${ }^{120}$ C. Szmytkowski, K. Maciag, and A. M. Krzysztofowicz, "NO 2 total absolute electron-scattering cross sections," Chem. Phys. Lett. 190, $141-144$ (1992).

${ }^{121}$ D. Gupta, R. Naghma, M. Vinodkumar, and B. Antony, "Electron scattering studies of nitrogen dioxide," J. Electron Spectrosc. Relat. Phenom. 191, $71-78$ (2013).

${ }^{122}$ D. Lukić, G. Josifov, and M. V. Kurepa, "Total electronionization cross sections of the $\mathrm{NO}_{2}$ molecule," Int. J. Mass Spectrom. 205, 1 - 6 (2001).

${ }^{123}$ K. N. Joshipura, S. Gangopadhyay, and B. G. Vaishnav, "Electron scattering and ionization of $\mathrm{NO}, \mathrm{N}_{2} \mathrm{O}, \mathrm{NO}_{2}, \mathrm{NO}_{3}$ and $\mathrm{N}_{2} \mathrm{O}_{5}$ molecules: theoretical cross sections," J. Phys. B: At., Mol. Opt. Phys. 40, $199-210$ (2007).

${ }^{124}$ H. Munjal, K. L. Baluja, and J. Tennyson, "Electron collisions with the $\mathrm{NO}_{2}$ radical using the $R$-matrix method," Phys. Rev. A 79, 032712 (2009).

${ }^{125}$ G. Herzberg, New York: Van Nostrand, Reinhold, 1966 (1966).

${ }^{126}$ S. Heitz, R. Lampka, D. Weidauer, and A. Hese, "Measurements of electric-dipole moments on $\mathrm{NO}_{2}$," J. Chem. Phys. 94, 2532-2535 (1991).

${ }^{127}$ S. Harrison, J. Tennyson, and A. Faure, "Calculated electron impact spin-coupled rotational cross sections for ${ }^{2 S+1} \Sigma^{+}$linear molecules: CN as an example," J. Phys. B: At. Mol. Opt. Phys. 45, $175202(2012)$.

${ }^{128} \mathrm{~J}$. W. Au and C. E. Brion, "Absolute oscillator strenghts for the valence-shell photoabsorption $(2-200 \mathrm{ev})$ and the molecular and dissociative photoionization (11-80 ev) of nitrogen dioxide," Chem. Phys. 218, $109-126$ (1997).

${ }^{129}$ C. Q. Jiao, C. A. DeJoseph, and A. Garscadden, "Absolute cross sections for electron impact ionization of $\mathrm{NO}_{2}$," J. Chem. Phys. 117, $161-165$ (2002).

${ }^{130}$ S. A. Rangwala, E. Krishnakumar, and S. V. K. Kumar, "Dissociative-electron-attachment cross sections: A comparative study of $\mathrm{NO}_{2}$ and $\mathrm{O}_{3}$," Phys. Rev. A 68, 052710 (2003).

${ }^{131}$ R. Abouaf, R. Paineau, and F. Fiquet-Fayard, "Dissociative attachment in $\mathrm{NO}_{2}$ and $\mathrm{CO}_{2}$," J. Phys. B: At. Mol. Phys. 9, $303-314$ (1976).

${ }^{132}$ G. P. Karwasz, P. Możejko, and M.-Y. Song, "Electronimpact ionization of fluoromethanes - Review of experiments and binary-encounter models," Int. J. Mass Spectrom. 365-366, 232 - 237 (2014), Special issue: Tilmann MÄerk.

${ }^{133}$ D. A. Parkes and T. M. Sugden, "Electron attachment and detachment in nitric oxide," J. Chem. Soc., Faraday Trans. 2 68, 600-614 (1972).

${ }^{134}$ M. F. Skinker and J. V. White, "The motion of electrons in CO, $\mathrm{N}_{2} \mathrm{O}$ and NO," Phil. Mag. 46, 630-637 (1923).

${ }^{135}$ V. Bailey and J. Somerville, "The Behaviour of Electrons in Nitric Oxide," Phil. Mag. 17, 1169-1176 (1934), https://doi.org/10.1080/14786443409462470.

${ }^{136}$ C. S. Lakshminarasimha and J. Lucas, "The ratio of radial diffusion coefficient to mobility for electrons in helium, argon, air, methane and nitric oxide," Journal of Physics D: Applied Physics 10, 313-321 (1977). 